Navegação de robôs móveis utilizando visão estéreo

Caio César Teodoro Mendes 

SERVIÇO DE PÓS-GRADUAÇÃO DO ICMC-USP

Data de Depósito: 08/05/2012

Assinatura:

\title{
Navegação de robôs móveis utilizando visão estéreo
}

\author{
Caio César Teodoro Mendes
}

Orientador: Prof. Dr. Denis Fernando Wolf

Dissertação apresentada ao Instituto de Ciências Matemáticas e de Computação - ICMC-USP, como parte dos requisitos para obtenção do título de Mestre em Ciências - Ciências de Computação e Matemática Computacional. VERSÃO REVISADA

USP - São Carlos

Maio de 2012 
Ficha catalográfica elaborada pela Biblioteca Prof. Achille Bassi e Seção Técnica de Informática, ICMC/USP, com os dados fornecidos pelo(a) autor(a)

\begin{tabular}{|c|c|}
\hline \multirow[t]{3}{*}{ M538n } & $\begin{array}{l}\text { Mendes, Caio César Teodoro } \\
\text { Navegação de robôs móveis utilizando visão estéreo } \\
\text { Caio César Teodoro Mendes; orientador Denis Fernando } \\
\text { Wolf. -- São Carlos, } 2012 \text {. } \\
86 \mathrm{p} \text {. }\end{array}$ \\
\hline & $\begin{array}{l}\text { Dissertação (Mestrado - Programa de Pós-Graduação en } \\
\text { Ciências de Computação e Matemática Computacional) -- } \\
\text { Instituto de Ciências Matemáticas e de Computação, } \\
\text { Universidade de São Paulo, } 2012 \text {. }\end{array}$ \\
\hline & $\begin{array}{l}\text { 1. Navegação Autônoma. 2. Visão Estéreo. 3. Robôs } \\
\text { Móveis. 4. Deteç̧ão de Obstáculos. I. Wolf, Denis } \\
\text { Fernando, orient. II. Título. }\end{array}$ \\
\hline
\end{tabular}




\section{Agradecimentos}

À todos os membros do Laboratório de Robótica Movel da USP - São Carlos pelo apoio e suporte durante todo o tempo em que realizei meu mestrado.

Ao meu orientador, Prof. Dr. Denis Fernando Wolf, pelas sugestões, ensinamentos e esforços dedicados a me ajudar na conclusão deste trabalho.

À FAPESP pela bolsa de estudos me que foi concedida. 



\section{Resumo}

$\mathrm{N}$ Avegação autônoma é um tópico abrangente cuja atenção por parte da comunidade de robôs móveis vem aumentando ao longo dos anos. O problema consiste em guiar um robô de forma inteligente por um determinado percurso sem ajuda humana. Esta dissertação apresenta um sistema de navegação para ambientes abertos baseado em visão estéreo. Uma câmera estéreo é utilizada na captação de imagens do ambiente e, utilizando o mapa de disparidades gerado por um método estéreo semi-global, dois métodos de detecção de obstáculos são utilizando para segmentar as imagens em regiões navegáveis e não navegáveis. Posteriormente esta classificação é utilizada em conjunto com um método de desvio de obstáculos, resultando em um sistema completo de navegação autônoma. Os resultados obtidos por está dissertação incluem a avaliação de dois métodos estéreo, esta sendo favorável ao método estéreo empregado (semi-global). Foram feitos testes visando avaliar a qualidade e custo computacional de dois métodos para detecção de obstáculos, um baseado em plano e outro baseado em cone. Tais testes deixaram claras as limitações de ambos os métodos e levaram a uma implementação paralela do método baseado em cone. Utilizando uma unidade de processamento gráfico, a versão paralelizada do método baseado em cone atingiu um ganho no tempo computacional de aproximadamente dez vezes. Por fim, os resultados demonstrarão o sistema completo em funcionamento, onde a plataforma robótica utilizada, um veículo elétrico, foi capaz de desviar de pessoas e cones alcançando seu objetivo seguramente.

Palavras-chave: Visão estéreo, navegação autônoma, método estéreo semi-global, robótica móvel, unidade de processamento gráfico. 



\title{
Abstract
}

\begin{abstract}
Utonomous navigation is a broad topic that has received increasing attention from the community of mobile robots over the ye1 ars. The problem is to guide a robot in a smart way for a certain route without human help. This dissertation presents a navigation system for open environments based on stereo vision. A stereo camera is used to capture images of the environment and based on the disparity map generated by a semi-global stereo method, two obstacle detection methods are used to segment the images into navigable and non-navigable regions. Subsequently, this classification is employed in conjunction with a obstacle avoidance method, resulting in a complete autonomous navigation system. The results include an evaluation two stereo methods, this being favorable to the employed stereo method (semi-global). Tests were performed to evaluate the quality and computational cost of two methods for obstacle detection, a plane based one and a cone based. Such tests have left clear the limitations of both methods and led to a parallel implementation of the cone based method. Using a graphics processing unit, a parallel version of the cone based method reached a gain in computational time of approximately ten times. Finally, the results demonstrate the complete system in operation, where the robotic platform used, an electric vehicle, was able to dodge people and cones reaching its goal safely.
\end{abstract}

Keywords: Stereo vision, autonomous navigation, semi-global stereo method, mobile robotics, graphics processing unit. 



\section{Sumário}

Resumo iii

Abstract $\quad$ v

Lista de Figuras $\quad$ ix

Lista de Tabelas $\quad$ xiii

1 Introdução 1

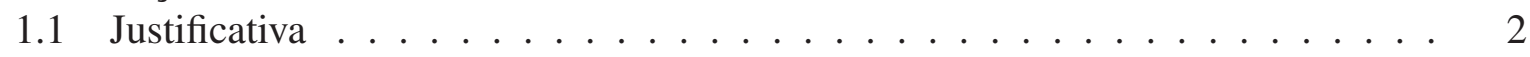

1.2 Estrutura da Dissertação . . . . . . . . . . . . . . . . . . . 4

2 Fundamentos Teóricos 5

2.1 Visão Estéreo . . . . . . . . . . . . . . . . . . . . . . . . . 5

2.1.1 Modelo Pinhole e Transformação Projetiva . . . . . . . . . . . . . . . 7

2.1.2 Distorções Provocadas pelo Uso de Lente . . . . . . . . . . . . . . . . . . . 9

2.1.3 Sistema Estéreo Canônico . . . . . . . . . . . . . . . . . . . . 10

2.1.4 Geometria Epipolar . . . . . . . . . . . . . . . . . . 11

2.1.5 Calibração . . . . . . . . . . . . . . . . . . 12

2.1 .6 Retificação . . . . . . . . . . . . . . . . . . . . . . . 13

2.1 .7 Métodos Estéreos . . . . . . . . . . . . . . . . . . . 13

2.1.7.1 Computação do Custo da Combinação entre pares de Píxeis . 15

2.1.7.2 Agregação de Custos . . . . . . . . . . . . . . . 15

2.1.7.3 Computação do Mapa de Disparidades . . . . . . . . . . . 16

2.1.7.4 Taxonomia dos Métodos Estéreos . . . . . . . . . . . . 16 
2.2 Random Sample Consensus . . . . . . . . . . . . . . . . . . . . . . . . . . 18

2.3 Unidade de Processamento Gráfico . . . . . . . . . . . . . . . . . . . . . . 19

2.3.1 Programação de Propósito Geral . . . . . . . . . . . . . . . . . . . . 21

2.3.1.1 Warp ....................... 23

2.3.1.2 Half-Warp . . . . . . . . . . . . . . 24

2.4 Vector Field Histogram . . . . . . . . . . . . . . . . . . . . . . . . . 24

3 Trabalhos Relacionados 27

3.1 Visão Monocular . . . . . . . . . . . . . . . . . . . . . . . . . . . . . 29

3.2 Visão Estéreo (Binocular) . . . . . . . . . . . . . . . . . . . . 31

4 Metodologia 37

4.1 Câmera Estéreo . . . . . . . . . . . . . . . . . . . . . 38

4.2 Método Estéreo Semi-global . . . . . . . . . . . . . . . . . 40

4.3 Detecção de Obstáculos . . . . . . . . . . . . . . . . . . . . . . 41

4.3.1 Detecção Baseada em Plano . . . . . . . . . . . . . . . . . . . . . 41

4.3.2 Detecção Baseada em Cone . . . . . . . . . . . . . . . . 43

4.3.3 Paralelização e Otimização . . . . . . . . . . . . . . . . . . . . . 45

4.4 Desvio de Obstáculos e Navegação Autônoma . . . . . . . . . . . . . . . . . 48

5 Resultados $\quad 53$

5.1 Métodos Estéreos . . . . . . . . . . . . . . . . . . . 53

5.2 Detecção de Obstáculos . . . . . . . . . . . . . . . . . . . 55

5.2 .1 Detecção Baseada em Plano . . . . . . . . . . . . . . . . 56

5.2 .2 Detecção Baseada em Cone . . . . . . . . . . . . . . . . . 56

5.2.2.1 Validando Aproximação Realizada . . . . . . . . . . . 58

5.2.2.2 Testes de Desempenho . . . . . . . . . . . . . 58

5.3 Navegação Autônoma . . . . . . . . . . . . . . . . . . . . . 60

6 Conclusão $\quad 65$

$\begin{array}{ll}\text { Referências Bibliográficas } & 67\end{array}$ 


\section{Lista de Figuras}

1.1 Número de mortes decorrentes de acidentes automobilísticos por ano no Brasil $(\mathrm{CNM}, 2009) \ldots \ldots \ldots \ldots \ldots \ldots \ldots$

2.1 Diagrama de blocos da metodologia proposta, com ênfase nas seções do capítulo de fundamentos teóricos. . . . . . . . . . . . . . . . . . . . . 6

2.2 Fluxo resumido presente na utilização de uma câmera estéreo. . . . . . . . . . 7

2.3 Modelo pinhole: apenas os raios de luz que interceptarem a abertura podem passar, tais raios são projetado no plano projetivo (Bradski e Kaehler, 2008). . . 7

2.4 Modelo pinhole com um plano virtual, equivalente ao plano projetivo porém sem a inversão (Bradski e Kaehler, 2008). . . . . . . . . . . . . . . . . . . . . 8

2.5 Sistema canônico (padrão) de uma câmera binocular com distância focal $f$ e lentes deslocadas por uma distância T (Bradski e Kaehler, 2008). . . . . . . . . . 10

2.6 Principais elementos presentes na geometria epipolar (Bradski e Kaehler, 2008). 11

2.7 Por conta do alinhamento imperfeito presente em qualquer sistema estéreo é necessário estimar as matrizes $R$ e $T$ que relacionam as câmeras (Bradski e Kaehler, 2008). . . . . . . . . . . . . . . . . . . . . . . .

2.8 Figura ilustrando o processo de retificação estéreo. As linhas horizontais enfatizam a diferença entre imagens não retificadas (superiores) e retificadas (Bradski e Kaehler, 2008). . . . . . . . . . . . . . . . . . . . . . . . . . . . . . . . . 14

2.9 Par de imagens estéreo e seu respectivo mapa de disparidades (Mattoccia, 2010). 14

2.10 Arquitetura comum aos métodos estéreos. . . . . . . . . . . . . 15

2.11 Resultado típico de um método estéreo que utiliza a técnica de programação dinâmica (Scharstein e Szeliski, 2002). . . . . . . . . . . . . . . . . . 17

2.12 Ilustração do resultado da técnica RANSAC utilizada a fim de encontrar uma reta em uma nuvem de pontos. . . . . . . . . . . . . . . . . . . . . . 
2.13 Comparação entre a capacidade de processamento de GPUs e CPUs ao longo dos anos (NVIDIA, 2010). . . . . . . . . . . . . . . 20

2.14 Arquitetura da placa de vídeo GeForce 6800GT (Kilgariff e Fernando, 2005). . 20

2.15 Arquitetura da placa de vídeo GeForce 8800GTX (Case, 2006). . . . . . . . . . 21

2.16 Arquitetura de um estágio programável (NVIDIA, 2010). . . . . . . . . . . . . 22

2.17 Programa para somar dois vetores utilizando a linguagem OpenCL. . . . . . . 23

2.18 Acesso desalinhado e alinhado às coordenadas de três pontos. . . . . . . . . . . . 24

2.19 Ilustração do histograma gerado pelo método VFH (Borenstein e Koren, 1991). 25

3.1 Plataformas veiculares brasileiras. . . . . . . . . . . . . . . 28

3.2 Direção autônoma realizada a partir do processamento de imagens (Broggi e Bertè, 1995). . . . . . . . . . . . . . . . . . . 29

3.3 Identificação das faixas de trânsito através da identificação de retas na imagem (Lu et. al., 2002). . . . . . . . . . . . . . . . . . . . . . . . 30

3.4 Identificação das linhas de trânsito (Wang et. al., 1999). . . . . . . . . . . . . . 30

3.5 Identificação da via navegável utilizando o algoritmo EM. . . . . . . . . . . . 32

3.6 Par de imagens estéreo e o respectivo mapa de disparidade em "V" (Broggi et. al., 2005). . . . . . . . . . . . . . . . . .

3.7 Sistema de visão adaptativa utilizada pelo robô Stanley. As linhas azuis delimitam o campo de atuação do laser utilizado e a parte avermelhada da imagem mostra o terreno navegável. . . . . . . . . . . . . . . . . .

3.8 Plataforma robótica utilizada no projeto LAGR. Possui quatro câmeras, um GPS e uma unidade de medida inercial (LAGR, 2005). . . . . . . . . . . . .

3.9 Classificação do método utilizado por Happold e Ollis (2006). A Figura da esquerda é a imagem de referência, ao centro a classificação feita com base no mapa de profundidades e por fim o resultado do classificador (Happold e Ollis, 2006)

4.1 Diagrama de blocos do funcionamento do sistema proposto. . . . . . . . . . . 37

4.2 Câmera estéreo utilizada no projeto. . . . . . . . . . . . . . . . . . 39

4.3 A correspondência de um píxel $p$ é formulada como um problema de otimização que engloba vários caminhos unidimensionais. . . . . . . . . . . . . .

4.4 O módulo "StereoCam" publica o par de imagens estéreo retificadas. O módulo "StereoMatcher" recebe as duas imagens e publica o mapa de disparidades, a nuvem de pontos e republica a imagem da esquerda (imagem de referência). . .

4.5 Mapa de navegabilidade resultante do método de detecção de obstáculos baseado em plano (píxeis vermelhos representam blocos não navegáveis e píxeis com sua coloração original blocos navegáveis). . . . . . . . . . . . . . .

4.6 Ilustração da busca por pontos compatíveis, onde pontos marrons pertencem a via navegável e pontos em azul são considerados obstáculos (Talukder et. al., 2002).

4.7 A busca por pontos compatíveis é aproximada pela projeção de um triângulo no plano da imagem (Talukder et. al., 2002). . . . . . . . . . . . . . . . . . 
4.8 Aproximação da área da busca por um quadrado no plano da imagem, onde os círculos vermelhos representam os pontos de referência e os pontos azuis a área de busca. . . . . . . . . . . . . . . . . . . . 44 44

4.9 Forma com que o processamento é distribuído entre os vários núcleos: cada linha de pivô é processada por um. . . . . . . . . . . . . . . . . . 46

4.10 Redistribuição das coordenadas na memória a fim de possibilitar o acesso alinhado aos dados pela GPU. . . . . . . . . . . . . . . .

4.11 Forma como o processamento foi distribuído pela GPU pela primeira implementação. . . . . . . . . . . . . . . . . . .

4.12 Forma como o processamento foi distribuído pela GPU pela segunda implementação. . . . . . . . . . . . . . . . . . .

4.13 Forma como a busca por pontos compatíveis em uma janela de 32 por 32 pontos é distribuída por um work-group de 64 work-itens ou processadores. Os processadores são divididos em dois grupos de 32 processadores, onde cada processador de cada grupo processa uma coluna de 16 pontos. Os pontos em azul representam os pontos processados pelo primeiro grupo, e os em verde os pontos processados pelo segundo. . . . . . . . . . . . .

4.14 Mapa de navegabilidade e seu respectivo histograma de densidade de obstáculos. 50

5.1 Imagens esquerda e direita utilizadas para o teste de desempenho. . . . . . . . 54

5.2 Gráfico de comparação entre o método local BM e o semi-global SGBM em termos de quadros por segundo e tamanho de bloco. . . . . . . . . . . . . . . 54

5.3 Gráfico de comparação entre o método local BM e o semi-global SGBM em termos de porcentagem de disparidades desconhecidas e tamanho do bloco. . . 55

5.4 Ilustração dos efeitos de um bloco grande circulado em azul. . . . . . . . . . . 55

5.5 Resultados da detecção de obstáculos baseada em plano onde píxeis vermelhos são considerados obstáculos. . . . . . . . . . . . . . . . . 56

5.6 Resultados da detecção de obstáculos baseada em plano em um terreno curvado. 57

5.7 Resultados da detecção de obstáculos baseada em cone. . . . . . . . . . . . . . 57

5.8 Comparação entre o resultado da classificação utilizando aproximação e o processamento completo. Píxeis amarelos representam os pontos não classificados pela aproximação. . . . . . . . . . . . . . . . . . . 59

5.9 Diagrama de blocos da metodologia utilizada no experimento final. . . . . . . . 61

5.10 Diagrama de classes da implementação final do sistema de navegação. . . . . . . 62

5.11 Sequência de imagens mostrando o veículo elétrico desviando de obstáculos e se encaminhando para o destino final. . . . . . . . . . . . . . . .

5.12 Trajetória do veículo (em verde) dada pelo sensor MTi-G. Cilindros vermelhos representam os cones de trânsito, os retângulos azuis os carros, o círculo amarelo uma pessoa e os círculos verdes o início e fim do trajeto. . . . . . . . . . . 



\section{Lista de Tabelas}

5.1 Parâmetros selecionados para os testes com o método de detecção de obstáculos baseado em cone. . . . . . . . . . . . . . . . . . . . . . . 57

5.2 Quantidade de pontos não classificados pela aproximação referente ao método de detecção de obstáculos baseado em cone. . . . . . . . . . . . . . . . 58

5.3 Comparação entre o tempo médio de processamento utilizando a aproximação e o processamento completo. . . . . . . . . . . . . . . . . . . . . 59

5.4 Tempos de processamento para cada forma diferente de implementação do método de detecção de obstáculos baseado em cone. . . . . . . . . . . . . . . . . 59

5.5 Detalhamento dos tempos de processamento do método pela GPU. . . . . . . . 60 

Boa parte das tarefas que realizamos no dia-a-dia requer nossa locomoção. Sem essa capacidade nossas ações estariam limitadas a um determinado espaço, tornando impossível a conclusão de muitos de nossos afazeres. Nos robôs essa capacidade se mostra igualmente fundamental e capacita-os a realizar uma enorme gama de tarefas.

A robótica móvel é uma área de pesquisa que lida com o controle de robôs autônomos ou semi-autônomos. A capacidade motora possibilita ao robô realizar funções que seriam impossíveis de serem executadas por robôs estáticos. A tecnologia envolvida é extremamente complexa e multidisciplinar, apresentando um enorme desafio para pesquisadores tanto a nível de software quanto de hardware. Apesar dos diversos problemas enfrentados, a comunidade de robótica móvel, como um todo, realizou grande progresso nos últimos anos (Siegwart e Nourbakhsh, 2004). Sendo a mobilidade o que distingue a robótica móvel da robótica industrial convencional, seu principal foco de estudo é a navegação.

Grande parte da pesquisa realizada na área leva em consideração apenas ambientes estruturados e internos, onde o problema da navegação pode ser simplificado de várias formas. A navegação em ambientes externos consiste em um problema mais complexo por contar com poucos padrões estruturais. Além do desvio de obstáculos, é necessário que o robô identifique o terreno em que pode navegar. A irregularidade do terreno e a dinâmica do ambiente são alguns dos fatores que dificultam a navegação de um robô e a correta interpretação da leitura dos sensores. Uma aplicação direta dessa tecnologia é o desenvolvimento de um veículo autônomo 
inteligente. Este tipo de projeto poderá contribuir para uma redução do número de acidentes de trânsito, na diminuição de engarrafamentos nas grandes cidades e na melhoria da mobilidade de deficientes físicos e idosos.

A competição DARPA Grand Challenge realizado pela Defense Advanced Research Projects Agency (DARPA) é um exemplo dos recursos humanos e tecnológicos que estão atualmente sendo dedicados a tal tarefa. Em 2005 o prêmio oferecido pelo projeto foi de 2 milhões de dólares para o veículo robótico que conseguisse atravessar $212 \mathrm{~km}$ de vias não-pavimentadas (DARPA, 2005). Em 2007, a DARPA realizou o Urban Challenge com um prêmio de 3 milhões de dólares, o desafio foi o de navegar $96 \mathrm{~km}$ em área urbana autonomamente (DARPA, 2007).

Este trabalho tem como foco o estudo e desenvolvimento de um sistema de navegação robótico utilizando uma câmera estéreo como sensor principal. Uma câmera estéreo se assemelha ao olho humano possuindo duas lentes deslocadas horizontalmente. A grande utilidade de múltiplas lentes em posições diferentes é a possibilidade de relacionar as imagens geradas e assim obter informações sobre a profundidade da cena. Estas informações irão guiar a navegação do robô detectando vias navegáveis e obstáculos.

\subsection{Justificativa}

Segundo a organização internacional Make Roads Safe, ocorrem 1.3 milhões de mortes no mundo por conta de acidentes de trânsito todo ano, 50 milhões de pessoas ficam feridas e muitas se tornam deficientes (MRS, 2009). Aproximadamente $90 \%$ destes acidentes acontecem nos países em desenvolvimento, grupo do qual o Brasil faz parte. Seu custo econômico é estimado em 100 bilhões de dólares, implicando diretamente no agravamento da desigualdade social.

Como mostra a Figura 1.1, ao contrário dos países desenvolvidos, no Brasil, a quantidade de fatalidades em acidentes de trânsito cresceu de 2000 a 2007. Em 2007 houve uma média de 183 mortes por dia no trânsito brasileiro (7,6 por hora) (CNM, 2009). Algumas das principais causas são: subavaliação da probabilidade de acidente, desatenção, cansaço e deficiências (visual, auditiva, motora). Segundo a associação Por Vias Seguras, o fator humano está presente em quase todos os acidentes de trânsito (PVS, 2012).

Pesquisadores da área da robótica vêm trabalhando no desenvolvimento de sistemas inteligentes para a condução de veículos desde os anos 80. Um dos principais objetivos da pesquisa realizada na área é o de diminuir o número de acidentes no trânsito. Outra motivação relevante para o desenvolvimento desse tipo de sistema é a facilitação da mobilidade para deficientes físicos e idosos. Segundo o Instituto Brasileiro de Geografia e Estatística (IBGE), em 2000, 11\% da população brasileira tinha mais de 55 anos (IBGE, 2004). Em 2050, esse percentual atingirá 


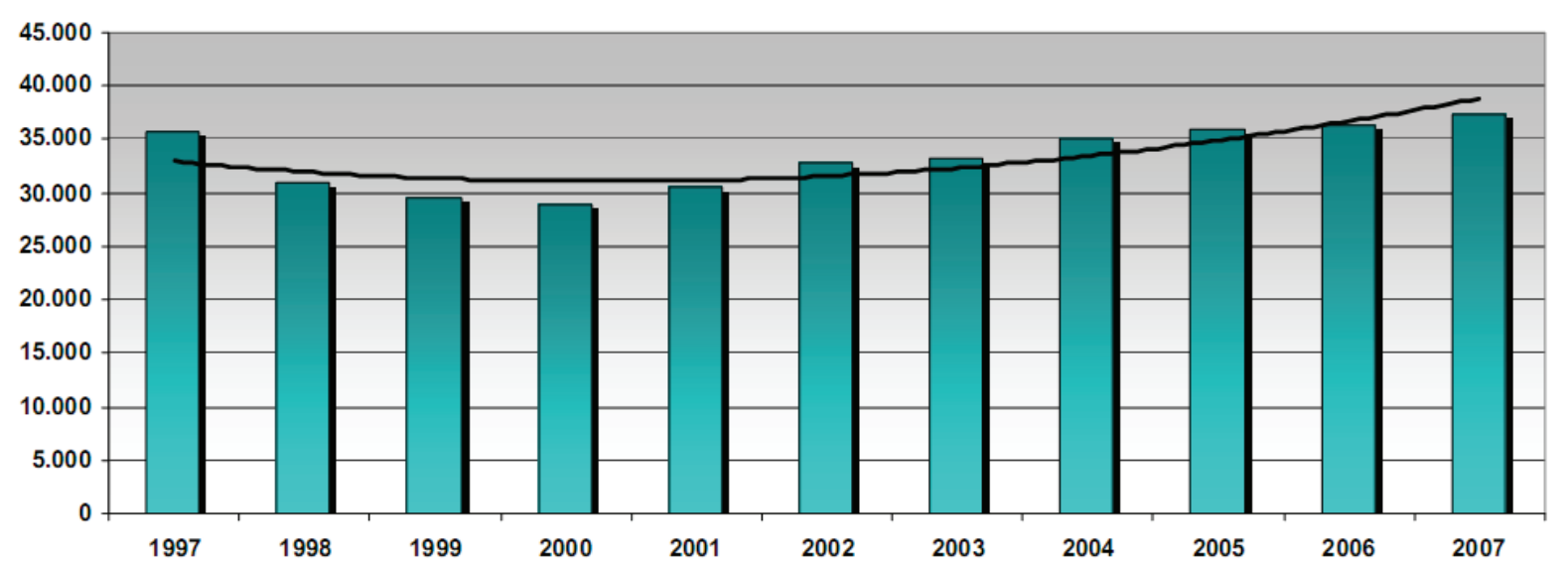

Figura 1.1: Número de mortes decorrentes de acidentes automobilísticos por ano no Brasil (CNM, 2009).

a taxa de 32,1\%, ou aproximadamente, 75 milhões de pessoas. É notório que pessoas idosas e portadoras de limitações físicas têm cada vez mais dificuldades em dirigir veículos em grandes cidades e rodovias, onde o ambiente é extremamente dinâmico e, até mesmo, agressivo.

Assim, uma pequena falta de atenção pode causar um acidente grave. Por isso, é praxe que ao menor sinal de limitação, o idoso não tenha a sua habilitação para dirigir renovada. Isso causa uma falta de mobilidade e consequentemente o isolamento e a falta de socialização do indivíduo, o que pode também provocar o surgimento de depressão e outras doenças.

Para que um sistema de navegação autônoma possa ser utilizado com o propósito de reduzir de acidentes, este deve estar apto a reconstruir o ambiente com precisão, fazendo necessária a utilização de sensores tal como lasers, sonares e câmeras. Os lasers são os principais sensores na maioria dos sistemas porque eles proveem informações de profundidade confiáveis e de alta qualidade. Câmeras também são amplamente utilizadas, mas em quase todos os sistemas de navegação práticos (i.e. passíveis de navegar autonomamente por um longo trajeto) o laser é o sensor principal (Thrun et. al., 2006). Motivos para isso são o ruído advindo da captação das imagens e sua dependência em relação a iluminação. Apesar disso, com o preço de um laser comum (ex.: SICK LMS 200), é possível comprar diversas câmeras. Uma câmera estéreo pode prover informações de profundidade em duas dimensões além das imagens associadas enquanto que o laser comum nesse tipo de aplicação fornece apenas as profundidades em um eixo. $\mathrm{O}$ principal desafio na utilização de uma câmera estéreo está em como estimar a profundidade da cena com precisão.

Existem diversos métodos para se extrair informações de profundidade a partir de uma câmera estéreo (métodos estéreos), seus resultados variam quanto a qualidade e custo computacional envolvido. Uma avaliação envolvendo vários desses métodos é apresentada por Scharstein 
e Szeliski (2002). A grande maioria dos sistemas de navegação com câmera estéreo utilizam métodos estéreos de correspondência locais providos pela própria empresa que comercializa a câmera (Erkan et. al., 2007; Murarka e Kuipers, 2009; Sermanet et. al., 2008). Esta dissertação tem como objetivo o desenvolvimento de um sistema de direção autônomo utilizando uma câmera estéreo, fazendo uma análise de cada um de seus componentes, em especial: avaliar um método estéreo semi-global de código aberto e métodos para detecção de obstáculos. Por fim, os módulos desenvolvidos serão integrados, formando um sistema de navegação autônomo e validando a abordagem utilizada.

\subsection{Estrutura da Dissertação}

O restante desta dissertação foi organizado em seis capítulos, sendo eles: O capítulo 2, intitulado Fundamentos Teóricos, descreve todos os principais fundamentos teóricos envolvidos no trabalho, isto é, todas as técnicas, paradigmas e métodos que já estão estabelecidos na literatura científica da área. Os principais trabalhos relacionados são citados e descritos no capítulo 3, com o objetivo de realizar um paralelo entre a literatura disponível e o presente trabalho. $\mathrm{O}$ capítulo referente a metodologia (capítulo 4) descreve detalhadamente todos os componentes presentes no sistema desenvolvido. Por fim, os resultados são apresentados no capítulo 5 e a conclusão no capítulo 6 . 


$=$

\section{Fundamentos Teóricos}

Neste capítulo os principais fundamentos teóricos envolvidos no desenvolvimento do sistema de navegação serão apresentados. Seu objetivo é servir de base teórica aos capítulos seguintes. Para facilitar o entendimento e a leitura optou-se por organizar o capítulo de maneira análoga ao capítulo referente à metodologia. Isto é, seguindo o diagrama de blocos de alto nível do sistema. A Figura 2.1 mostra o diagrama de blocos referente ao sistema desenvolvido, onde as informações do ambiente são captadas através de uma câmera estéreo (Seção 2.1). O par de imagens captadas é então processada por um método estéreo semi-global (Seção 2.1.7), gerando informações de profundidade do ambiente. Tais informações de profundidade são utilizadas por um método de detecção de obstáculos a fim de segmentar as imagens em regiões navegáveis ou não navegáveis (Seções 2.2 e 2.3). Os atuadores são acionados por um método de desvio de obstáculos, que utiliza as imagens classificadas pelo método de detecção de obstáculos (Seção 2.4).

\subsection{Visão Estéreo}

Uma câmera estéreo funciona de maneira análoga ao sistema de visão humano, duas lentes horizontalmente deslocadas capturam duas imagens similares. Esse par de imagens possui um pequeno deslocamento entre posições relativas de partes locais de uma imagem da cena em relação a outra, dependendo da distância que estes componentes locais estão da câmera. Ao saber a 


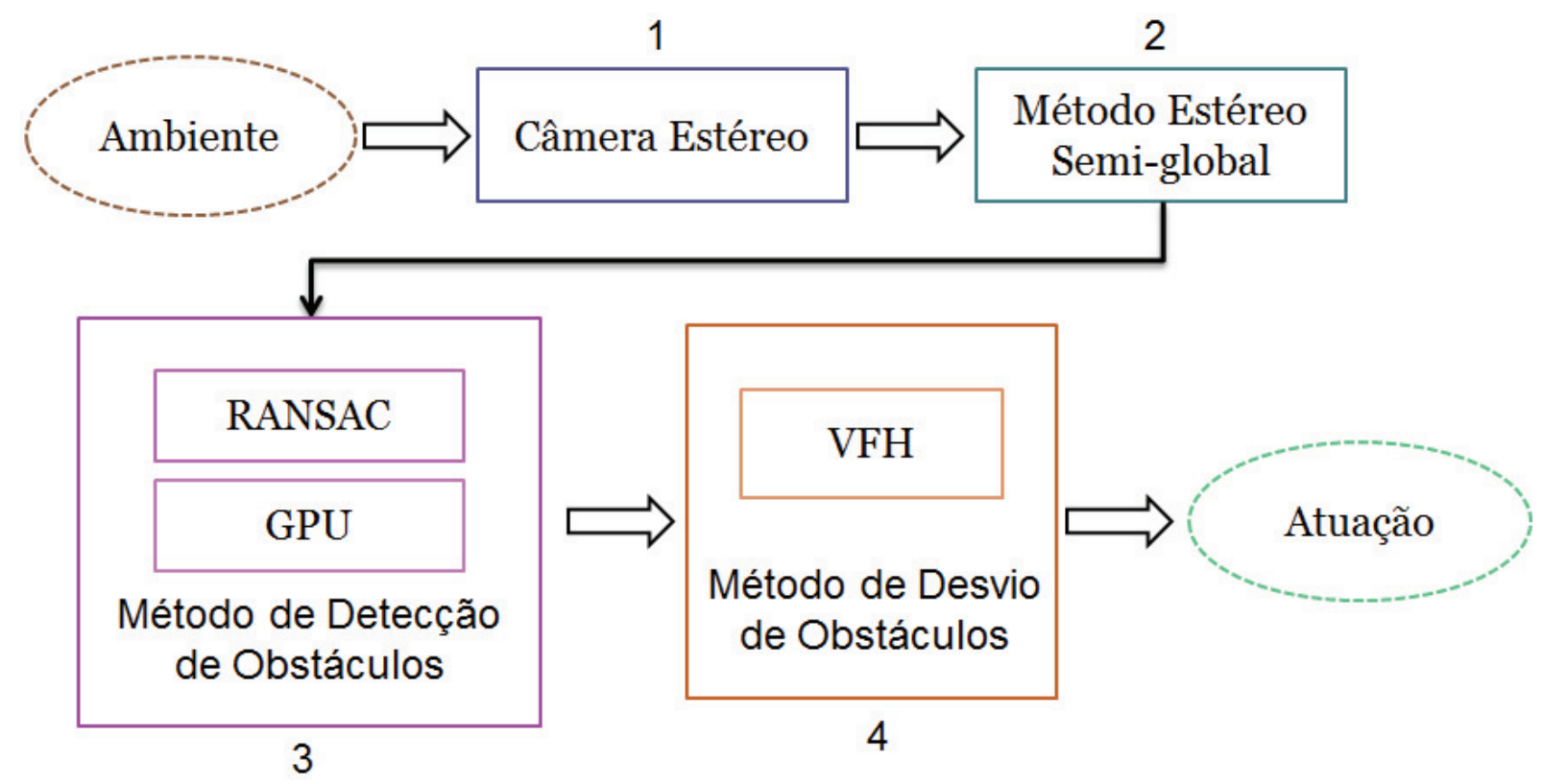

Figura 2.1: Diagrama de blocos da metodologia proposta, com ênfase nas seções do capítulo de fundamentos teóricos.

diferença da posição de um ponto entre uma imagem e outra é possível aferir sua profundidade relativa. É dessa forma que a visão humana nos proporciona uma noção de profundidade.

A Figura 2.2 mostra o fluxo resumido referente a utilização de uma câmera estéreo. A calibração estima os parâmetros intrínsecos e extrínsecos que possibilitam a remoção de distorção presente na imagem e sua retificação. Utilizando o par de imagens retificadas (i.e. alinhadas horizontalmente), um método estéreo procura por pontos correspondentes gerando, por fim, o mapa de disparidades.

A Seção começa introduzindo a geometria de uma câmera comum (monocular) na Seção 2.1.1; as possíveis distorções e as modelagens matemáticas referentes são apresentadas na Seção 2.1.2; na Seção 2.1.3 o sistema estéreo canônico é descrito; a geometria epipolar é apresentada na Seção 2.1.4. O restante da Seção segue o fluxo apresentado na Figura 2.2, em sequência, calibração (Seção 2.1.5), retificação (Seção 2.1.6) e métodos estéreos (Seção 2.1.7).

É importante salientar que existem alguns problemas inerentes à obtenção de profundidade na técnica apresentada. Um deles é a limitação de proximidade já que, caso o objeto esteja muito próximo da câmera, apenas uma de suas lentes irá capturá-lo, e caso o objeto esteja muito longe, a diferença entre as imagens se tornará nula. Em ambos os casos o cálculo da disparidade se torna impossível. Além disso, a câmera estéreo sofre de algumas das mesmas limitações de uma câmera comum, como a necessidade de iluminação. 


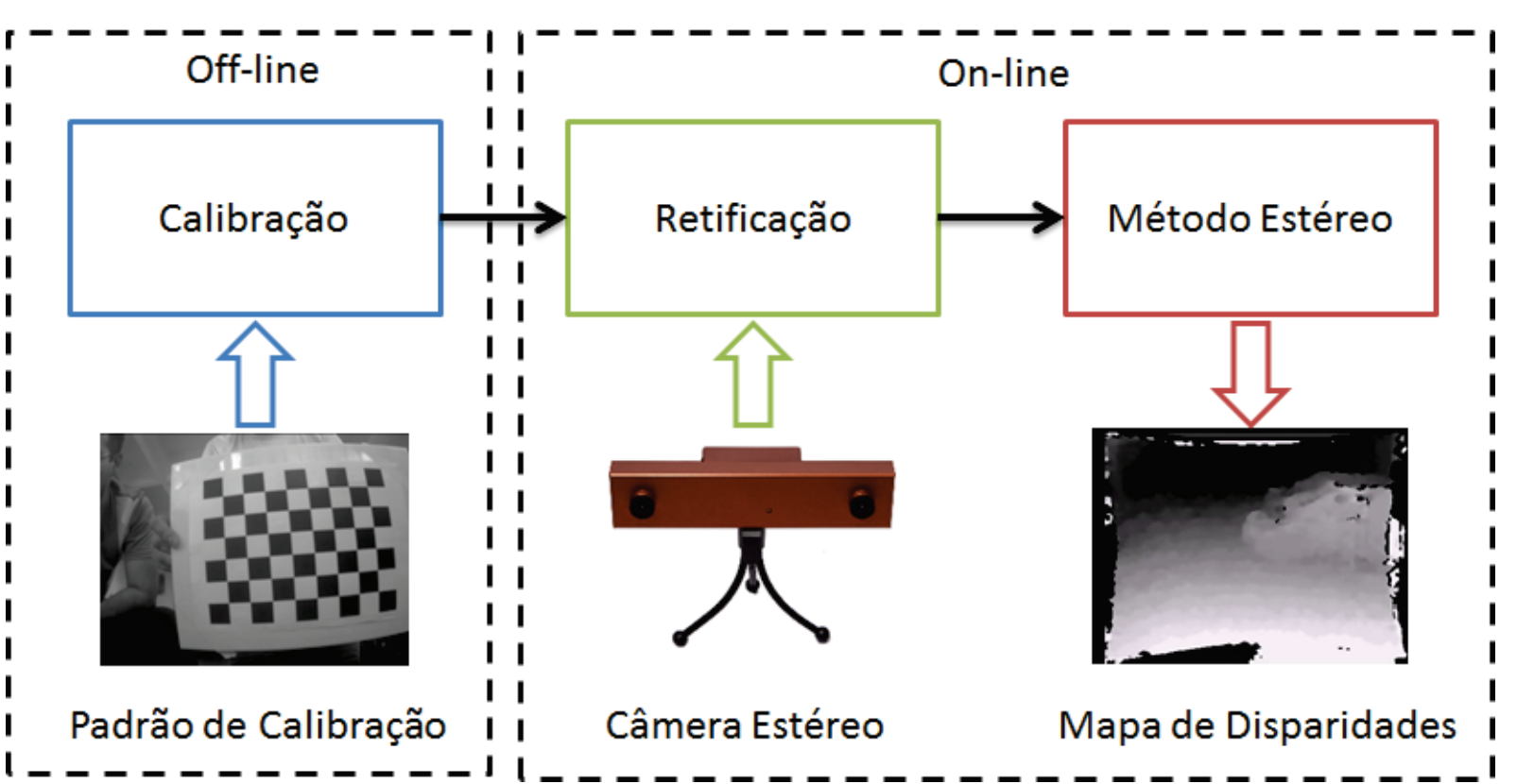

Figura 2.2: Fluxo resumido presente na utilização de uma câmera estéreo.

\subsubsection{Modelo Pinhole e Transformação Projetiva}

Para compreender o funcionamento de uma câmera estéreo e a geometria envolvida em um sistema estéreo convém primeiro apresentar a geometria de uma câmera monocular e a partir dai, a de uma câmera estéreo. O modelo geométrico mais simples de uma câmera real é chamado de modelo pinhole ou "buraco de agulha". O mesmo é apresentado na Figura 2.3.

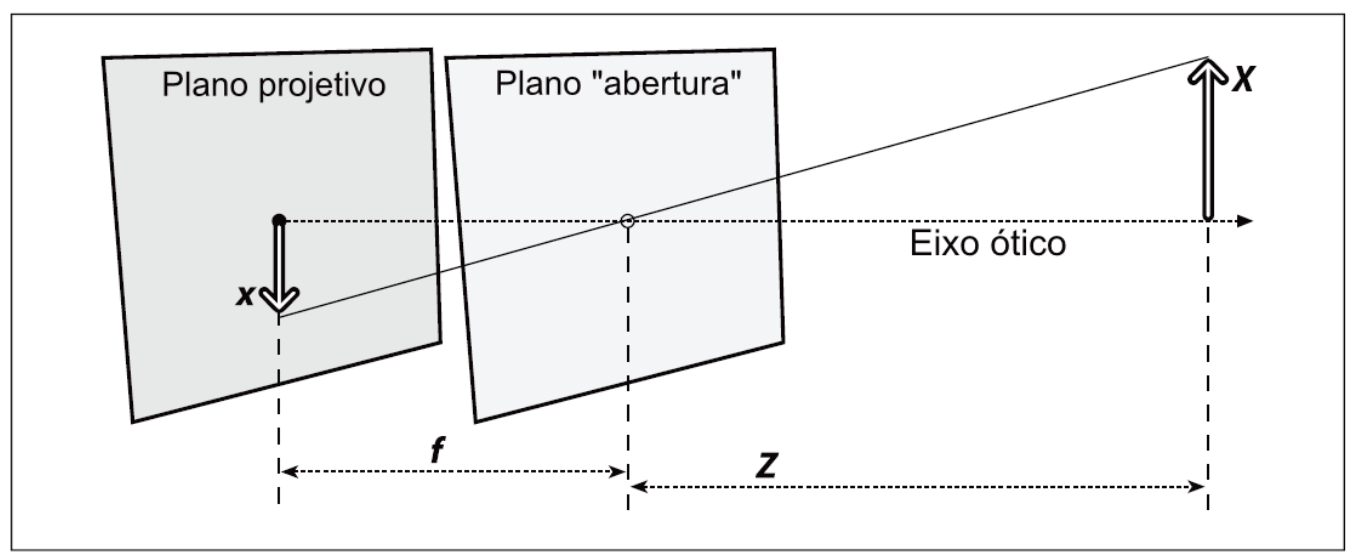

Figura 2.3: Modelo pinhole: apenas os raios de luz que interceptarem a abertura podem passar, tais raios são projetado no plano projetivo (Bradski e Kaehler, 2008).

O modelo é composto por um "buraco" ou abertura, através do qual a luz passa, e um plano (plano projetivo), onde a luz é projetada. Como a abertura é a única passagem ligando o mundo exterior ao plano, toda luz emitida ou refletida deve passar através da abertura para então ser 
projetada. O principal parâmetro do modelo é chamado de distância focal, isto é, a distância entre a abertura e o plano projetivo. Na Figura 2.3 a distância focal é representada por $f, Z$ se refere a distância entre a abertura e um dado objeto, $X$ ao comprimento deste objeto e $x$ ao seu comprimento no plano projetivo. Sabendo-se a distância focal $f$ é possível aferir o comprimento no plano projetivo de qualquer ponto projetado. Com base na similaridade entre triângulos, se deduz a seguinte formula:

$$
x=-f \frac{X}{Z}
$$

Uma maneira mais conveniente de trabalhar com o modelo pinhole é criando um plano virtual a frente da abertura por uma distância igual a distância focal $f$. O plano virtual acaba por possuir as mesmas propriedades do plano projetivo, porém evita que os pontos projetados sejam invertidos. Neste modelo a abertura passa a ser interpretada como o centro de projeção e a interseção entre o eixo ótico e o plano virtual é chamada de ponto principal. A Figura 2.4 ilustra a ideia.

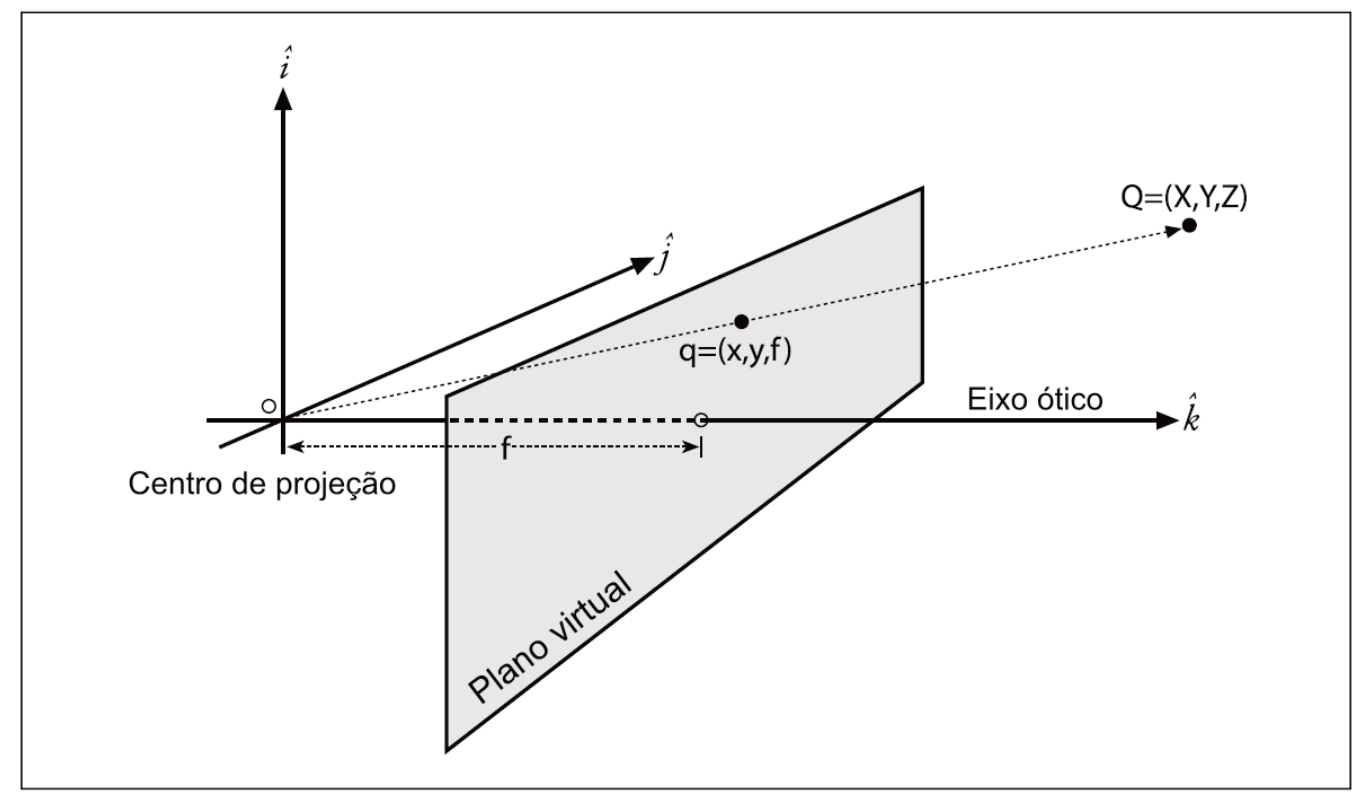

Figura 2.4: Modelo pinhole com um plano virtual, equivalente ao plano projetivo porém sem a inversão (Bradski e Kaehler, 2008).

A Figura 2.4 mostra um ponto $Q$ e sua projeção no plano virtual, o ponto $q$. Para um modelo mais próximo de uma câmera real, é necessário introduzir os novos parâmetros $c_{x} \mathrm{e}$ $c_{y}$. Tais parâmetros são referentes ao deslocamento entre o ponto principal (centro do plano projetivo) e a abertura. Os parâmetros mencionados se fazem necessário porque em câmeras reais os sensores de luz não estão perfeitamente alinhados com a abertura, dai que esta diferença 
necessita ser levada em consideração. Utilizando os novos parâmetros chegamos à seguinte transformação projetiva entre o ponto $Q$ e o ponto projetado $q$ :

$$
x=f \frac{X}{Z}+c_{x} \quad y=f \frac{Y}{Z}+c_{y}
$$

Utilizando coordenadas homogêneas podemos representar a transformação por uma multiplicação entre matrizes (Bradski e Kaehler, 2008):

$$
q=M Q, \quad \text { onde }: \quad q=\left[\begin{array}{c}
x \\
y \\
w
\end{array}\right], \quad M=\left[\begin{array}{ccc}
f & 0 & c_{x} \\
0 & f & c_{y} \\
0 & 0 & 1
\end{array}\right], \quad Q=\left[\begin{array}{l}
X \\
Y \\
Z
\end{array}\right]
$$

A Equação $q=M Q$ propicia uma maneira simples e compacta de representar a transformação projetiva sofrida pelo ponto $Q$. A matriz $M$ encapsula parte dos parâmetros ditos "intrínsecos" da câmera, o restante destes parâmetros são referentes à distorção sofrida durante a transformação projetiva e são descritos na Seção 2.1.2.

\subsubsection{Distorções Provocadas pelo Uso de Lente}

Em se tratando de uma câmera real, ainda há a necessidade de modelar as distorções provocadas pelo uso de lentes. Estas distorções são significantes especialmente em câmeras mais baratas, como a maior parte das webcams disponíveis no mercado, e tendem a diminuir conforme a qualidade (e usualmente o preço) da câmera aumenta.

A mais comum delas é chamada de distorção radial, provocada pelo próprio formato imperfeito da lente. Isso acontece porque é mais barato manufaturar lentes esféricas do que as matematicamente perfeitas parabólicas. Tal distorção afeta principalmente os pontos projetados na borda do sensor (representado pelo plano projetivo), pode-se modelá-la utilizando os primeiros termos de uma série de Taylor. Os pontos são corrigidos utilizando as seguintes equações (Bradski e Kaehler, 2008):

$$
\begin{aligned}
& x_{\text {corrigido }}=x\left(1+k_{1} r^{2}+k_{2} r^{4}+k_{3} r^{6}\right) \\
& y_{\text {corrigido }}=y\left(1+k_{1} r^{2}+k_{2} r^{4}+k_{3} r^{6}\right)
\end{aligned}
$$

Nas equações acima, $(x, y)$ é a posição original dos pontos distorcidos enquanto que $\left(x_{\text {corrigido }}, y_{\text {corrigido }}\right.$ representa a nova posição, já corrigida. Os coeficientes $k_{n}$ são os parâmetros necessários para realizar a correção. 
Outra distorção comum é a distorção tangencial, provocada pelo alinhamento imperfeito da lente em relação ao sensor e pode ser modelada pelas seguintes equações (Bradski e Kaehler, 2008):

$$
\begin{aligned}
& x_{\text {corrigido }}=x+\left[2 p_{1} y+p_{2}\left(r^{2}+2 x^{2}\right)\right] \\
& y_{\text {corrigido }}=y+\left[p_{1}\left(r^{2}+2 y^{2}\right)+2 p_{2} x\right]
\end{aligned}
$$

Onde $p_{1}$ e $p_{2}$ são os dois parâmetros que caracterizam a distorção tangencial. Todos os parâmetros referentes a distorção podem ser encapsulados em um único vetor de 5 linhas e uma coluna, chamado de vetor de distorção ou $D$. Portanto a matriz $M$ vista na Seção 2.1.1 e o vetor $D$ englobam todos os parâmetros intrínsecos de uma câmera.

\subsubsection{Sistema Estéreo Canônico}

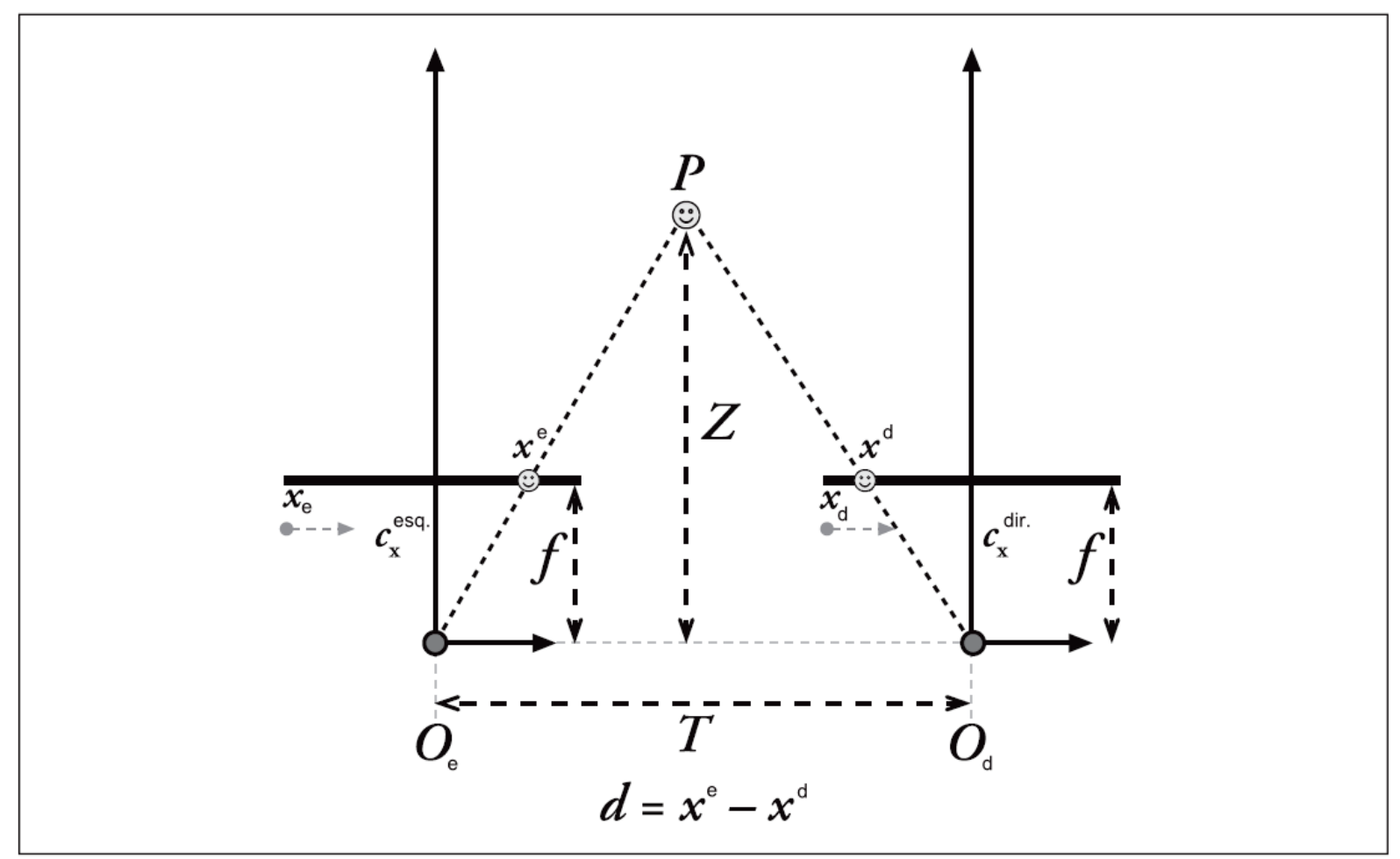

Figura 2.5: Sistema canônico (padrão) de uma câmera binocular com distância focal $f$ e lentes deslocadas por uma distância $T$ (Bradski e Kaehler, 2008).

A Figura 2.5 mostra a geometria do sistema canônico. A disparidade ou $d$, isto é, a distância no eixo $x$ dos pontos correspondentes $x^{e}$ e $x^{d}$ é dada pela Equação: $d=x^{e}-x^{d}$. Em um sistema ideal, sabendo-se a distância focal $f$, o deslocamento base $T, x_{e}$ e $x_{d}$ é possível, por triangulação, saber a distância relativa do ponto $P$ à base da câmera $(Z)$. As equações seguintes 
mostram, do lado esquerdo, a similaridade entre os triângulos $O_{e} P O_{d}$ e $x^{e} P x^{d}$ e a parte direita o cálculo do valor de $Z$ (Bradski e Kaehler, 2008):

$$
\frac{T-\left(x^{e}-x^{d}\right)}{Z-T}=\frac{T}{Z} \quad \Rightarrow \quad Z=\frac{f T}{x^{e}-x^{d}}=\frac{f T}{d}
$$

Para encontrar os pontos correspondentes $x^{e}$ e $x^{d}$ é necessário utilizar um algoritmo de correspondência ou método estéreo cujo objetivo é achar os pontos correspondentes entre o par de imagens estéreo. Tal procura tem um alto custo computacional e por isso deve-se minimizar ao máximo sua área de busca. Em um sistema canônico perfeito tal busca poderia ser limitada horizontalmente, porém na realidade não é possível construir este sistema: câmeras possuem distorções e não podem ser perfeitamente alinhadas. Portanto se faz necessário um alinhamento virtual das câmeras, a geometria envolvida neste alinhamento é descrita na Seção 2.1.4.

\subsubsection{Geometria Epipolar}

Geometria epipolar se refere a geometria de um sistema estéreo, onde os modelos pinhole das duas câmeras são levados em consideração. A Figura 2.6 apresenta os principais componentes da geometria epipolar.

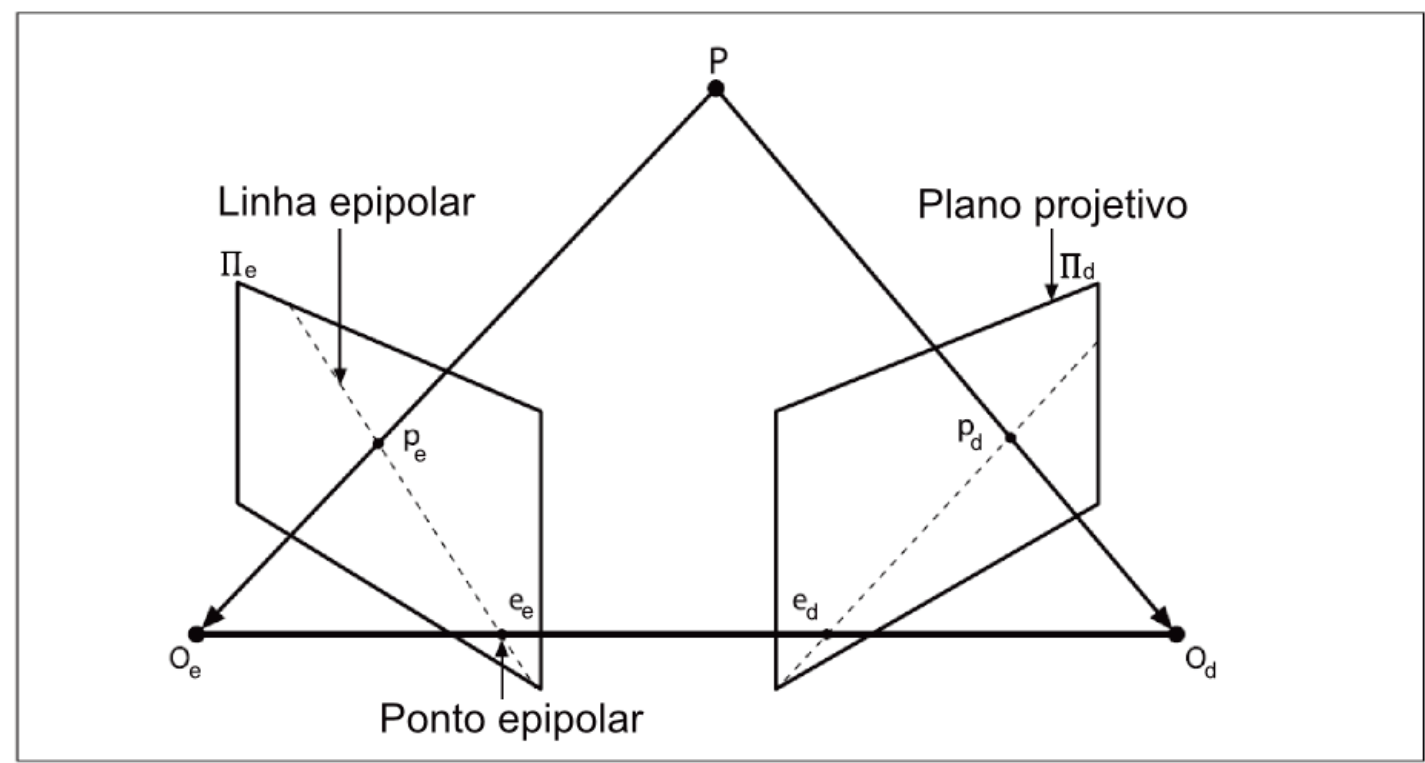

Figura 2.6: Principais elementos presentes na geometria epipolar (Bradski e Kaehler, 2008).

Tem-se portanto os centros de projeção para a câmera da esquerda $O_{e}$, para câmera da direita $O_{d}$ e seus respectivos planos de projeção $\Pi_{e}$ e $\Pi_{d}$. As intersecções entre a linha que liga os centros de projeção e os planos de projeção são chamadas de pontos epipolares, no caso, 
temos $e_{e}$ e $e_{d}$. Se levarmos em consideração um ponto $P$, ainda temos o plano epipolar formado pelos pontos $p_{e}, p_{d}, e_{e}$ e $e_{d}$. A intersecção do plano epipolar com cada plano projetivo resulta nas linhas epipolares.

A utilidade deste modelo está na chamada restrição epipolar. Suponha-se que, utilizando um sistema estéreo, pretende-se procurar na imagem da direita o ponto correspondente ao ponto $p_{e}$, projeção do ponto $P$ na imagem da direita. A princípio, o ponto correspondente poderia estar em qualquer parte do plano projetivo da direita $\left(\Pi_{d}\right)$. Nesse caso, seria necessário realizar uma busca bidimensional no plano projetivo $\Pi_{d}$. Mas a "restrição epipolar" diz que o ponto correspondente ao ponto $p_{e}$ só pode estar na linha epipolar da direita. Como os valores de $e_{e}$, $p_{e}$ e $e_{d}$ são conhecidos, podemos então calcular a linha epipolar da direita e restringir a busca pelo ponto $p_{d}$ a esta linha. Isso reduz o escopo da busca de duas dimensões para apenas uma, economizando um possível gasto computacional ao realizar esta busca.

Para fazer valer a "restrição epipolar" é preciso calibrar o sistema estéreo. O processo de calibração é descrito na Seção 2.1.5.

\subsubsection{Calibração}

Na realidade câmeras não são perfeitas, por conta do uso de lentes, a imagem formada possui distorções e seu centro ótico não é perfeitamente alinhado. Portanto é necessário um processo para estimar os parâmetros intrínsecos de cada câmera, isto é, a matriz $M$ descrita na Seção 2.1.1 e o vetor $D$ apresentado na Seção 2.1.2. No caso de um sistema estéreo, por conta de um alinhamento naturalmente imperfeito das câmeras, ainda se faz necessário estimar a matriz de rotação $R$ e o vetor de translação $T$ que relacionam as duas câmeras. As matrizes $R$ e $T$ são chamados de parâmetros extrínsecos e são ilustrados pela Figura 2.7.

Os parâmetros extrínsecos são necessários para estimar os pontos epipolares, e assim fazer valer a "restrição epipolar". Além disso, é possível alinhar as linhas epipolares horizontalmente, simplificando ainda mais a busca por pontos correspondentes. O processo de alinhar as imagens horizontalmente é chamado de retificação e é descrito na Seção 2.1.6.

Existem vários métodos para estimar os parâmetros intrínsecos e extrínsecos (Zhang, 2008) de uma câmera, porém a descrição de tais métodos foge ao escopo desta dissertação. O método utilizado nesse projeto consiste na apresentação de um padrão conhecido para câmera estéreo (um tabuleiro de xadrez) onde é possível a identificação de pontos correspondentes entre o par de imagens estéreo. Isto possibilita ao método de calibração estimar todos os parâmetros necessários. 


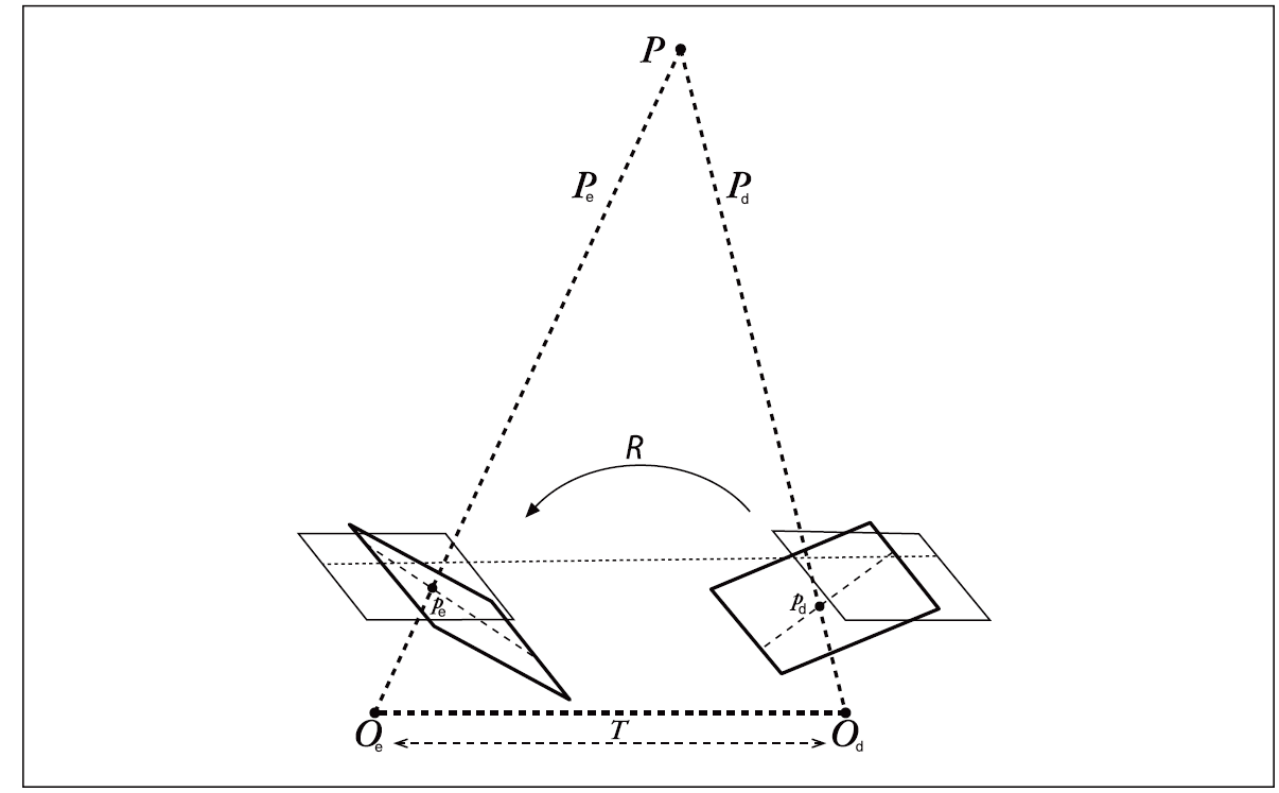

Figura 2.7: Por conta do alinhamento imperfeito presente em qualquer sistema estéreo é necessário estimar as matrizes $R$ e $T$ que relacionam as câmeras (Bradski e Kaehler, 2008).

\subsubsection{Retificação}

O processo de retificação consiste em realizar uma transformação no par de imagens estéreo para alinhá-las horizontalmente, limitando assim a busca realizada pelo método estéreo, de duas, para uma dimensão. Utilizando as informações vindas da calibração os algoritmos de retificação objetivam minimizar a distorção a ser realizada nas imagens e ao mesmo tempo maximizar a área vista em comum pelas câmeras (Bradski e Kaehler, 2008). A Figura 2.8 ilustra o resultado da retificação.

\subsubsection{Métodos Estéreos}

Os métodos estéreos objetivam achar pontos homólogos em um par de imagens estéreo, a Figura 2.9 ilustra o problema. Mesmo em imagens retificadas o custo computacional de um método estéreo é alto, grande parte dos métodos existentes não são passíveis de serem usados em tempo real (Wang et. al., 2006b). Distorção projetiva, oclusão, descontinuidade e ambiguidade são alguns dos desafios que estes métodos tem de superar (Mattoccia, 2010). Por contar com tantos desafios, este tema é um dos mais investigados da área de visão computacional (Scharstein e Szeliski, 2002). Uma revisão geral sobre o tema é apresentada por Scharstein (1999) e Scharstein e Szeliski (2002). 


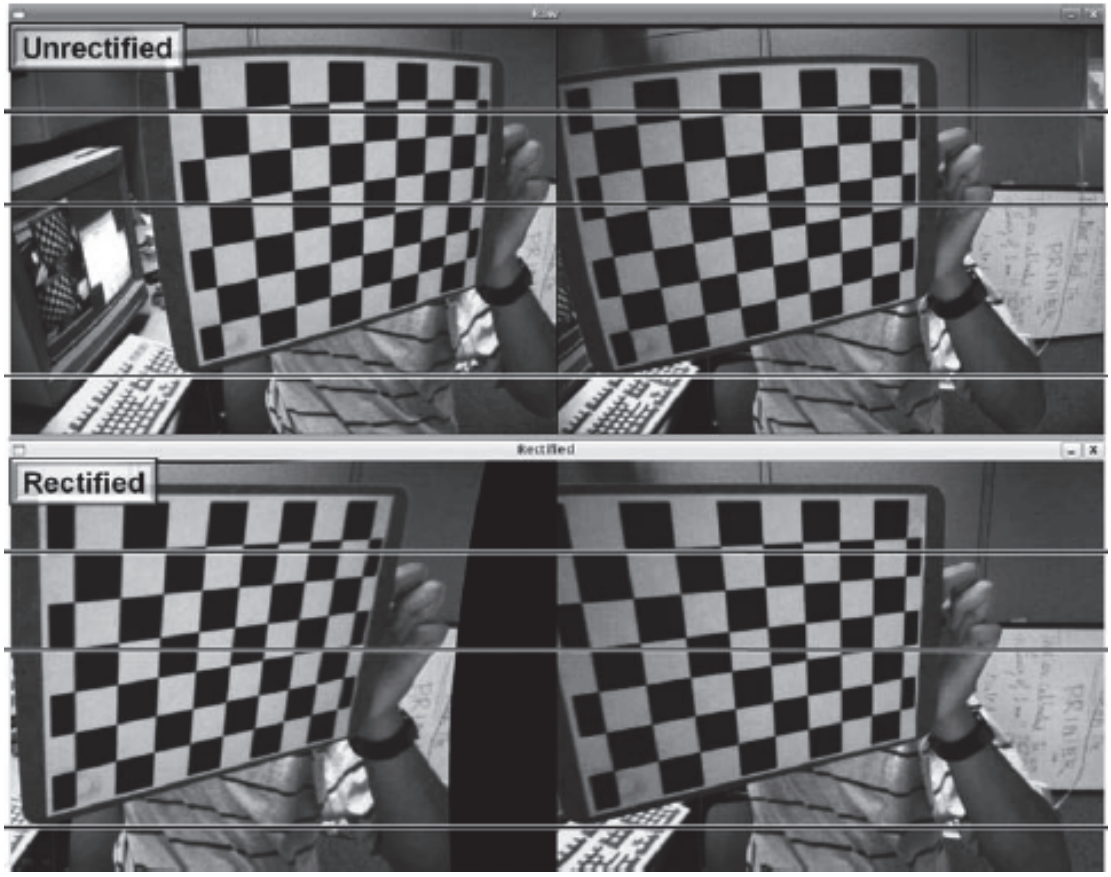

Figura 2.8: Figura ilustrando o processo de retificação estéreo. As linhas horizontais enfatizam a diferença entre imagens não retificadas (superiores) e retificadas (Bradski e Kaehler, 2008).
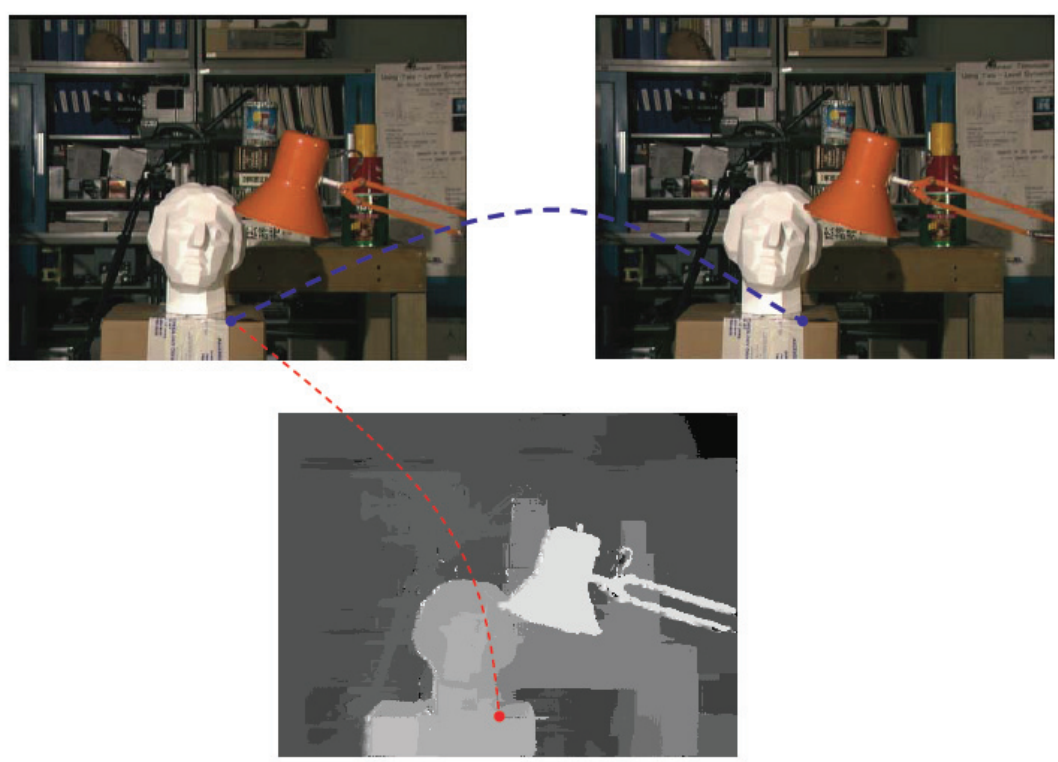

Figura 2.9: Par de imagens estéreo e seu respectivo mapa de disparidades (Mattoccia, 2010).

Apesar da diversidade de métodos desenvolvidos nos últimos anos, existe uma arquitetura geral comum a sua maioria (Brown et. al., 2003; Scharstein e Szeliski, 2002). A Figura 2.10 ilustra esta arquitetura na forma de uma sequencia de computações realizadas. 


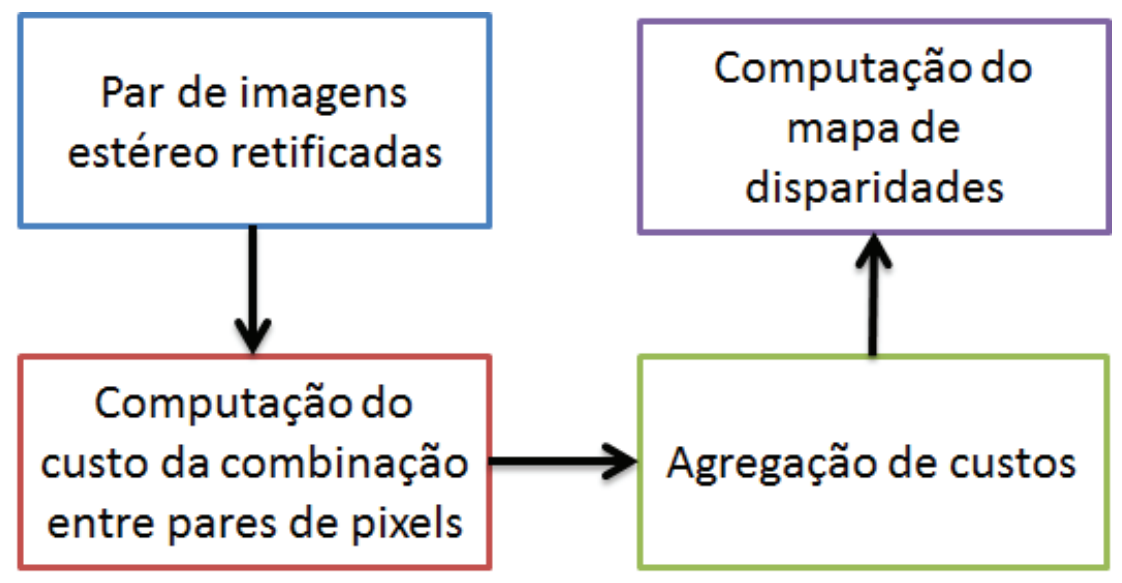

Figura 2.10: Arquitetura comum aos métodos estéreos.

\subsubsection{Computação do Custo da Combinação entre pares de Píxeis}

Na primeira etapa é computada o custo da combinação entre todos píxeis dada uma métrica a ser utilizada na comparação. As mais comuns são a diferença absoluta de intensidade e a diferença quadrática de intensidade por conta da simplicidade e baixo custo computacional (Cyganek, 2007; Scharstein e Szeliski, 2002). O custo entre píxeis é usualmente referido como cost matching e representa a diferença entre píxeis em uma dada métrica. A Equação 2.1 ilustra o cálculo utilizando a métrica de diferença absoluta onde $C$ é o custo, $p$ é o um píxel da imagem esquerda ou base, $q$ da imagem direita ou alvo, $d$ a disparidade e $I$ representa a intensidade.

$$
C(p, q, d)=\left|I_{p}(x, y)-I_{q}(x+d, y)\right|
$$

\subsubsection{Agregação de Custos}

A comparação apenas entre píxeis apresenta diversas limitações: baixo poder discriminativo, sensibilidade a ruídos, entre outros. Sendo assim, é necessária a etapa de agregação, onde uma região geometricamente próxima (região de suporte) é selecionada e utilizada no cálculo da similaridade (cost matching). O tipo mais simples e comum é a agregação em bloco ou janela, onde a região de suporte tem o formato de um quadrado e como centro o píxel a ser comparado. O grande problema em relação a agregação é a suposição implícita de disparidade constante. Assume-se que a intensidade dos píxeis contidos no mesmo bloco é constante, o que, no caso de uma descontinuidade, não é verdade.

Tem-se então a difícil escolha do tamanho do bloco a ser utilizado: por um lado, quanto maior, menor a ambiguidade e mais denso o mapa de disparidade gerado; por outro lado, bordas e pequenos objetos aparecem borrados no mapa de disparidades (Hirschmuller, 2008). Uma 
possível solução seria a utilização de blocos com tamanho adaptativo, porém tal técnica não resolve o problema por completo (Hirschmuller, 2008). Uma análise de alguns dos tipos de agregação pode ser vista em Wang et. al. (2006a). Baseando-se na agregação em bloco e na diferença absoluta de intensidade temos a Equação 2.2 ilustrando esta fase, onde $U$ é o conjunto contendo os valores de $x$ e $y$ determinado pelo tamanho do bloco escolhido. É importante ressaltar que métodos estéreos globais costumam pular esta etapa, como será explicado na Seção 2.1.7.3.

$$
C(p, q, d)=\sum_{i, j \in U}\left|I_{p}(x+i, y+j)-I_{q}(x+i+d, y+j)\right|
$$

\subsubsection{Computação do Mapa de Disparidades}

Por fim, tem-se a escolha das combinações (matchings) a serem feitas, efetivamente, para geração do mapa de disparidades. Nessa etapa é imprescindível realizarmos uma distinção entre métodos globais e locais. Métodos locais utilizam apenas valores de intensidade limitados geometricamente ao redor dos pontos candidatos, enquanto que método globais tendem a usar uma maior quantidade de valores e ainda modelar como um problema de minimização energética (problema de otimização). Tendo feita tal distinção, nessa etapa os métodos locais se limitam à escolha da combinação com menor custo (winner-takes-all) enquanto que métodos globais realizam a maior parte de seu trabalho, minimizando uma função energética previamente definida. Tal distinção deverá ficar mais clara na Seção 2.1.7.4.

\subsubsection{Taxonomia dos Métodos Estéreos}

Apesar de não existir uma taxonomia clara e consensual por conta da grande variedade de métodos, é importante salientar algumas distinções entre os métodos existentes. Uma das maneiras de se classificar um método é referente ao mapa de disparidades gerado, podendo este ser esparso ou denso. Os mapas esparsos têm utilidade limitada já que parte da imagem carece de informações de profundidade (Cyganek, 2007). Uma outra maneira é classificar, como citado na Seção 2.1.7.3, em relação ao modo com que as combinações são efetivamente selecionadas. Métodos locais levam em consideração apenas intensidades próximas aos píxeis candidatos, são geralmente mais simples de se implementar e possuem um custo computacional relativamente baixo (Cyganek, 2007).

Métodos globais modelam a tarefa de correspondência entre píxeis como um problema de minimização energética (problema de otimização), sendo o objetivo achar a função $d$ de disparidades que minimize a energia global. Em geral estes podem ser descritos pela Equação 2.3, 
onde $E_{\text {dados }}$ se refere ao custo das combinações entre o par de imagens, $E_{\text {restricao à restrições ou }}$ suposições feitas a fim de tornar a busca computacionalmente tratável e $\lambda$ regula as restrições. Uma restrição muito utilizada é referente as intensidades de píxeis vizinhos, estas devem variar suavemente.

$$
E(d)=E_{\text {dados }}(d)+\lambda E_{\text {restricao }}(d)
$$

Segundo Scharstein e Szeliski (2002), usado de referência na taxonomia de métodos estéreos, existem apenas métodos globais e locais ${ }^{1}$. No entanto, os autores Hirschmuller (2005) e Haller et. al. (2010) passaram a usar o termo semi-global para distinguir métodos que realizam várias otimizações parciais (em uma dimensão) a fim de aproximar uma otimização global, daqueles que realizam a otimização global diretamente envolvendo toda imagem (duas dimensões). Um exemplo de método semi-global vem de parte dos algoritmos que utilizam a técnica de programação dinâmica em sua otimização, onde é realizada uma otimização linha a linha e, por não assegurar uma consistência vertical, estes métodos geram mapas de disparidades bem característicos como pode ser visto na Figura 2.11.

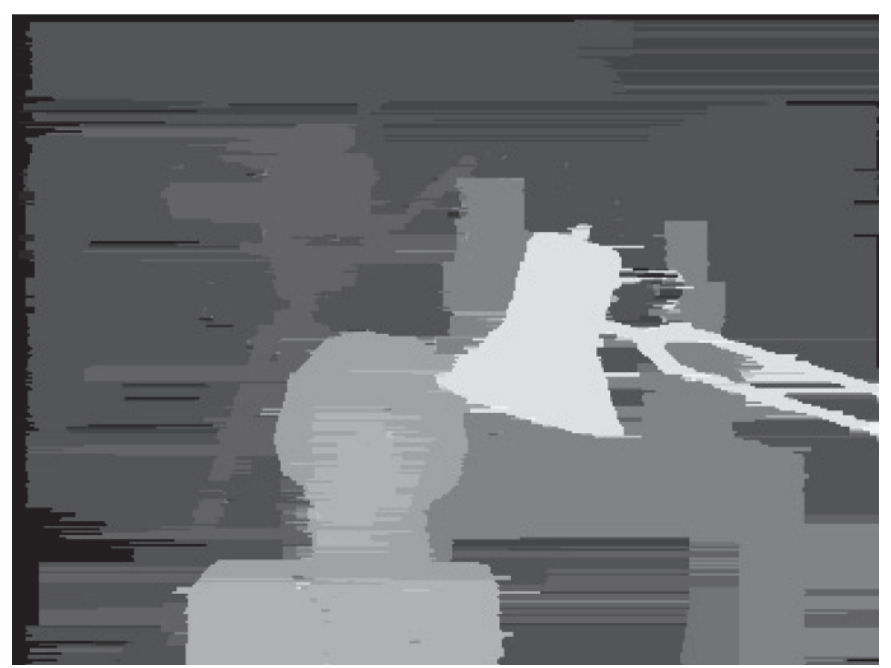

Figura 2.11: Resultado típico de um método estéreo que utiliza a técnica de programação dinâmica (Scharstein e Szeliski, 2002).

Métodos globais costumam produzir mapas de disparidades mais precisos que métodos locais (Scharstein e Szeliski, 2002), mas o custo computacional envolvido impede a maioria de ser utilizada em aplicações que necessitem de informações de profundidade em tempo real. Apenas recentemente algumas implementações (Na et. al., 2009) de métodos globais conseguiram superar tal limitação e usualmente envolvem a utilização de uma unidade de processamento

\footnotetext{
${ }^{1}$ Apesar de não criar uma nova classe de métodos o autor deixa claro as diferenças entre métodos que realizam otimização unidimensional dos que a realizam em duas dimensões.
} 
gráfico. Alguns métodos semi-globais possuem qualidade comparável a de um método global, porém com um custo computacional muito menor (Haller et. al., 2010; Hirschmuller, 2005).

\subsection{Random Sample Consensus}

Proposto por Fischler e Bolles (1981), RANSAC (RANdom SAmple Consensus) é um paradigma para se enquadrar um determinado modelo matemático em um conjunto de dados. Tal paradigma vem sendo utilizado com frequência pela comunidade de robôs móveis (Happold e Ollis, 2006; Konolige et. al., 2008). Sua simplicidade, desempenho e robustez para lidar com dados experimentais são alguns dos motivos que levaram à sua escolha.

O paradigma localiza, iterativamente, a melhor combinação entre os dados e um dos modelos disponíveis, estimando os melhores valores para os parâmetros livres do modelo. Uma diferença para as técnicas convencionais é que ao invés de utilizar a maior quantidade de dados possível para se obter a solução inicial, o paradigma RANSAC começa com um pequeno conjunto de dados e o expande com dados consistentes quando possível (Fischler e Bolles, 1981). A ideia é simples: o paradigma começa por selecionar alguns dados aleatoriamente que satisfaçam os parâmetros livres do modelo e então checa, usando uma margem de erro pré-definida $\epsilon$, a quantidade de dados que se encaixa neste modelo. O processo se repete $N$ vezes ou até encontrar os parâmetros do modelo que se enquadre em $\tau$ por cento da amostra. A Figura 2.12(a) mostra um conjunto de pontos bidimensionais onde a técnica RANSAC foi utilizada para encontrar os parâmetros de uma linha, a Figura 2.12(b) mostra o resultado.

Os principais passos do paradigma RANSAC podem ser resumidos pelo algoritmo 1 .

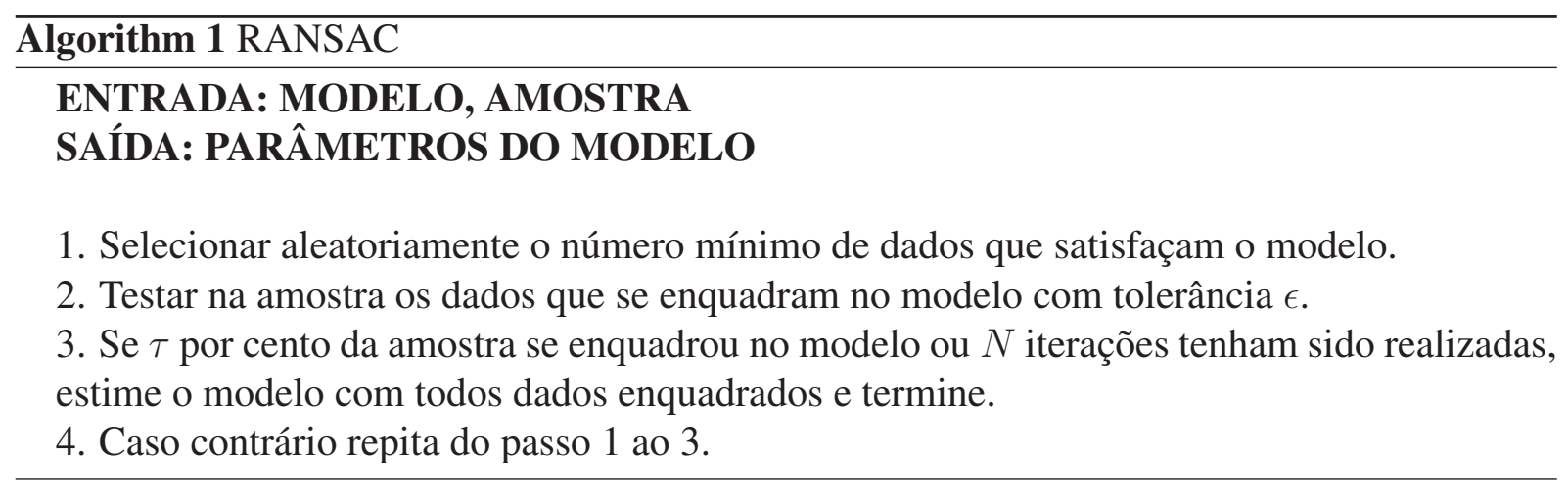




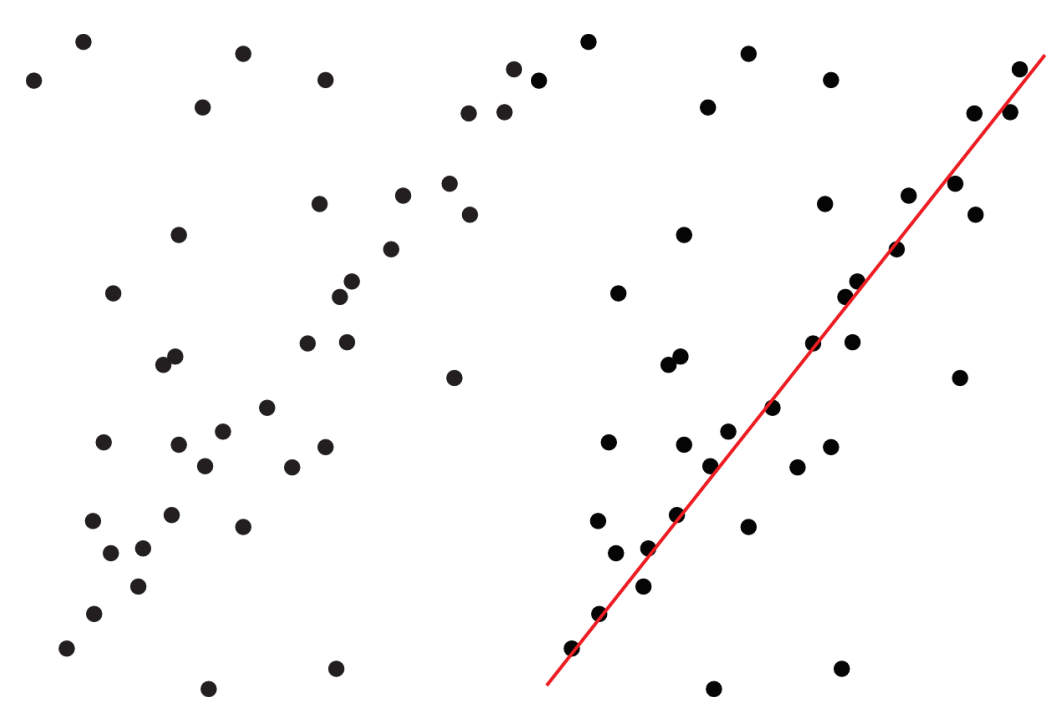

(a) Conjunto de pontos onde a téc- $\quad$ (b) Reta estimada pelo método. nica RANSAC será aplicada.

Figura 2.12: Ilustração do resultado da técnica RANSAC utilizada a fim de encontrar uma reta em uma nuvem de pontos.

\subsection{Unidade de Processamento Gráfico}

Unidade de processamento gráfico ou Graphics Processing Unit (GPU) é o principal componente de uma placa de vídeo, uma unidade dedicada ao processamento gráfico. Sua estrutura paralelizada a torna mais hábil a este tipo de tarefa que uma CPU (Central Processing Unit). Desde o começo dos anos 90 as GPUs têm evoluído por uma insaciável demanda do mercado por gráficos 3D em tempo real e de alta definição. GPUs modernas são um processador massivamente paralelo, multithread, multicore, com uma tremenda capacidade de processamento e uma largura de banda muito alta (NVIDIA, 2010).

A Figura 2.13 faz uma comparação entre a capacidade de processamento de CPUs e GPUs ao longo dos anos utilizando bilhões de operação com ponto flutuante por segundo (GFLOP) como fator comparativo.

Toda a arquitetura de uma GPU tem como propósito o processamento de gráficos, essa estrutura era formada por um conjunto de estágios com diferentes funções inerentes ao processamento gráfico, como pode ser visto na Figura 2.14

Alguns destes estágios se tornaram programáveis através de sharders, que são um conjunto de instruções executadas pela GPU a fim de alterar alguma característica de um vértice ou píxel. Estes eram utilizados para trazer mais realismo sem muitos prejuízos ao desempenho de aplicações que deles se valem. Com seu hardware ficando cada vez mais programável, 


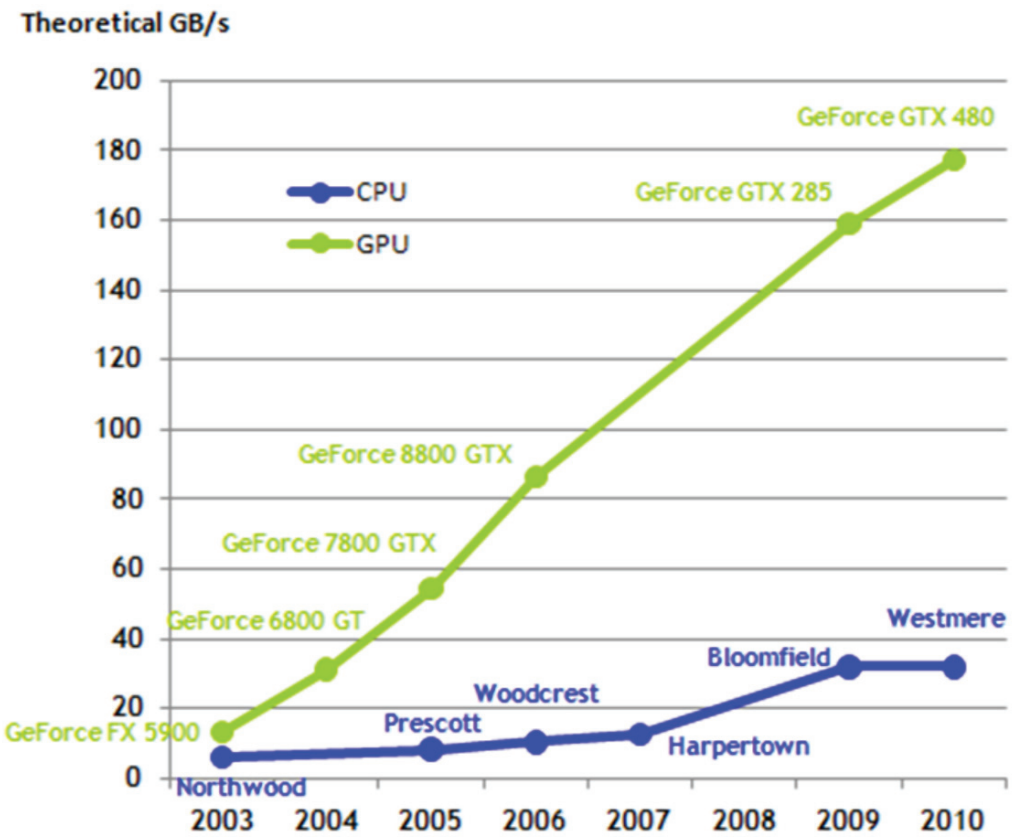

Figura 2.13: Comparação entre a capacidade de processamento de GPUs e CPUs ao longo dos anos (NVIDIA, 2010).

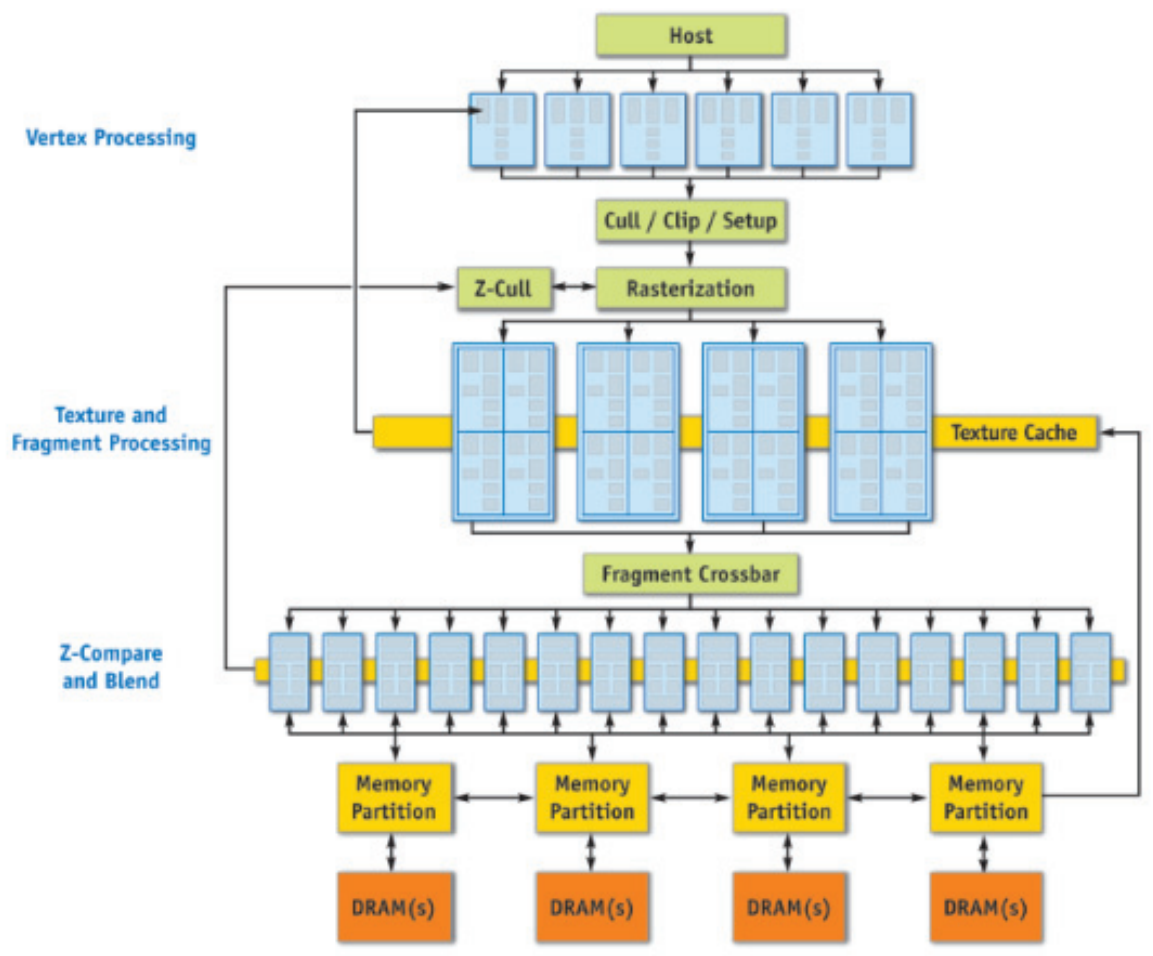

Figura 2.14: Arquitetura da placa de vídeo GeForce 6800GT (Kilgariff e Fernando, 2005).

aplicações não relacionadas com gráficos se tornaram aptas para execução em GPU (Kilgariff 
e Fernando, 2005). Daí surgiu a ideia de utilizar uma GPU para o processamento de aplicações de propósito geral.

GPUs modernas unificaram os estágios onde eram processados os shaders, dando origem a arquitetura unificada de shader ou Unified Shading Architecture, possibilitando um uso mais flexível do hardware de renderização (Case, 2006). Um exemplo de arquitetura unificada pode ser vista na Figura 2.15, onde diferentes tipos de shaders (de vértice e de píxel) são computados pelas mesmas unidades de processamento.

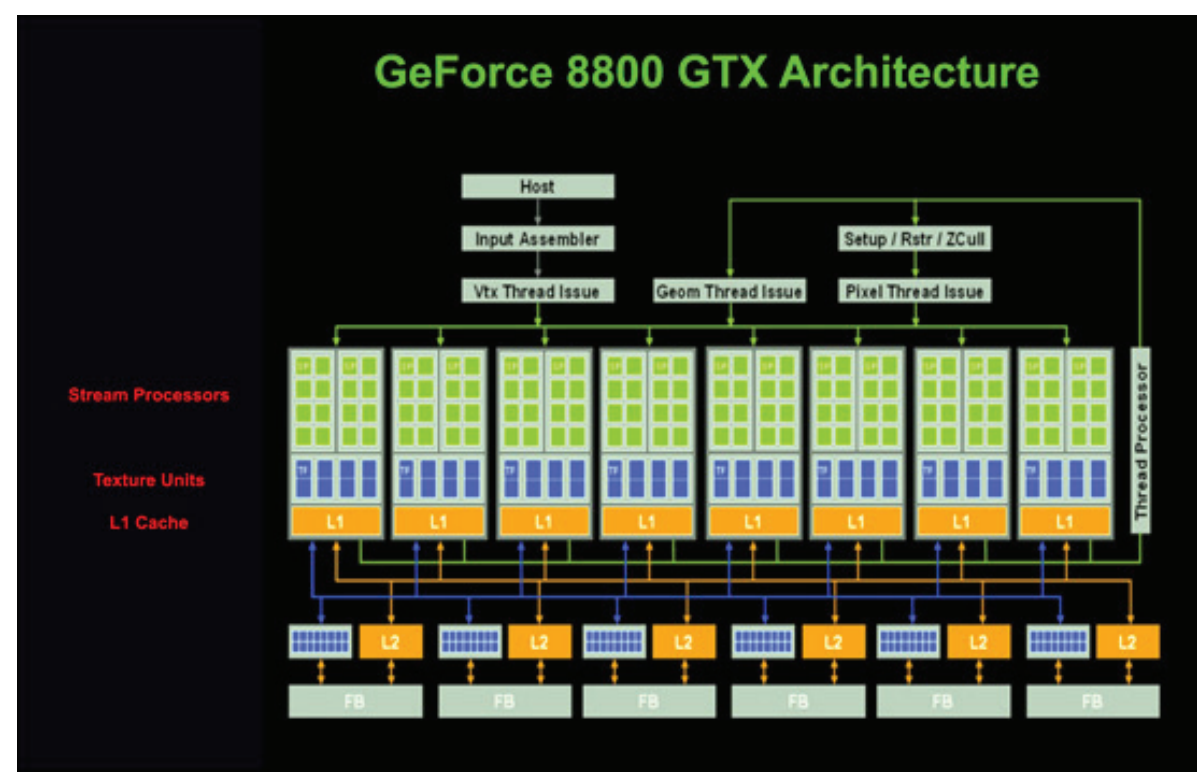

Figura 2.15: Arquitetura da placa de vídeo GeForce 8800GTX (Case, 2006).

\subsubsection{Programação de Propósito Geral}

Apesar de ter se tornado programável com o propósito de possibilitar efeitos gráficos, viu-se ai a possibilidade de explorar a capacidade computacional de um GPU para aplicações de propósito geral. Para entender como pode ser possível utilizar uma GPU para aplicações comuns é interessante conhecer a arquitetura de um estágio programável.

Como mostra a Figura 2.16, uma GPU é dividida em grupos de processadores (multiprocessadores). Cada um desses multiprocessadores é constituído de vários processadores que executam uma thread ou work-item cada, e caso estejam dentro de um mesmo multiprocessador estas threads podem se comunicar através de uma memória rápida (shared memory ou local memory) ou ainda serem sincronizadas.

Threads de multiprocessadores diferentes só podem se comunicar através da memória global (Device Memory ou Global Memory) a qual todos processadores tem acesso, mas não podem 


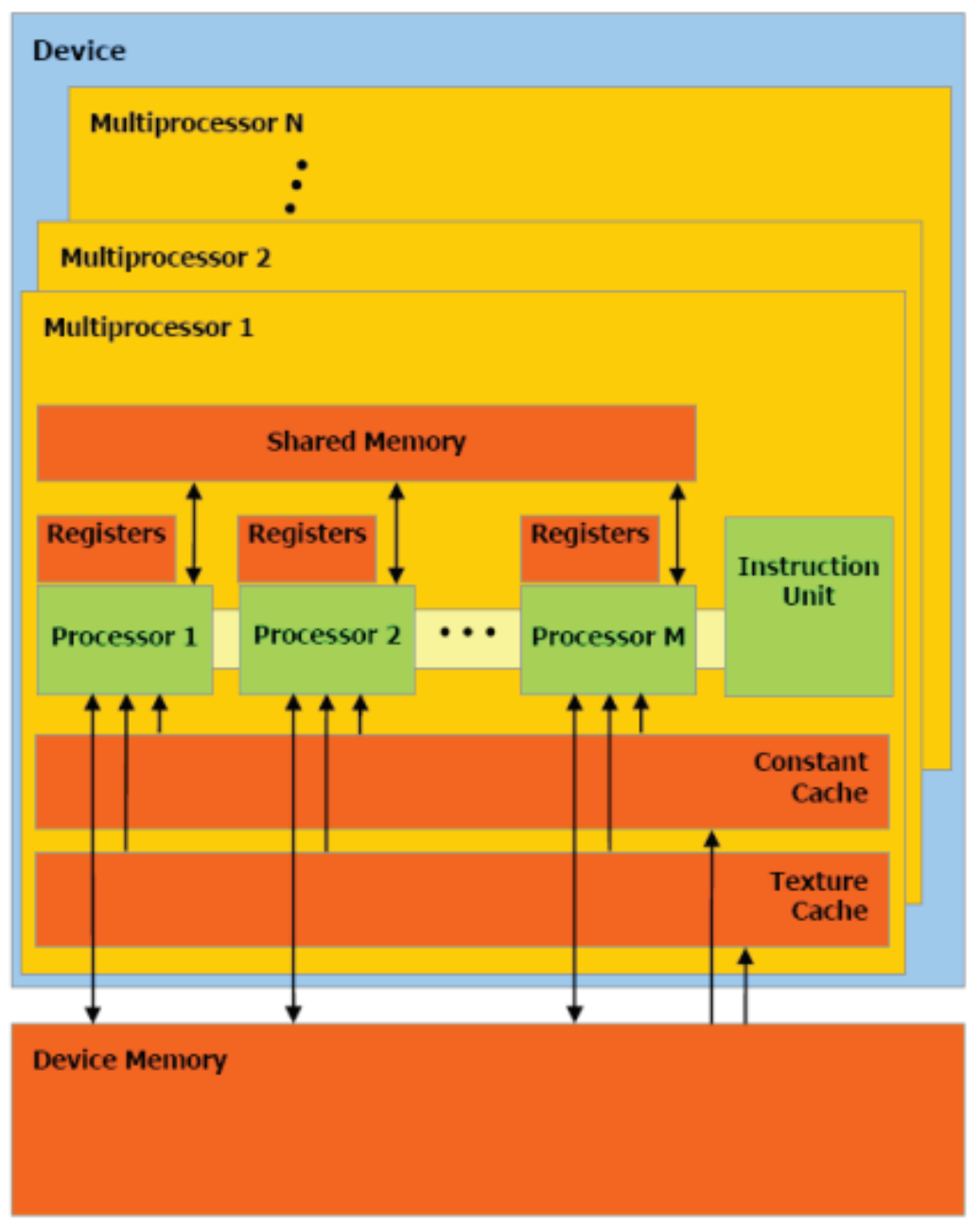

Figura 2.16: Arquitetura de um estágio programável (NVIDIA, 2010).

ser sincronizadas. As threads referidas aqui são diferentes das threads comuns, estas são mais leves devido ao fato de que a GPU implementa o controle de thread em hardware, diferentemente das threads que rodam em uma CPU, que são controladas pelo sistema operacional. Na programação de uma GPU existe o conceito de grupo de threads ou work-group, todas as threads pertencentes a um mesmo grupo serão executadas por um mesmo multiprocessador, podendo então compartilhar a memória local e serem sincronizadas.

É importante lembrar que é o programador quem vai escolher quantos grupos e qual o tamanho da cada grupo que será executado em uma GPU e que a cada chamada todos os processadores irão executar o mesmo programa ou kernel. A Figura 2.17 apresentam um programa que exemplifica como é feita a soma de dois vetores ( $a$ e $b$ ) utilizando-se uma GPU, em OpenCL (Open Computing Language $)^{2}$.

\footnotetext{
${ }^{2}$ http://www.khronos.org/opencl/
} 


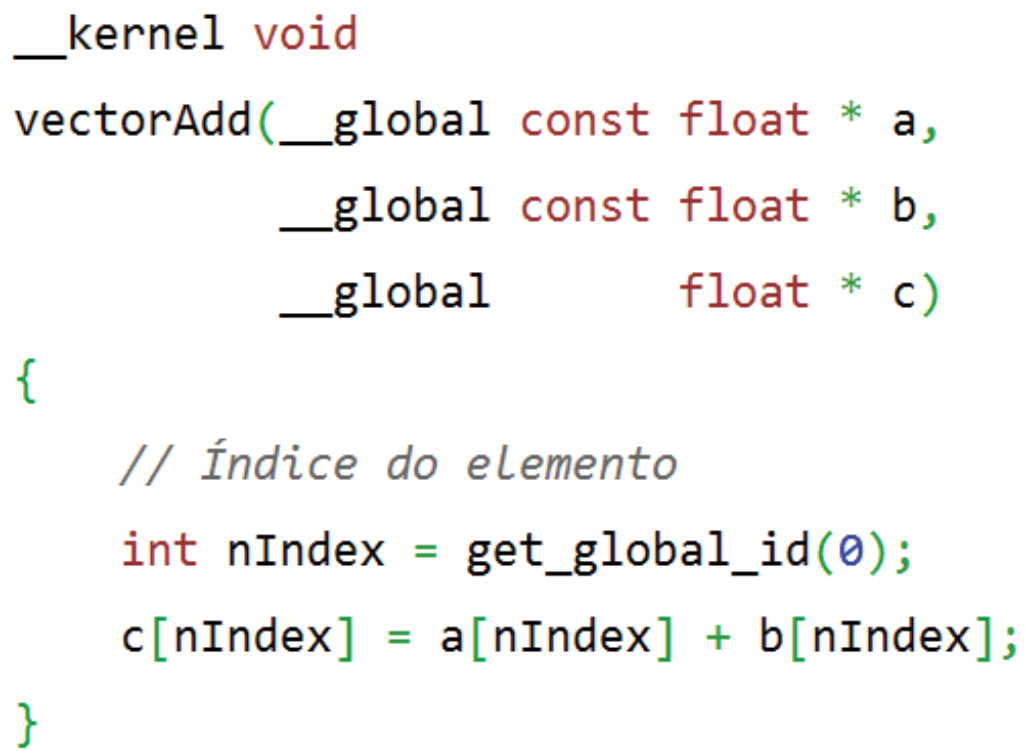

Figura 2.17: Programa para somar dois vetores utilizando a linguagem OpenCL.

Nota-se a ausência de um laço, isso porque esta mesma função (kernel) será executada em uma quantidade de vezes igual ao tamanho do vetor. Nesse caso cada thread faz uma soma e a guarda no vetor destino $(c)$. Neste simples exemplo não existe preocupação com grupos já que não é feita nenhuma otimização.

Para entender melhor o código é necessário uma explicação das palavras chaves que não existem na linguagem C. _ kernel significa que esta função será processada pela GPU, _ global significa que o vetor esta alocado na memória global ao passo que _local significa que o vetor esta alocado na memória de um multiprocessador (shared memory ou local memory).

A função get_global_id() retorna índice da thread atual em absoluto, independente do grupo ao qual esta pertence. A função get_local_id() retorna o índice da thread em relação ao grupo, get_group_id() retorna o índice do grupo e get_local_size() retorna o tamanho do grupo. Sendo assim, get_global_id() é calculado da seguinte forma: get_group_id() * get_local_size() + get_local_id(). Ou seja, para calcular o número da thread em absoluto é necessário saber o grupo atual, multiplica-lo pelo tamanho de cada grupo e ainda somar sua posição relativa ao grupo atual.

\subsubsection{Warp}

Warp se refere ao conjunto de threads dentro de um mesmo grupo cujas instruções são executadas estritamente em paralelo, ou seja, uma warp sempre executa a mesma instrução ao mesmo tempo. O número de threads que compõem uma warp é atualmente 32 na maioria das GPUs (NVIDIA, 2010). Caso exista uma instrução condicional que afete parte de uma warp, as thre- 
ads que não executarem o trecho condicional ficarão esperando o resto da warp terminá-lo, isso compromete o desempenho do programa e deve ser evitado.

\subsubsection{Half-Warp}

Representa metade de uma warp, ou seja, 16 threads de um mesmo grupo. Se algumas condições forem satisfeitas, o acesso a memória do dispositivo é feita em paralelo por uma half-warp. A principal condição para que o acesso seja realizado em paralelo é que a memória a ser acessada esteja em sequência (acesso alinhado), caso contrário o acesso será feito sequencialmente, o que compromete significativamente o desempenho da aplicação. A Figura 2.18 ilustra um acesso desalinhado (sequencial) e um alinhado (paralelo) às coordenadas $(x, y, z)$ de três pontos $P^{1}$ (vermelho), $P^{2}$ (amarelo) e $P^{3}$ (verde).

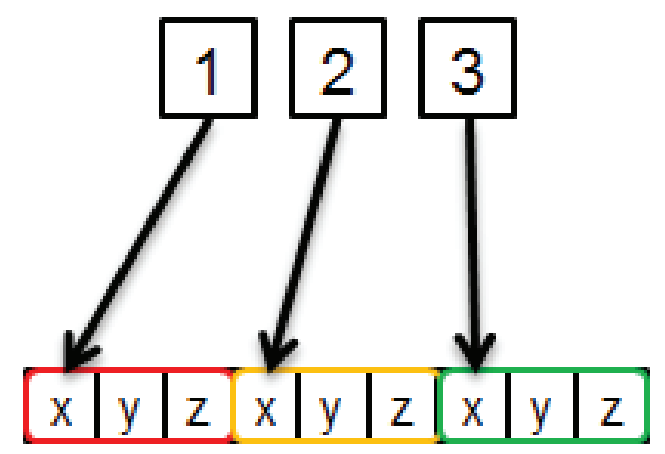

Acesso desalinhado

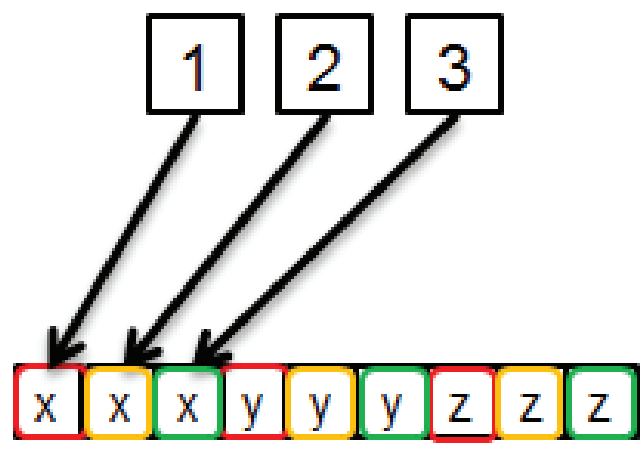

Acesso alinhado

Figura 2.18: Acesso desalinhado e alinhado às coordenadas de três pontos.

\subsection{Vector Field Histogram}

Vector Field Histogram (VFH) é um método para desvio de obstáculos em tempo real (Borenstein e Koren, 1991). Este método foi escolhido por ser simples e de fácil implementação. Apesar de ser um método local, isto é, não realiza planejamento de trajetória, o método atende aos requisitos impostos para validação dos demais módulos desenvolvidos.

O método possui três níveis de representação de dados. O primeiro se trata de um mapa cartesiano discreto bidimensional $C$ onde, com base nas informações do sensor utilizado, cada célula $(i, j)$ contém um valor $c_{i, j}$ que representa a probabilidade da existência de um obstáculo. O nível intermediário é criado com base no primeiro, consistindo de um histograma polar $H$ contando com $n$ setores angulares. Em cada um dos setores $k$ existe um valor $h_{k}$ que representa 
a densidade de obstáculos na direção do ângulo $k$. O último nível consiste nas saídas para a direção e aceleração do robô.

Simplificadamente, o mapeamento do primeiro nível $C$, no histograma $H$, é feito com base em uma região em $C$ ao redor da posição do robô e dependente de sua orientação. As células de $C$ que estiverem no ângulo $k$ constituem o valor $h_{k}$ e cada célula tem um peso inversamente proporcional a distância de sua posição em relação a posição do robô. A Figura 2.19 ilustra o histograma gerado pelo método, onde A, B e C são prováveis obstáculos.

\section{Histograma Polar}

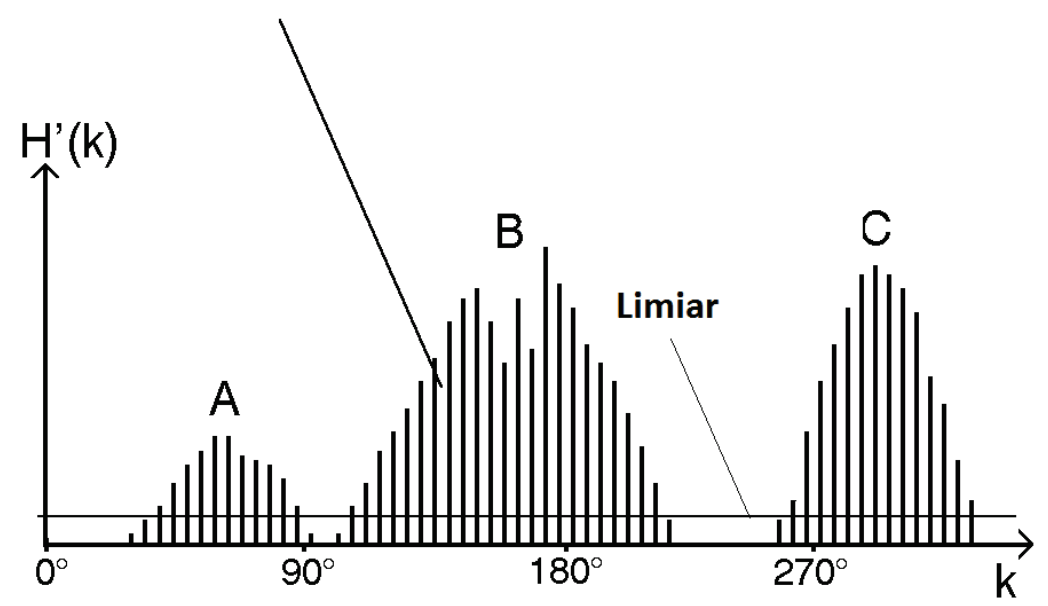

Figura 2.19: Ilustração do histograma gerado pelo método VFH (Borenstein e Koren, 1991).

De acordo com um limiar pré-definido, são definidos setores navegáveis $h_{k}<L I M I A R \mathrm{e}$ não navegáveis $h_{k}>=L I M I A R$. Posteriormente são definidos vales candidatos, um vale candidato é constituído por sequência de setores navegáveis. Vales candidatos são então divididos em vales estreitos e vales largos, tal divisão é feita baseada no número de setores de que são constituídos. Caso o número de setores seja maior que $S_{\max }$ o vale é considerado largo, caso contrário estreito. Usualmente existem dois ou mais vales candidatos e o método seleciona o vale mais próximo do setor alvo $k_{\text {alvo }}$. Para selecionar setor dentro do vale o método utiliza a seguinte equação:

$$
\theta=\frac{k_{n}+k_{f}}{2}
$$

Onde $\theta$ é o setor selecionado (e portanto, o ângulo de esterçamento), $k_{n}$ é o setor, dentro do vale selecionado, mais próximo do setor $k_{a l v o}$ e $k_{f}=k_{n}+S_{\text {max }}$. A aceleração do carro pode ser constante e definida por $V_{\max }$ ou então pode ser reduzida com base na densidade de obstáculos presente na orientação atual do carro $h_{c}{ }^{\prime}$ utilizando as seguintes Equações: 


$$
V^{\prime}=V_{\max }\left(1-h_{c}^{\prime \prime} / h_{m}\right)
$$

$\mathrm{e}$

$$
h_{c}{ }^{\prime \prime}=\min \left(h_{c}{ }^{\prime}, h_{m}\right)
$$

Onde $h_{m}$ é uma constante que escala a redução de velocidade. A velocidade ainda é reduzida proporcionalmente ao ângulo de esterçamento de acordo com a Equação:

$$
V=V^{\prime}\left(1-\Omega / \Omega_{\max }\right)+V_{\min }
$$

Onde $V_{\min }$ é a velocidade mínima que se deseja atingir, $\Omega$ o ângulo de esterçamento atual e $\Omega_{\max }$ o ângulo máximo de esterçamento da plataforma utilizada. 


$=$

\section{Trabalhos Relacionados}

A detecção de vias navegáveis e obstáculos, sendo um complemento do outro, constitui uma das partes fundamentais da navegação autônoma. Diversas técnicas e tipos de sensores são empregados nesta tarefa, estes dependem, na maior parte das vezes, do tipo do ambiente em que se pretende navegar.

A maioria das pesquisas na área começou por ambientes internos e controlados, entretanto com o avanço das técnicas, atualmente boa parte das pesquisas se dedica à navegação em ambientes externos, utilizando robôs de grande porte e veículos automotores. O maior exemplo disso é a competição DARPA Urban Challenge (DARPA, 2007) realizada pelo exército americano que, em 2007, tinha como desafio criar um carro autônomo capaz de atravessar 97 quilômetros em área urbana. Para isso diversas técnicas de detecção de vias navegáveis foram utilizadas (Campbell et. al., 2007; Newman e Lead, 2007; Thrun et. al., 2006).

Na Europa também existe uma iniciativa relacionada, a The European Robot Trial (ELROB) (ELROB, 2011), que por sua vez é dividida em C-ELROB, que promove o desenvolvimento de veículos autônomos para fins civis e a M-ELROB, que se destina a fins militares. A competição é dividida em várias tarefas e cenários, consistindo principalmente na realização autônoma de um percurso em dado ambiente.

No Brasil existem alguns projetos relacionados com navegação robótica veicular, os três principais são: CARINA sediado na Universidade de São Paulo, no Laboratório de Robótica Móvel (LRM/ICMC) do qual este trabalho faz parte (Figura 3.1(a)); o Carro Autônomo De- 
senvolvido pela Universidade de Minas Gerais (UFMG), também conhecido como CADU que utiliza um Chevrolet Astra 2003 (Figura 3.1(b)) como plataforma experimental. E ainda existe o projeto Driving $4 u$ desenvolvido pela Universidade Federal de Itajubá (UNIFEI) que conta com um veículo Chevrolet Zafira (Figura 3.1(c)) para realização de experimentos.

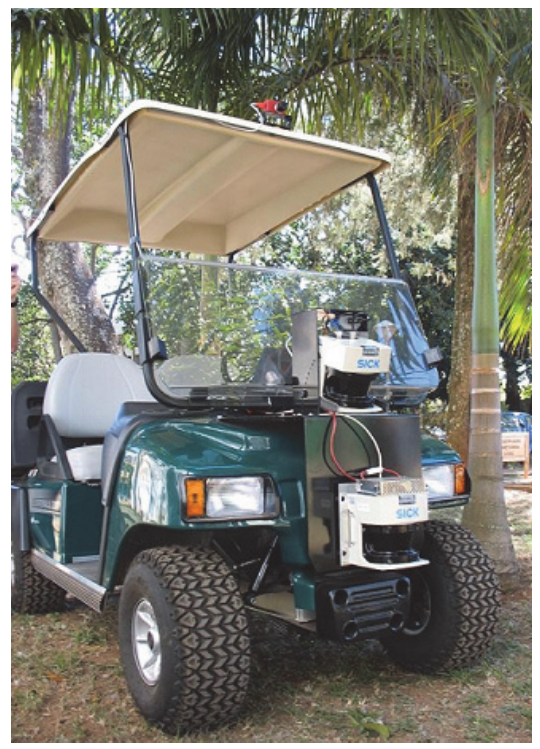

(a) Plataforma robótica do projeto CARINA.

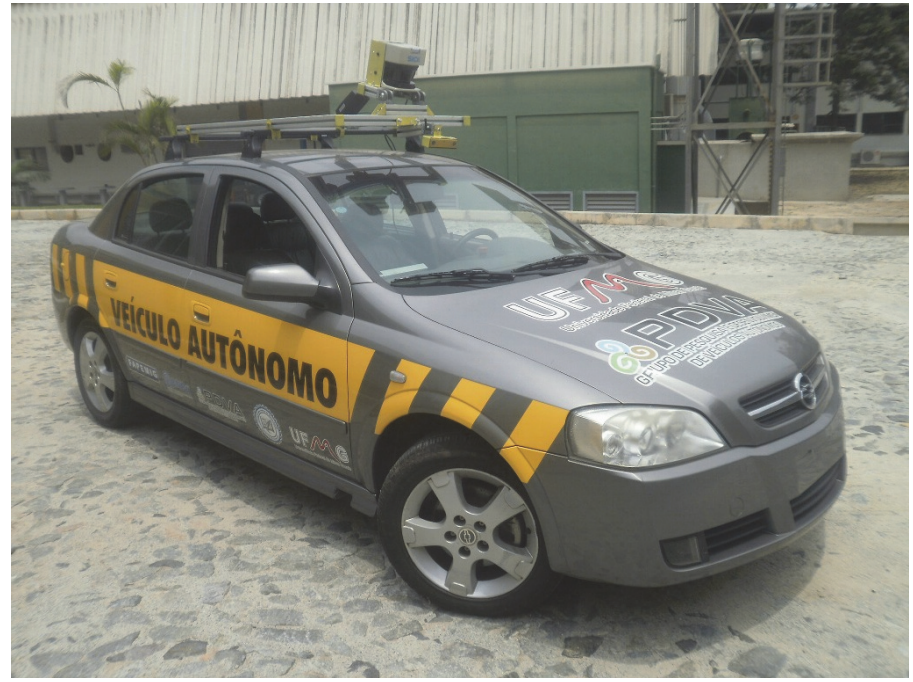

(b) Chevrolet Astra utilizado como plataforma de testes pelo projeto CADU.

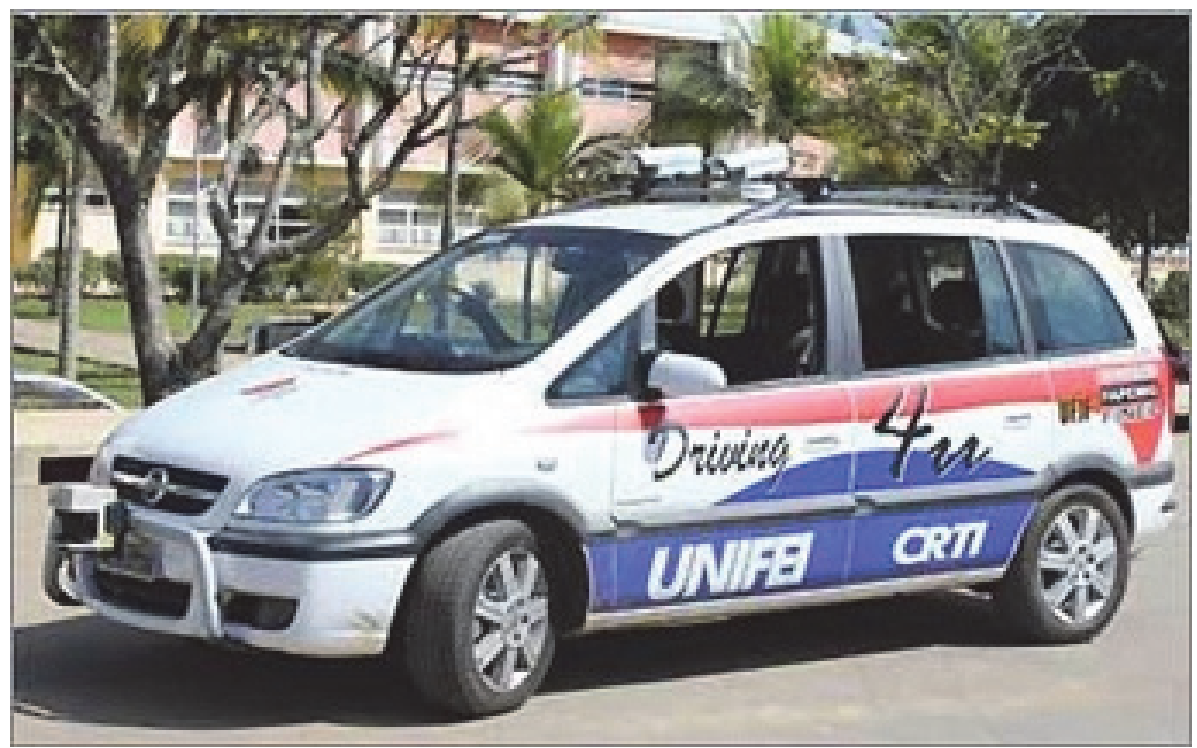

(c) Carro utilizado no projeto Driving $4 u$ da UNIFEI.

Figura 3.1: Plataformas veiculares brasileiras. 


\subsection{Visão Monocular}

Muitos trabalhos utilizam uma câmera comum (monocular) na obtenção das imagens e uma determinada técnica para processar essa imagem e assim identificar áreas navegáveis. Dentre esses trabalhos, podemos citar Broggi e Bertè (1995), que utiliza uma combinação de filtros de imagem para detectar as faixas pintadas no asfalto e, posteriormente, a região em que o veículo deve se manter como mostra a Figura 3.2.

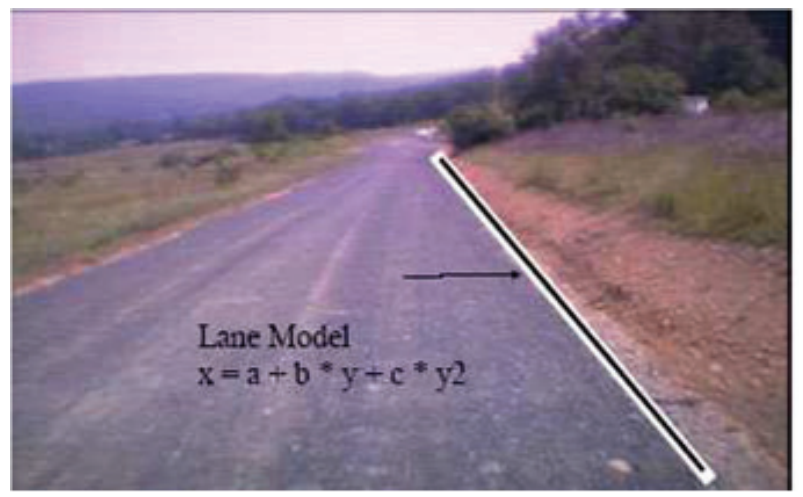

(a) Detecção dos limites da rua através de processamento de imagem.
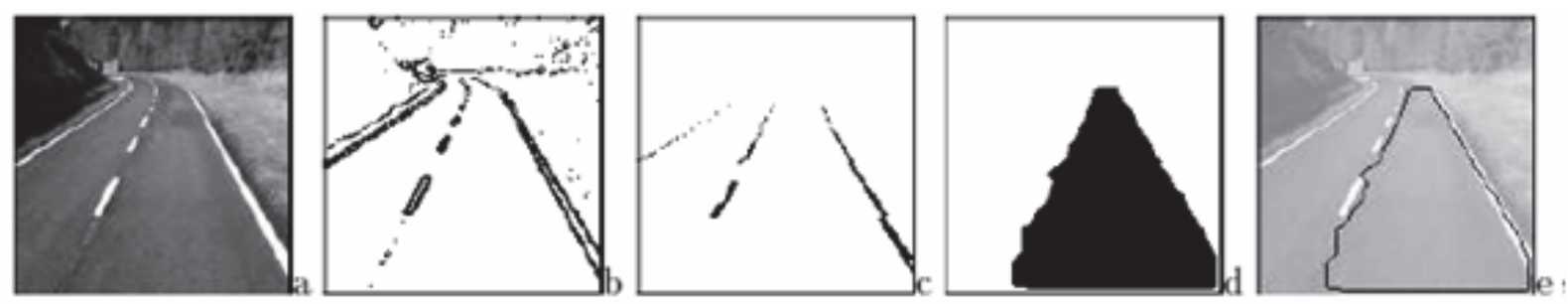

(b) Utilização de técnicas de segmentação para identificação das áreas navegáveis

Figura 3.2: Direção autônoma realizada a partir do processamento de imagens (Broggi e Bertè, 1995).

Grande parte das técnicas propostas para identificar faixas de trânsito utiliza filtros de borda, e posteriormente, detectores de padrão para identificar retas, que normalmente representa as faixas de trânsito, conforme apresentado em Lu et. al. (2002) e mostra a Figura 3.3.

Técnicas como Wang et. al. (1999) utilizam complexas funções matemáticas para identificar e representar as linhas que definem as faixas de trânsito (Figura 3.4). Comparado com o trabalho descrito anteriormente, essa técnica permite a detecção correta mesmo em curvas bastante acentuadas.

Outros trabalhos na área de processamento de imagens vêm obtendo bons resultados na subárea de road following, como Rasmussen (2004), Chaturvedi et. al. (2004), Ramstrom e 

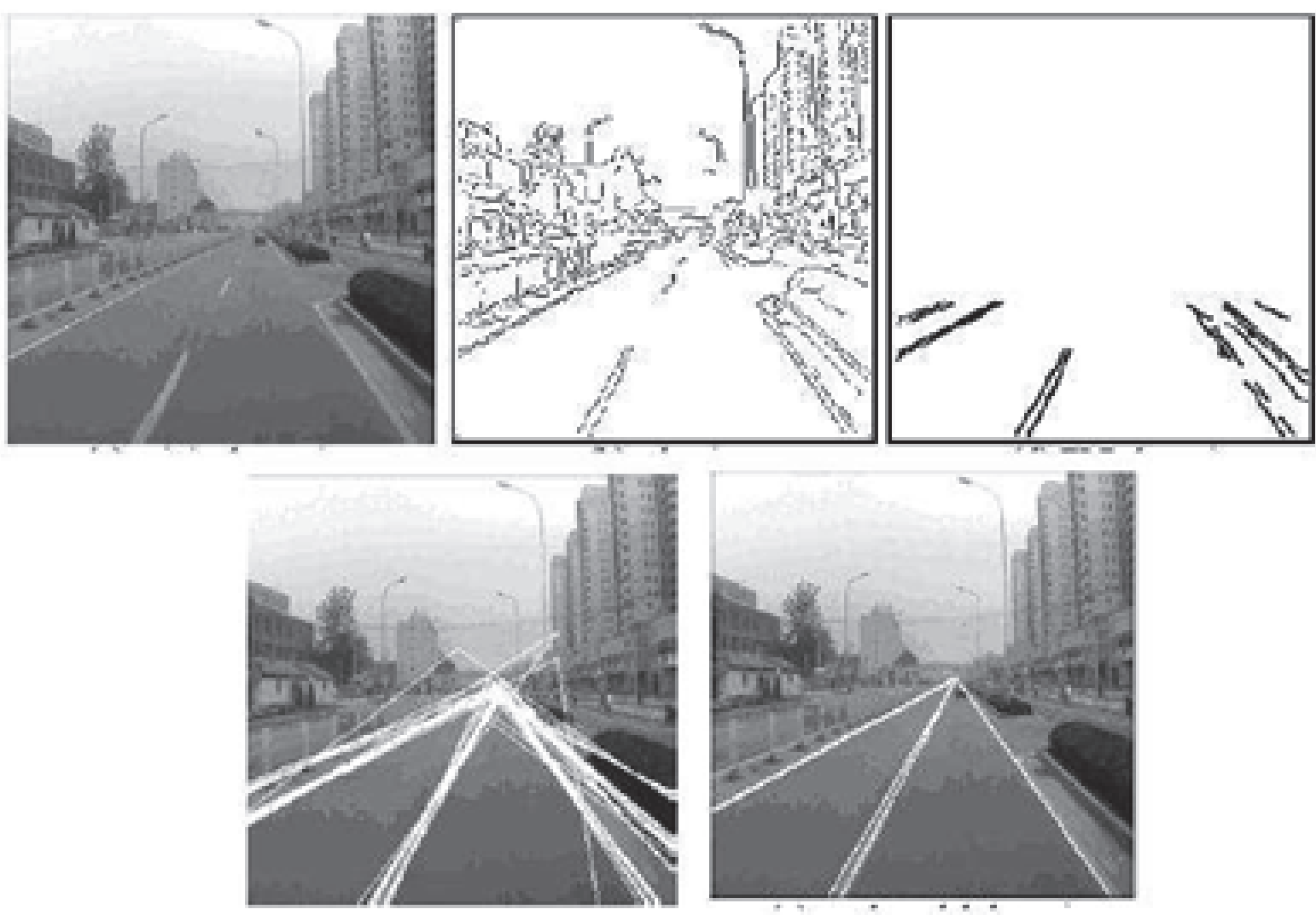

Figura 3.3: Identificação das faixas de trânsito através da identificação de retas na imagem (Lu et. al., 2002).
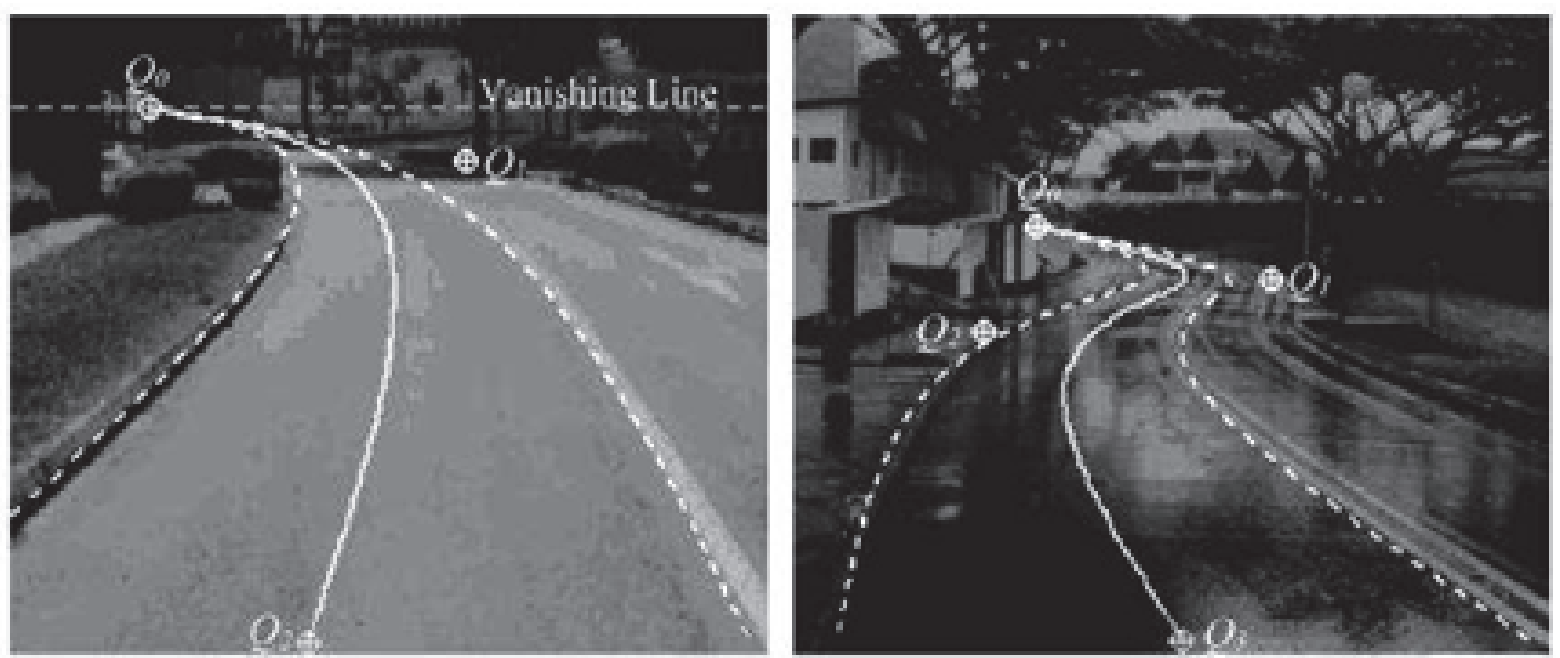

Figura 3.4: Identificação das linhas de trânsito (Wang et. al., 1999).

Christensen (2005), Jeong e Nedevschi (2006) e Guo et. al. (2006). Um dos mais recentes é o Tan et. al. (2006) que apresentou um modelo baseado em cor com aprendizado em tempo real para determinação de rua. Este modelo se baseia na ideia de separar a rua da paisagem 
usando histogramas de cores. Para a rua é usado um conjunto de histogramas e para a paisagem é usado apenas um. Manter vários modelos de cor para a rua ajuda o algoritmo a detectá-la mesmo perante variações de iluminação e presença de sombra. $\mathrm{O}$ algoritmo cria o histograma de uma parte da imagem baseando-se na heurística de que a região bem à frente do veículo faz parte da rua. $\mathrm{O}$ algoritmo começa com um histograma da primeira imagem. Para cada imagem subsequente um novo histograma é criado e este pode ser adicionado ao conjunto de modelos de cores ou substituir um já existente no conjunto. Normalmente o mais antigo é descartado, assim o algoritmo é capaz de se adaptar as variações de cor e textura da rua. Além da construção e atualização do conjunto de modelos de cor para a rua, é feito um cálculo de probabilidade para determinar se um determinado píxel faz parte ou não da via navegável.

O trabalho Lee e Crane (2006) faz uma comparação entre o algoritmo de classificação Expectation-Maximization (EM) e Bayesian (Figura 3.5). Ele mostra como o algoritmo EM possui um desempenho superior ao Bayesian, principalmente quando a imagem possui sombra, diferenças de luz ou vibração induzida pelo motor. Esse algoritmo também foi utilizado no DARPA Grand Challenge pela equipe CIMAR.

\subsection{Visão Estéreo (Binocular)}

Vários trabalhos utilizaram uma câmera estéreo para detecção de obstáculos e encontrar caminhos navegáveis. Sua utilização está intimamente ligada com o método estéreo utilizado, podendo este computar um mapa de disparidade esparso ou denso e com maior ou menor precisão. De fato, por conta de seu alto custo computacional, apenas por volta do ano de 1997 métodos estéreos densos começaram a ser utilizados na navegação robótica. Ainda assim limitados a uma velocidade de 2 hertz e uma resolução de 128 x 120 como apresenta o trabalho de Murray e Jennings (1997). Hoje a grande maioria dos trabalhos envolvendo câmera estéreo utiliza o mesmo método estéreo utilizado por Murray e Jennings (1997) devido à sua simplicidade e baixo custo computacional.

Como mostra o trabalho de Rankin et. al. (2005), grande parte das técnicas de detecção de obstáculos se baseiam na procura de descontinuidades e elevações no mapa de profundidade, além disso é comum a utilização das intensidades naturalmente associadas às informações de profundidade. Alguns trabalhos tem como primeira tarefa a estimação do plano em que o veículo esta situado dentro do mapa de disparidades, para isso a técnica de gerar um mapa de disparidade em "V"é amplamente utilizada (Broggi et. al., 2005; Caraffi et. al., 2007; Labayrade et. al., 2002). A criação deste mapa é feita transformando o mapa de disparidade original em um novo mapa, de forma que as colunas representem os valores de disparidade em ordem 

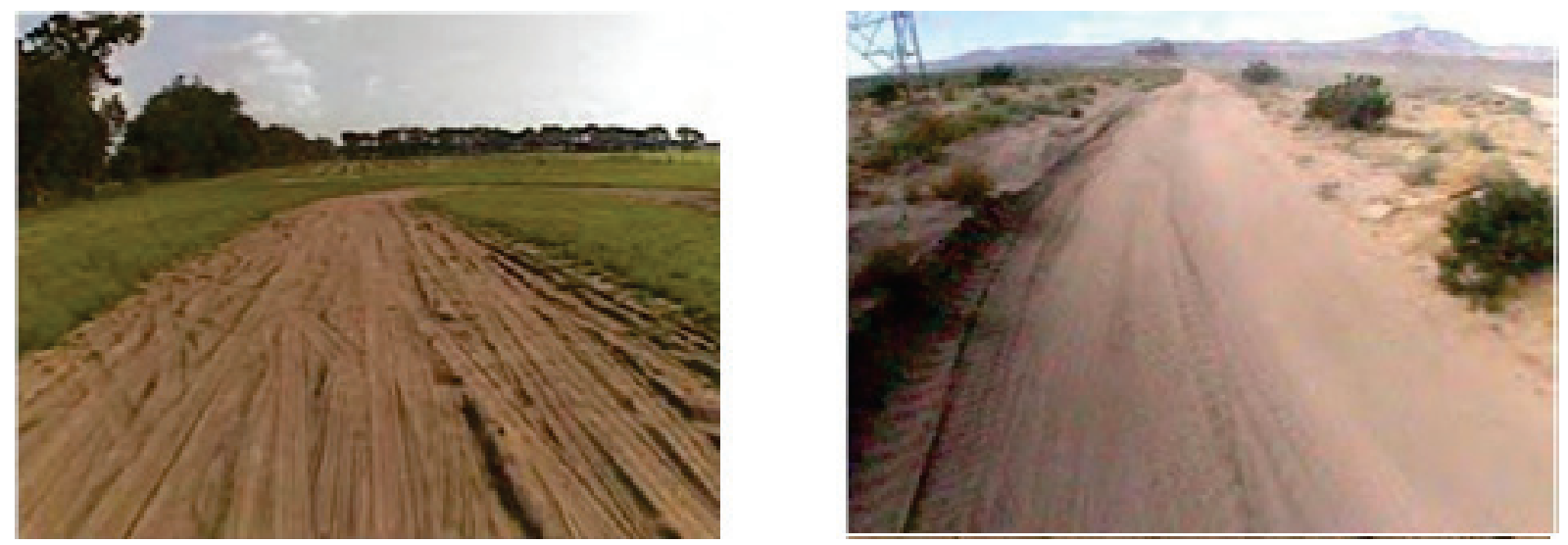

(a) Imagens originais do terreno.
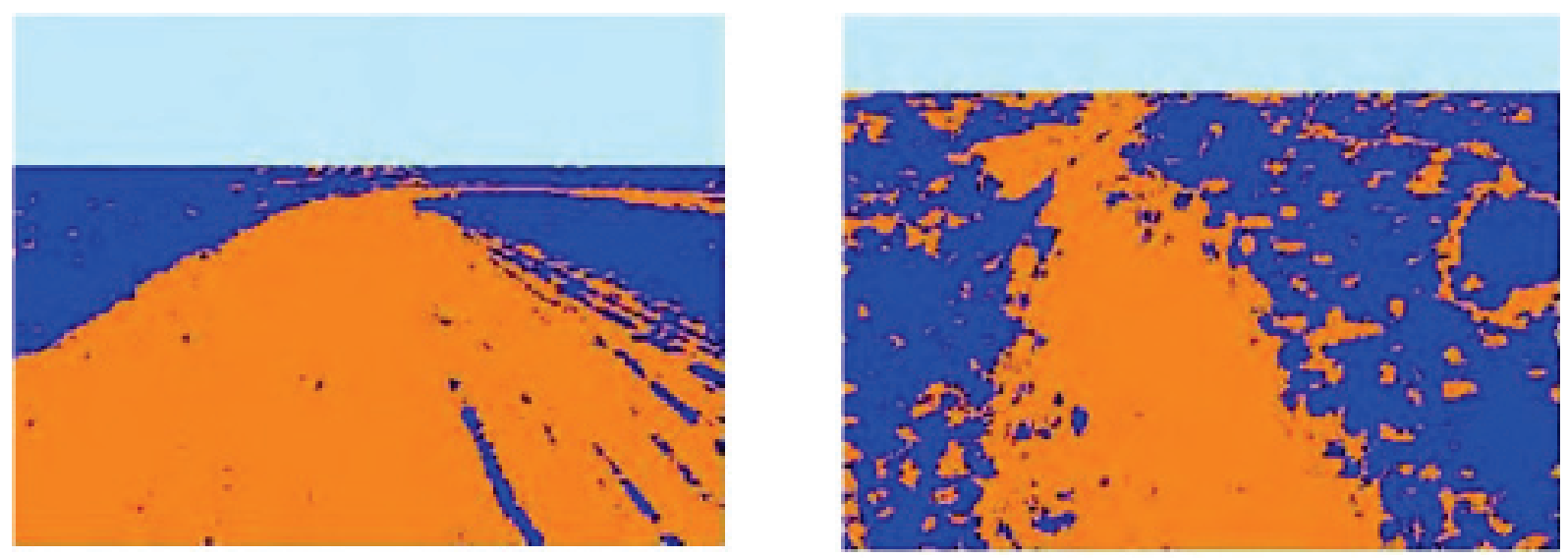

(b) Imagens classificadas pelo algoritmo EM.

Figura 3.5: Identificação da via navegável utilizando o algoritmo EM.

crescente, as linhas sejam mantidas na mesma ordem e a intensidade pode ser ajustada para representar a quantidade de disparidades iguais. Na Figura 3.6, são apresentadas duas imagens e seu respectivo mapa de disparidade em "V", o plano navegável pode ser estimado com base na linha diagonal presente no mapa em "V". Utilizando-se heurísticas simples também é possível estimar a localização dos obstáculos, como foi realizado no trabalho de Lima e G.A.S. (2010).

Alguns trabalhos (Happold e Ollis, 2006; Konolige et. al., 2008) utilizaram o método RANSAC (Seção 2.2) para estimar os parâmetros do plano geométrico em que o veículo se situa. Com o plano estimado é possível calcular a distância de qualquer ponto do mapa de profundidade em relação ao plano e então os pontos que não fizerem parte do plano são considerados obstáculos. Um problema desta técnica é que o modelo geométrico de um plano não é adequado para representar regiões curvas ou acidentadas. Hadsell et. al. (2009) utilizou vários planos para modelar o terreno como forma de tentar contornar o problema. 

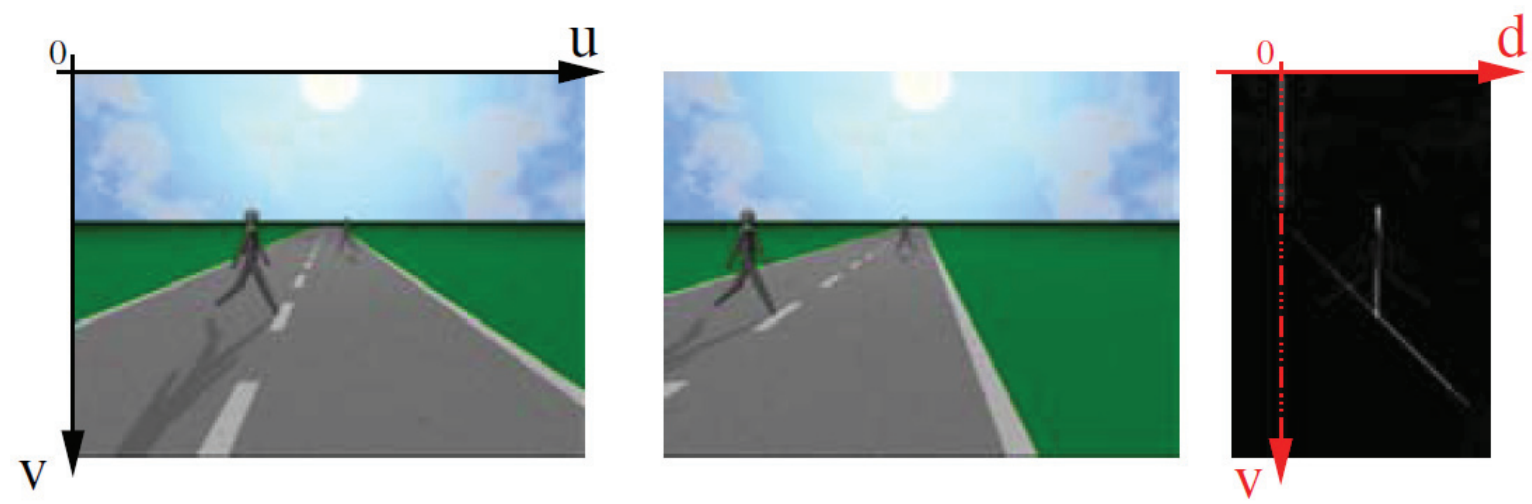

Figura 3.6: Par de imagens estéreo e o respectivo mapa de disparidade em "V" (Broggi et. al., 2005).

Como as informações de profundidade estão naturalmente relacionadas com a imagem original, boa parte dos trabalhos com câmera estéreo utiliza a região da imagem classificada como navegável como conjunto de treinamento para outro classificador (ex.: algoritmo de aprendizado de máquina) podendo então utilizar características da imagem (ex.: textura), para complementar a classificação baseada em profundidade. Conhecida como near-to-far, esta técnica utiliza a classificação de sensores com campo de atuação limitado (câmera estéreo, laser em diagonal) para classificar os dados de um outro sensor com campo de atuação mais amplo. Thrun et. al. (2006) utilizou esta técnica, onde o classificação do laser era a fonte de treino para uma classificação baseada em imagem. Desta forma, a área classificada foi maior, possibilitando acelerar o deslocamento do robô. O funcionamento da técnica é ilustrada pela Figura 3.7.

O projeto Learning Applied to Ground Robots (LAGR) (LAGR, 2005) realizado pela DARPA teve como objetivo aprimorar a percepção e controle robótico por meio de técnicas de aprendizado de máquina, onde seus competidores teriam que realizar um determinado trajeto. A plataforma utilizada nos testes foi um robô sem sensores ativos, dependendo apenas de quatro câmeras (duas estéreo) como pode ser visto na Figura 3.8. Como resultado do projeto, inúmeros artigos referentes a navegação com câmera estéreo foram publicados (Erkan et. al., 2007; Happold e Ollis, 2006; Sermanet et. al., 2008).

Happold e Ollis (2006), assim como outros participantes, utilizaram a técnica near-to-far onde a classificação da imagem feita com base nas informações de profundidade providas pela câmera estéreo foram utilizadas no treinamento de um outro classificador, superando assim a limitação de alcance da câmera estéreo. A Figura 3.9 mostra a efetividade do método.

O trabalho de Murarka et. al. (2008) utilizou um método estéreo global baseado em segmentação por cores e enquadramento de planos para construir um modelo tridimensional do ambiente. Em conjunto com um método baseado em movimento para detecção de quedas, o 

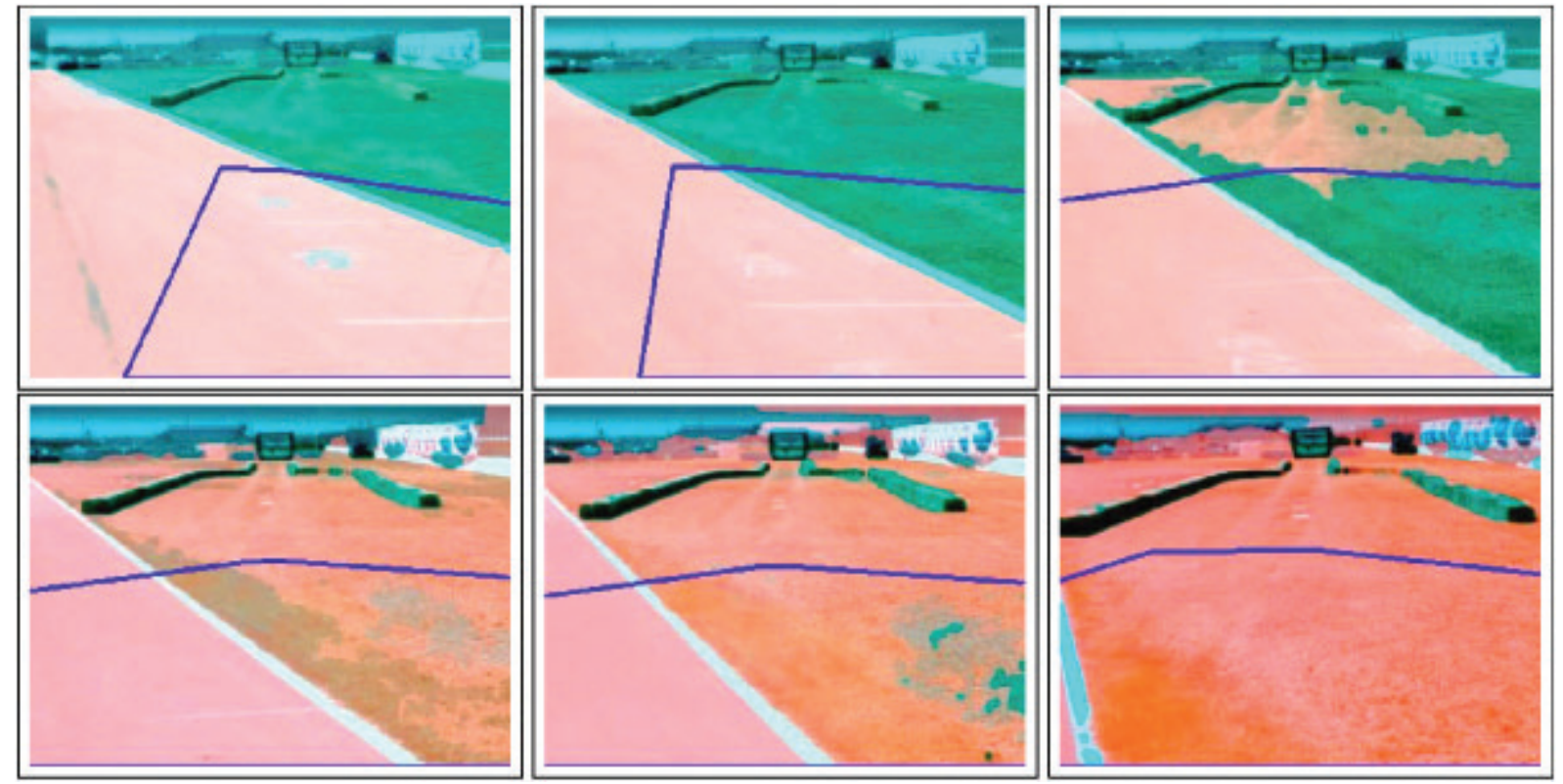

Figura 3.7: Sistema de visão adaptativa utilizada pelo robô Stanley. As linhas azuis delimitam o campo de atuação do laser utilizado e a parte avermelhada da imagem mostra o terreno navegável.

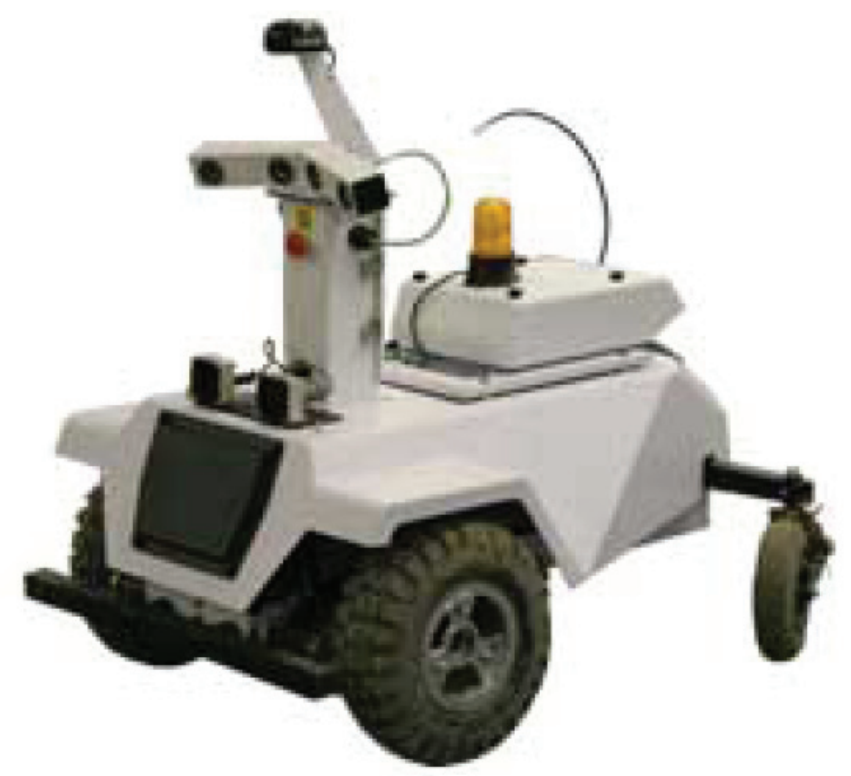

Figura 3.8: Plataforma robótica utilizada no projeto LAGR. Possui quatro câmeras, um GPS e uma unidade de medida inercial (LAGR, 2005).

trabalho construiu um mapa bidimensional discreto onde cada célula poderia possuir os seguintes valores: chão, acima do chão, abaixo do chão, borda da queda e indefinido. Apesar de ter obtido certa precisão na criação do mapa, apenas o cálculo do mapa de disparidades demorava 

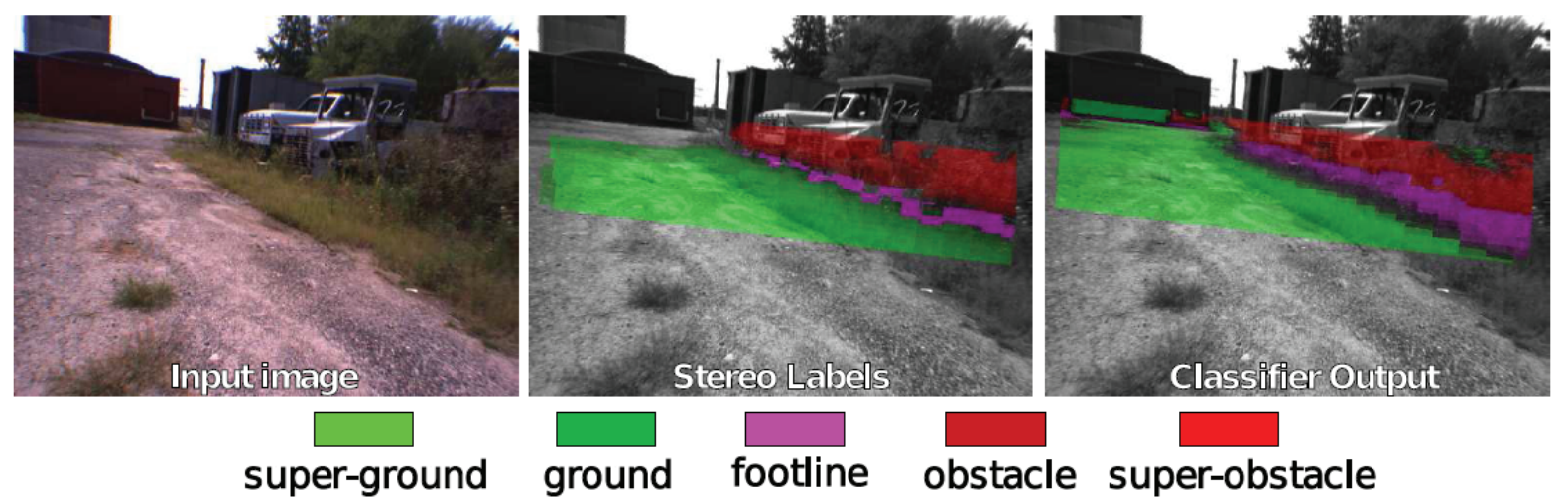

Figura 3.9: Classificação do método utilizado por Happold e Ollis (2006). A Figura da esquerda é a imagem de referência, ao centro a classificação feita com base no mapa de profundidades e por fim o resultado do classificador (Happold e Ollis, 2006).

4,5 segundos, limitando suas aplicações. O trabalho também não realizou navegação, utilizando a plataforma experimental apenas para obtenção dos dados.

É possível notar diversas similaridades entre esta dissertação e outros trabalhos: utilização do paradigma RANSAC para estimação do plano navegável (Happold e Ollis, 2006; Konolige et. al., 2008); emprego de métodos estéreos não-locais no contexto de navegação autônoma (Murarka et. al., 2008); uso do método VFH para desvio de obstáculos (Lima e G.A.S., 2010). Em se tratando do método de detecção de obstáculos baseado em cone (Seção 4.3.2), os principais trabalhos relacionados são os de van der Mark et. al. (2007) e Santana et. al. (2008). Em ambos os casos objetivou-se uma redução do custo computacional do método. O trabalho de Santana et. al. (2008), utilizando um conjunto de parâmetros pré-calculados, atingiu um tempo computacional de 62 milissegundos ou 16,12 Hz. O menor tempo encontrado na literatura.

Os méritos deste trabalho estão na análise de métodos estéreos para fins de navegação autônoma e na análise de métodos para detecção de obstáculos. Além disso, utilizando uma GPU, foi realizada uma implementação paralela do método de detecção de obstáculos baseado em cone. Apesar de não serem diretamente comparáveis, devido a variações de parâmetros e ambiente, o tempo de processamento do método neste trabalho foi significativamente menor que o mencionado por Santana et. al. (2008). Concluindo, este trabalho possui uma significante sobreposição com os trabalhos relacionados, partilhando de métodos e objetivos com outros pesquisadores. 



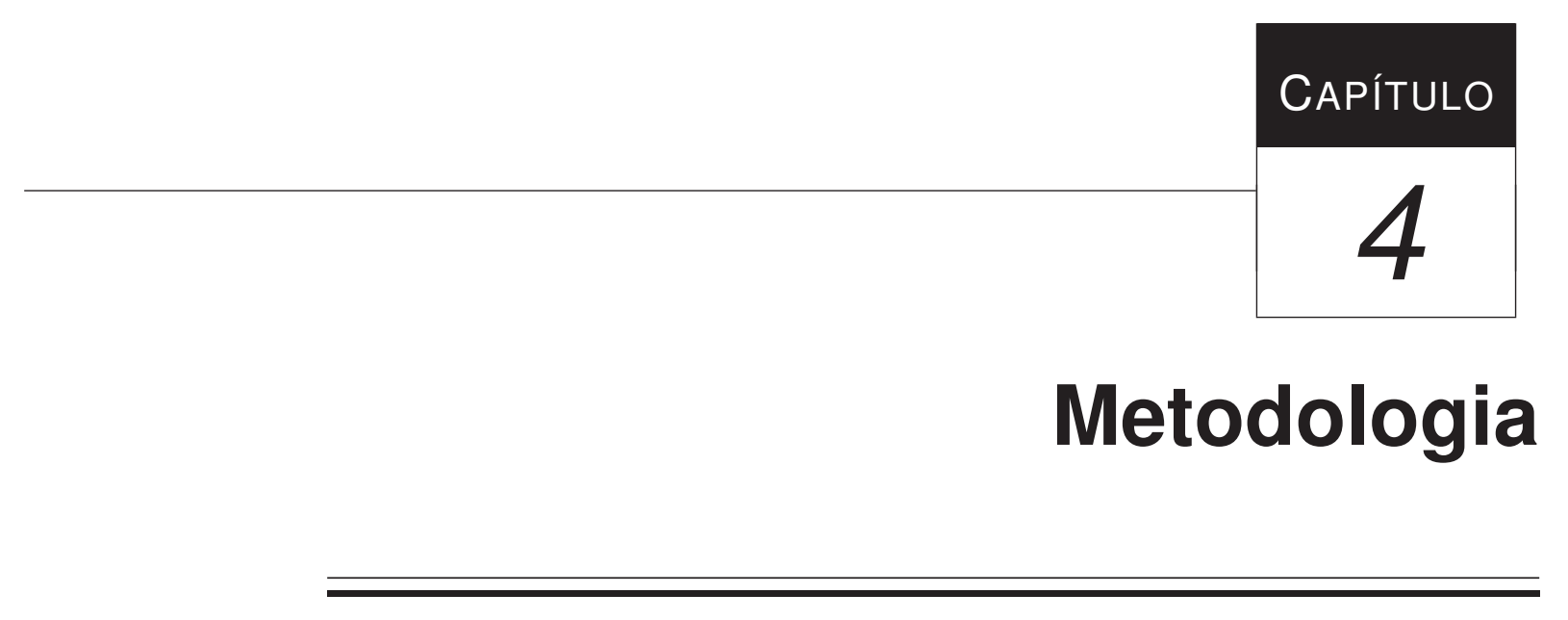

Neste capítulo é apresentada a metodologia envolvida no presente trabalho. Seu objetivo é descrever, em detalhes, todos os módulos desenvolvidos durante o mestrado. Optou-se por organizar o capítulo seguindo o diagrama de blocos que pode ser visto na Figura 4.1.

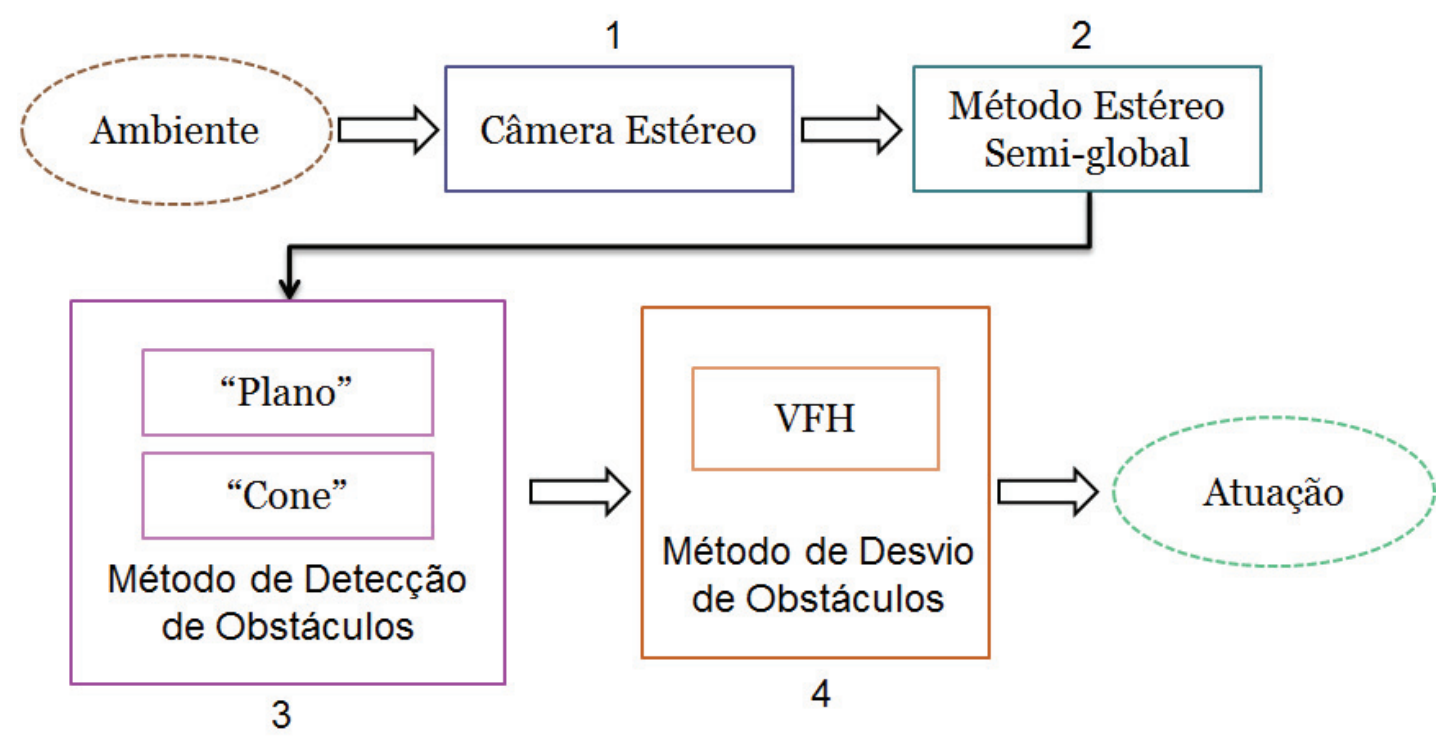

Figura 4.1: Diagrama de blocos do funcionamento do sistema proposto. 
Conforme a figura mostra, as informações do ambiente são capturadas pela câmera estéreo (Seção 4.1), resultando em um par de imagens estéreo, estas imagens são retificadas e processadas pelo método estéreo semi-global (Seção 4.2). As informações de profundidade obtidas pelo método são enviadas ao método de detecção de obstáculos (baseado em plano ou baseado em cone) (Seção 4.3), tal método segmenta a imagem em regiões navegáveis e não navegáveis. Utilizando esta classificação, o método de desvio de obstáculos guia o veículo até um ponto predeterminado (Seção 4.4).

Como planejado, utilizou-se uma câmera estéreo como forma de se obter informações do ambiente. O par de imagens estéreo dado pela câmera é processado por um algoritmo de correspondência semi-global, para então se obter o mapa de disparidades/profundidade. O mapa de disparidades é então transformado em uma nuvem de pontos com base nos parâmetros extrínsecos da câmera.

Na etapa de detecção de obstáculos foram feitos experimentos com dois métodos distintos: método baseado em plano e método baseado em cone. O método baseado em cone foi escolhido para a navegação por conta de seu desempenho e foram realizadas algumas otimizações para superar seu alto custo computacional.

O método VFH foi empregado para realização do desvio de obstáculos. O GPS informa o ângulo entre a frente do veículo e a posição de destino (previamente determinada), e o VFH encaminha o veículo para o destino desviando dos obstáculos encontrados. Nas seções seguintes cada uma destas etapas será explicada em detalhes.

\subsection{Câmera Estéreo}

Como esperado utilizou-se uma câmera estéreo como principal sensor do sistema desenvolvido. Uma câmera estéreo é formada por, usualmente, duas câmeras deslocadas horizontalmente por certa distância. A câmera utilizada neste projeto foi uma câmera da marca Videre Design ${ }^{1}$, modelo STOC, que pode ser vista na Figura 4.2. A câmera, conectada por uma interface firewire disponibiliza um fluxo de imagens, mais precisamente um fluxo de imagens estéreo (par de imagens) capturadas ao mesmo tempo. A única maneira de acessar estas imagens é através da biblioteca proprietária SVS.

Tanto a calibração da câmera e a retificação das imagens foram realizadas utilizando a biblioteca de código fonte aberto Open Computer Vision (OpenCV) (Bradski e Kaehler, 2008). Para possibilitar o uso da biblioteca foi necessário fazer uma "ligação" entre a biblioteca proprietária da câmera (SVS) e a biblioteca OpenCV. Como a documentação define a codificação utilizada

\footnotetext{
${ }^{1}$ http://www.videredesign.com/
} 


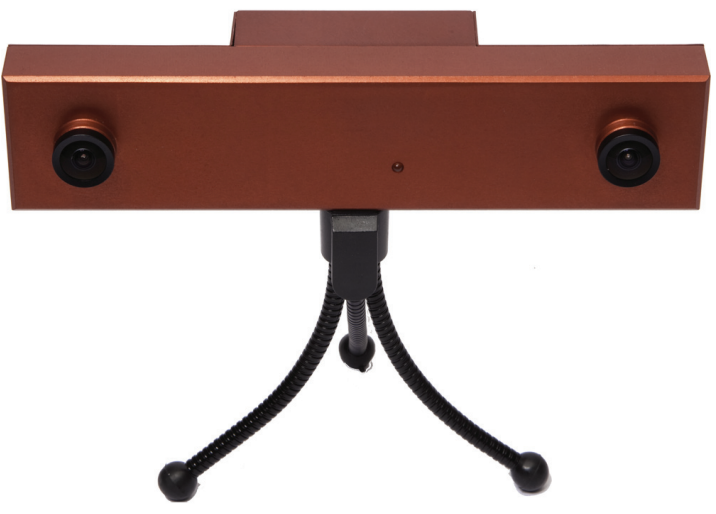

Figura 4.2: Câmera estéreo utilizada no projeto.

nas imagens, esta ligação foi realizada de maneira trivial por um programa feito em linguagem $C++$, chamado de "cSvsOpencv". O programa converte as imagens do espaço de cores RGBA ${ }^{2}$ para RGB, utilizando a função $c v C v t$ Color disponível na biblioteca $O p e n C V$.

O processo de calibração utilizado neste trabalho é similar ao encontrado nos exemplos da biblioteca $O p e n C V$, onde é necessário obter uma quantidade mínima de imagens estéreo de um padrão conhecido aparente para ambas as lentes. Com isso, a função stereoCalibrate encontra todos os parâmetros intrínsecos e extrínsecos da câmera estéreo. Utilizando estes parâmetros a função stereoRectify gera um matriz que possibilita remapear as imagens de forma a corrigir as distorções e alinha-las horizontalmente.

Como forma de facilitar o desenvolvimento optou-se pelo uso do framework para robótica Robot Operating System $(R O S)^{3}$ que provê um sistema de pacotes e troca de mensagens, além de uma enorme quantidade de bibliotecas voltadas para robótica em geral. Utilizando o framework foi criado um módulo chamado de "StereoCam" que captura o par de imagens estéreo, as remapeia e as publica prontas para o cálculo de disparidades em forma de mensagens.

\footnotetext{
${ }^{2}$ RGBA significa "Red, Green, Blue and Alpha" ou "Vermelho, Verde, Azul e Alfa" e se refere a forma como as cores são codificadas. A diferença deste para o espaço de cores RGB é a ausência do alfa, normalmente utilizado como a opacidade da cor.

${ }^{3} \mathrm{http} / / / \mathrm{www}$. ros.org
} 


\subsection{Método Estéreo Semi-global}

Optou-se pelo uso de um método semi-global para realizar a correspondência do par de imagens estéreo. Como confirmado pelos testes realizados (Seção 5.1), os métodos semi-globais são uma boa alternativa aos métodos locais e globais, apresentando um balanço entre desempenho e custo computacional. No contexto de navegação robótica, o custo computacional é um ponto crítico: são necessárias informações sensoriais em tempo real. Por outro lado, a qualidade destas informações devem ser consistentes, daí a escolha pelo método estéreo semi-global.

O método utilizado é uma implementação contida na biblioteca OpenCV do método apresentado por Hirschmuller. Tal implementação se diferencia do método original principalmente por possibilitar a correspondência entre blocos, portanto o nome Semi-global Block Matching.

Como um método semi-global, a correspondência leva em consideração vários caminhos unidimensionais (linhas) a fim de aproximar uma otimização global (bidimensional) e é formulada como um problema de otimização. A diferença do método utilizado para o método que utiliza programação dinâmica mencionado na Seção 2.1.7.4 é que não só caminhos horizontais são levados em consideração, mas também caminhos verticais e diagonais como mostra a Figura 4.3. Isso ajuda a garantir a consistência vertical do mapa de disparidades resultante.

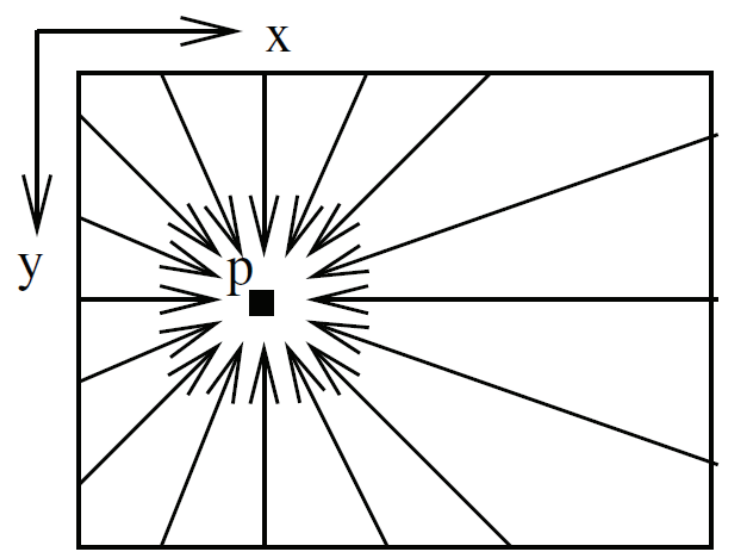

Figura 4.3: A correspondência de um píxel $p$ é formulada como um problema de otimização que engloba vários caminhos unidimensionais.

A exemplo do módulo "StereoCam" mencionado na Seção 4.1, foi criado um módulo chamado "StereoMatcher" para realizar a correspondência estéreo. Tal módulo recebe as duas imagens publicadas pelo módulo "StereoCam", calcula o mapa de disparidades, a nuvem de pontos derivada do mapa de disparidades e os publica como mensagens. A Figura 4.4 mostra os módulos "StereoCam" e o módulo "StereoMatcher" juntamente com as suas mensagens. A correspondência em si é feita utilizando a classe "StereoSGBM" e a geração da nuvem de pontos com a função "reprojectImageTo3D”, ambas disponíveis na biblioteca OpenCV. 


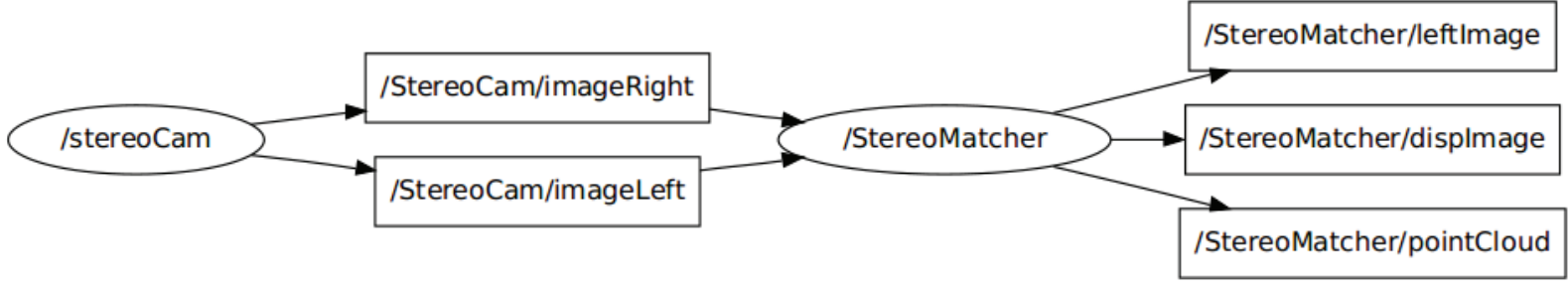

Figura 4.4: O módulo "StereoCam" publica o par de imagens estéreo retificadas. O módulo "StereoMatcher" recebe as duas imagens e publica o mapa de disparidades, a nuvem de pontos e republica a imagem da esquerda (imagem de referência).

A fim de justificar a escolha pelo método semi-global foi realizada uma comparação com um método local. A exemplo do método semi-global foi utilizada uma implementação disponível na biblioteca $O p e n C V$, a classe "StereoBM" possui uma implementação otimizada do método block-matching.

\subsection{Detecção de Obstáculos}

Nesta Seção são apresentados os dois métodos implementados para realização da detecção de obstáculos. O objetivo dos métodos é segmentar os dados do sensor em regiões navegáveis e regiões não navegáveis ou em obstáculos e não-obstáculos. A primeira abordagem Detecção Baseada em Plano, se baseia completamente na estimação de um plano que deve representar a rua ou caminho livre. Com o plano estimado, a distância (altura) de todos os pontos são testados em relação a este plano, caso o ponto esteja próximo ao plano, isso quer dizer que o ponto faz parte da via navegável, caso contrário o ponto não faz parte da região navegável.

Apesar de ser largamente utilizada, a primeira abordagem sofre de diversas limitações: (i) o modelo de um plano não é apropriado para representar terrenos curvos; (ii) é difícil garantir que o plano estimado represente a via navegável ao invés de qualquer outra região plana (ex.: calçada). Estes motivos levaram a implementação de outro método, proposto por Talukder et. al. (2002), aqui chamado de Detecção Baseada em Cone.

Ambos os métodos produzem resultados de naturezas diferentes e consequentemente não são diretamente comparáveis. As seções 4.3.1 e 4.3.2 descrevem o métodos Detecção Baseada em Plano e Detecção Baseada em Cone respectivamente.

\subsubsection{Detecção Baseada em Plano}

O mapa de disparidades gerado pelo método estéreo semi-global é transformado em uma nuvem de pontos tridimensional com base nos parâmetros extrínsecos da câmera. Dada a nuvem de 
pontos, o paradigma RANSAC, devido a sua robustez a ruídos, é empregado para estimar o plano onde o veículo está. Isto é feito toda vez que a câmera é montada no veículo e serve como uma etapa de calibração. Os parâmetros do plano são então utilizados para rotacionar a nuvem de pontos alinhando assim o plano calculado com os eixos $x$ e $z$, portanto, a coordenada $y$ representa a altura dos pontos em relação ao plano.

A fim de reduzir o ruído, as alturas são agrupados em blocos. Usando a altura média, os blocos são classificados em não navegáveis ou navegáveis. A Equação 4.1 mostra como a altura de um bloco $(B h)$ é calculado, onde $P_{y}$ é a coordenada $y$ de um ponto $P$. $B$ é o conjunto contendo todos os pontos pertencentes a um bloco do mapa de navegabilidade e é definido como $B_{k}=\left\{P^{1}, P^{2}, \ldots, P^{n}: P \in\right.$ um bloco quadrado definido $\}$.

$$
B h_{k}=\sum_{i=1}^{N} P_{y}^{i}: P \in B_{k}
$$

A classificação de cada bloco $B_{k}$ é feita de acordo com a função $C$ definida abaixo. $M h$ é o parâmetro que define o limiar entre alturas navegáveis e não navegáveis. A Figura 4.5 ilustra a classificação (mapa de navegabilidade) onde píxeis vermelhos representam blocos não navegáveis e píxeis com sua coloração original são blocos navegáveis.

$$
C\left(B_{k}\right)=\left\{\begin{array}{ll}
\text { Não navegável } & \text { se } \quad B h_{k} \geq M h \\
\text { Navegável } & \text { se } \quad B h_{k}<M h
\end{array}: B_{k} \in\right. \text { Frame atual }
$$

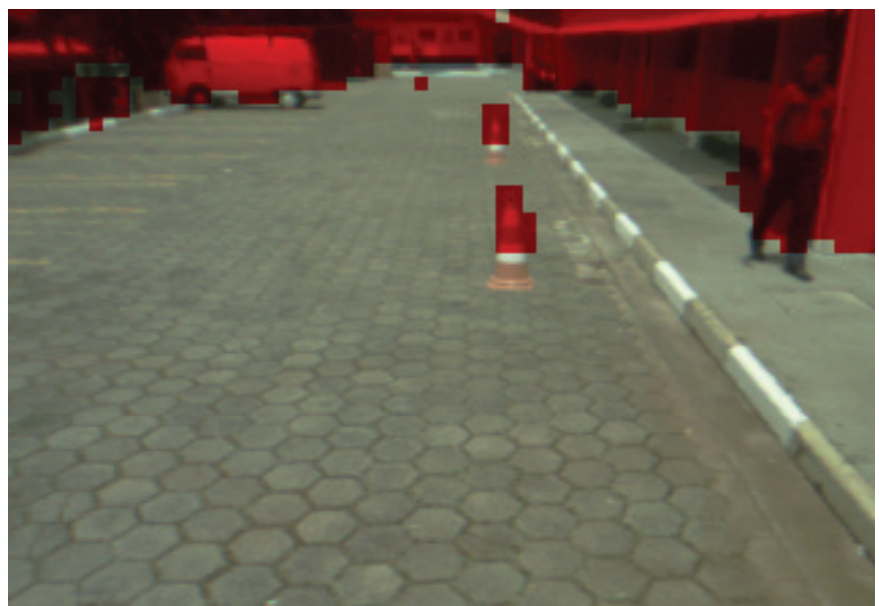

Figura 4.5: Mapa de navegabilidade resultante do método de detecção de obstáculos baseado em plano (píxeis vermelhos representam blocos não navegáveis e píxeis com sua coloração original blocos navegáveis). 


\subsubsection{Detecção Baseada em Cone}

Como diversas limitações foram constatadas nos testes com o método de detecção baseado em plano, optou-se por analisar um outro método para detecção de obstáculos. O método descrito no artigo Talukder et. al. (2002) procura por pontos compatíveis (ilustrada pela Figura 4.6), onde $P^{1}=\left(p_{x}, p_{y}, p_{z}\right)$ e $P^{2}=\left(p_{x}, p_{y}, p_{z}\right)$ são ditos compatíveis e são considerados obstáculos caso satisfaçam as seguintes condições:

1. $H_{T}<\left|p_{y}^{2}-p_{y}^{1}\right|<H_{\max }$

2. $\left|p_{y}^{2}-p_{y}^{1}\right| /|| P^{2}-P^{1}||>\cos \left(\theta_{T}\right)$;

onde $H_{T}, H_{\max }$ e $\theta_{T}$ são constantes selecionadas adequadamente.

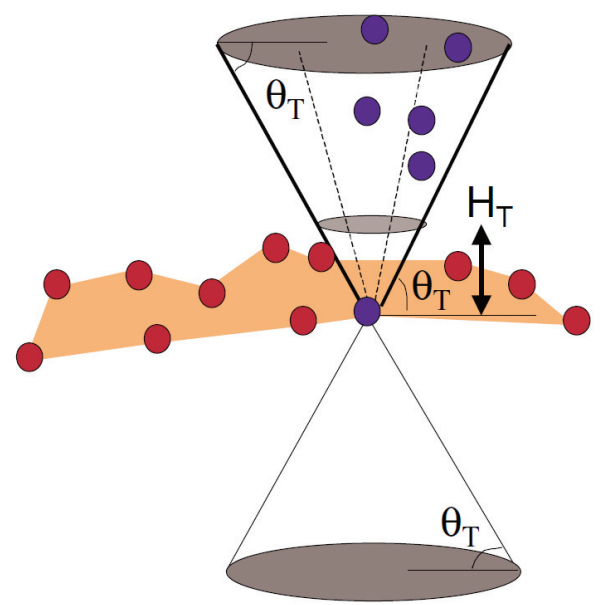

Figura 4.6: Ilustração da busca por pontos compatíveis, onde pontos marrons pertencem a via navegável e pontos em azul são considerados obstáculos (Talukder et. al., 2002).

A primeira condição se refere a diferença de altura entre os dois pontos e a segunda ao ângulo formado pelos pontos. Uma maneira direta de se implementar o método seria comparar todos os pontos entre si, o que resultaria em um elevado custo computacional. Neste caso a complexidade seria igual à $\mathrm{O}\left(N^{2}\right)$ onde $N$ é o número de pontos. Uma forma de reduzir a área da busca é aproxima-la a uma região da imagem levando em consideração os parâmetros $H_{\text {max }}$, $\theta_{T}$ e a distância focal da câmera $f$. Assumindo-se que a coordenada $y$ do plano da imagem esteja associada com a altura do ponto $P$, a área de busca por pontos compatíveis pode ser aproximada à um triângulo projetado no plano da imagem como ilustra a Figura 4.7.

A altura do triângulo projetado no plano da imagem para cada pivô é igual a $k / p_{z}$, onde $k=f H_{\max }$ e o ângulo de abertura do triângulo é igual a $\theta_{T}$. Nesse caso, a complexidade 


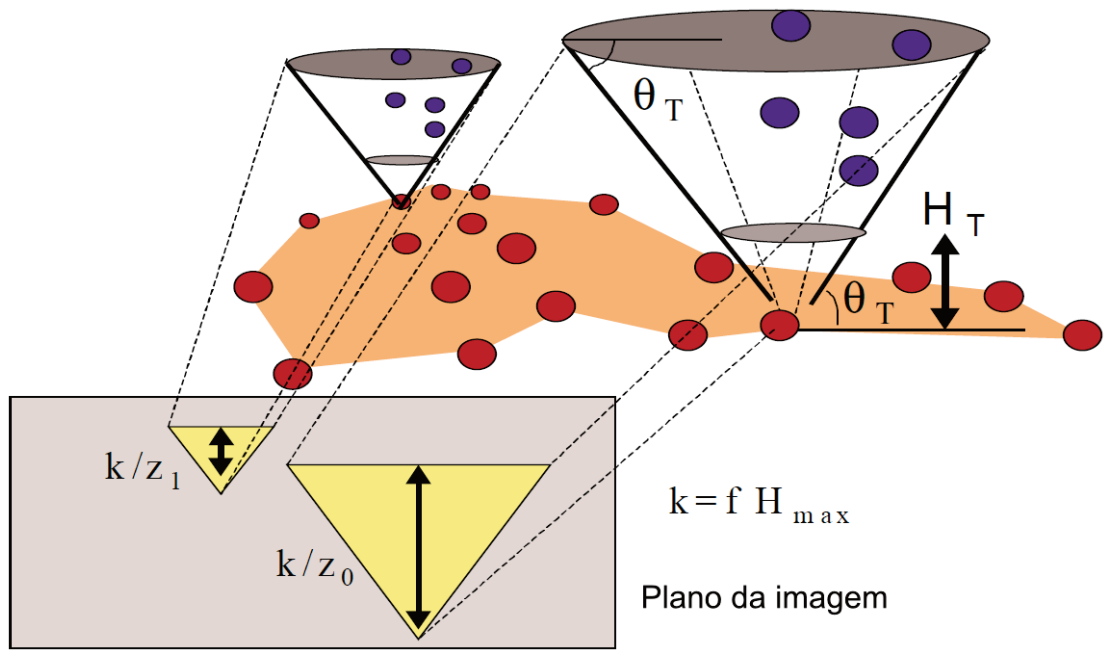

Figura 4.7: A busca por pontos compatíveis é aproximada pela projeção de um triângulo no plano da imagem (Talukder et. al., 2002).

diminui para $\mathrm{O}(N K)$, onde $N$ é o número de pontos e $K$ a área do triângulo projetado no plano da imagem. Existe porém um problema com tal abordagem: é impossível garantir que a coordenada $y$ do plano da imagem esteja associada com a altura de um ponto $P$. A exemplo da implementação original optou-se por realizar tal aproximação utilizando uma janela quadrada, isso garante certa robustez em relação à variação do ângulo da câmera para com a cena e simplifica a implementação. A Figura 4.8 ilustra a implementação realizada onde pivô é ponto de referência para a busca por pontos compatíveis.

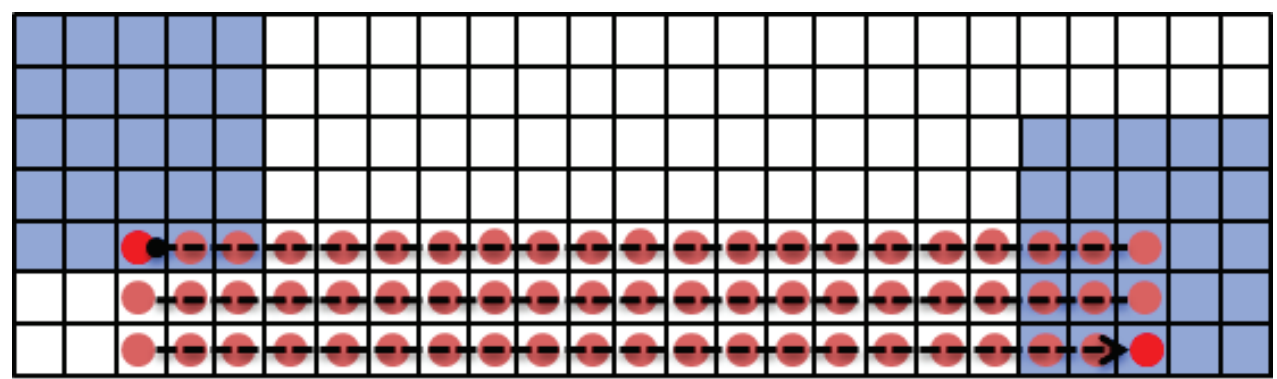

Ponto de referência

Área de busca

Figura 4.8: Aproximação da área da busca por um quadrado no plano da imagem, onde os círculos vermelhos representam os pontos de referência e os pontos azuis a área de busca.

Segundo Talukder et. al. (2002), o tamanho lateral da janela quadrada para cada pivô deve ser no mínimo de $\left(H_{T}^{2} \cos ^{2}\left(\theta_{T}\right)+H_{T}^{2}\right)^{\frac{1}{2}} f / z$. Na prática, devido a limitações da resolução espacial do sistema estéreo, é mais conveniente definir o tamanho lateral da janela como $s / z$, onde $s$ 
é um parâmetro definido empiricamente a fim acomodar todos os possíveis pontos compatíveis. Como mencionado no artigo original, o tamanho da janela tende a ser de 3 a 4 vezes maior que o tamanho mínimo. Isso garante que nenhum dos pontos compatíveis sejam perdidos. A equação 4.2 define como o tamanho lateral da janela é calculado, onde $J$ é a função que retorna o tamanho, $P$ o pivô, e $P_{z}$ a coordenada $z$ do pivô.

$$
J(P)=s / P_{z}
$$

Uma limitação do método é que este assume a coordenada $y$ de um ponto $P$ como sendo referente à altura, o que a princípio, não é verdade. Portanto, assim como o método baseado em plano, este método também requer o cálculo de um plano, e a rotação e translação da nuvem de pontos a fim de tornar a coordenada $y$ aproximadamente equivalente à altura. A diferença para o método anterior é que além de levar em consideração o ângulo, a diferença de altura é relativa a outros pontos da cena e não ao plano, o que torna o método muito mais robusto em ambientes não-planos, como mostra a Seção de resultados.

\subsubsection{Paralelização e Otimização}

Na prática, a principal limitação do método de detecção de obstáculos baseado em cone é seu custo computacional. Mesmo com uma aproximação da área de busca, o tempo para processar uma nuvem de pontos pode ser alto. Tendo isto em mente, o método foi paralelizado para fazer uso de todos os núcleos de um processador e posteriormente, foi realizada uma implementação em GPU. Esta Seção descreve as duas implementações realizadas.

A primeira implementação, voltada a utilização dos múltiplos núcleos de um processador, foi realizada utilizando a biblioteca Open Multi-Processing $(\text { OpenMP })^{4}$. Esta escolha se deu porque a biblioteca OpenMP é multiplataforma, voltada para um desenvolvimento ágil e foi integrada ao compilador GNU Compiler Collection $(G C C)^{5}$ a partir de sua versão 4.2.

A biblioteca OpenMP provê uma diretiva que paraleliza e distribui automaticamente um laço entre vários processadores ou núcleos. Na caso da implementação realizada do método, foi necessário apenas a adição de uma linha com tal diretiva antes do laço mais externo. Tal laço se refere as linhas de pivô e consequentemente as janelas referentes, como resultado cada linha é enviada a um núcleo, sendo que o número de linhas processadas em paralelo depende da quantidade de núcleos do processador empregado. A Figura 4.9 ilustra a execução em paralelo.

Para diminuir ainda mais o tempo de processamento do método, foi realizada uma implementação em GPU. Para garantir o uso eficiente da taxa de transferência entre a memória RAM

\footnotetext{
${ }^{4}$ http://www.openmp.org/

${ }^{5}$ http://gcc.gnu.org/
} 


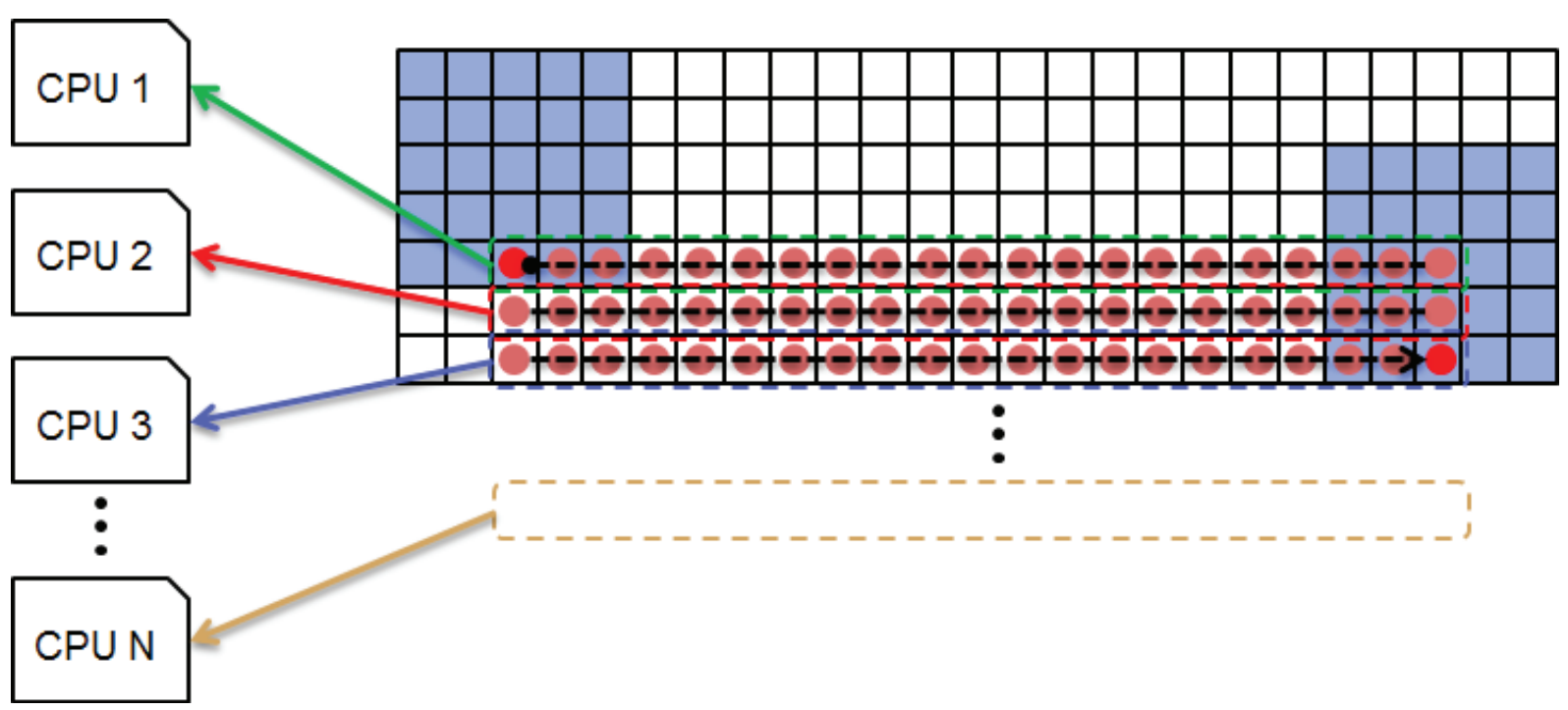

Figura 4.9: Forma com que o processamento é distribuído entre os vários núcleos: cada linha de pivô é processada por um.

(Random Acess Memory) e a memória global da GPU, isto é, possibilitar o acesso alinhado aos dados, foi necessário redistribuir os dados conforme ilustra a Figura 4.10.
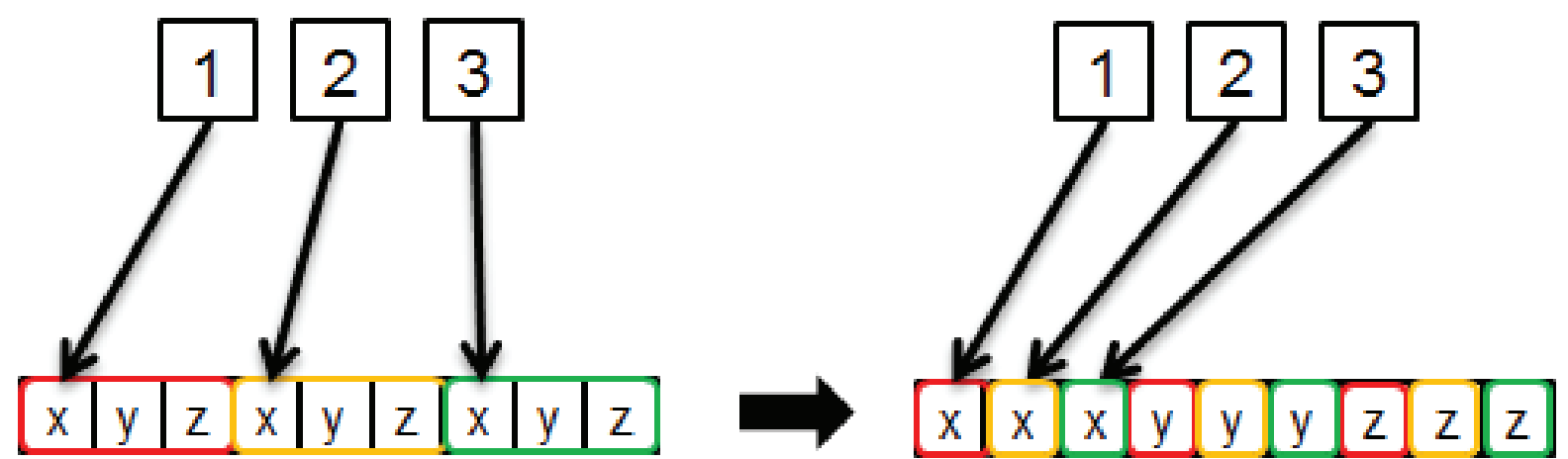

Figura 4.10: Redistribuição das coordenadas na memória a fim de possibilitar o acesso alinhado aos dados pela GPU.

A primeira maneira encontrada de se distribuir o processamento pela GPU foi o processamento de um pivô (uma área de busca) por multiprocessador, onde cada processador checa a compatibilidade com um dos pontos da janela referente. A Figura 4.11 ilustra a distribuição. O problema com esta distribuição é que, na prática, o limite de tamanho de um work-group é facilmente atingido: uma área de busca de 20 por 20 pontos resulta em um work-group com 400 work-itens, bem acima do limite de 256.

Um forma de se contornar tal limite é aumentar a carga de trabalho dos processadores, onde ao invés de checar a compatibilidade de um ponto, cada processador checa a compatibilidade 


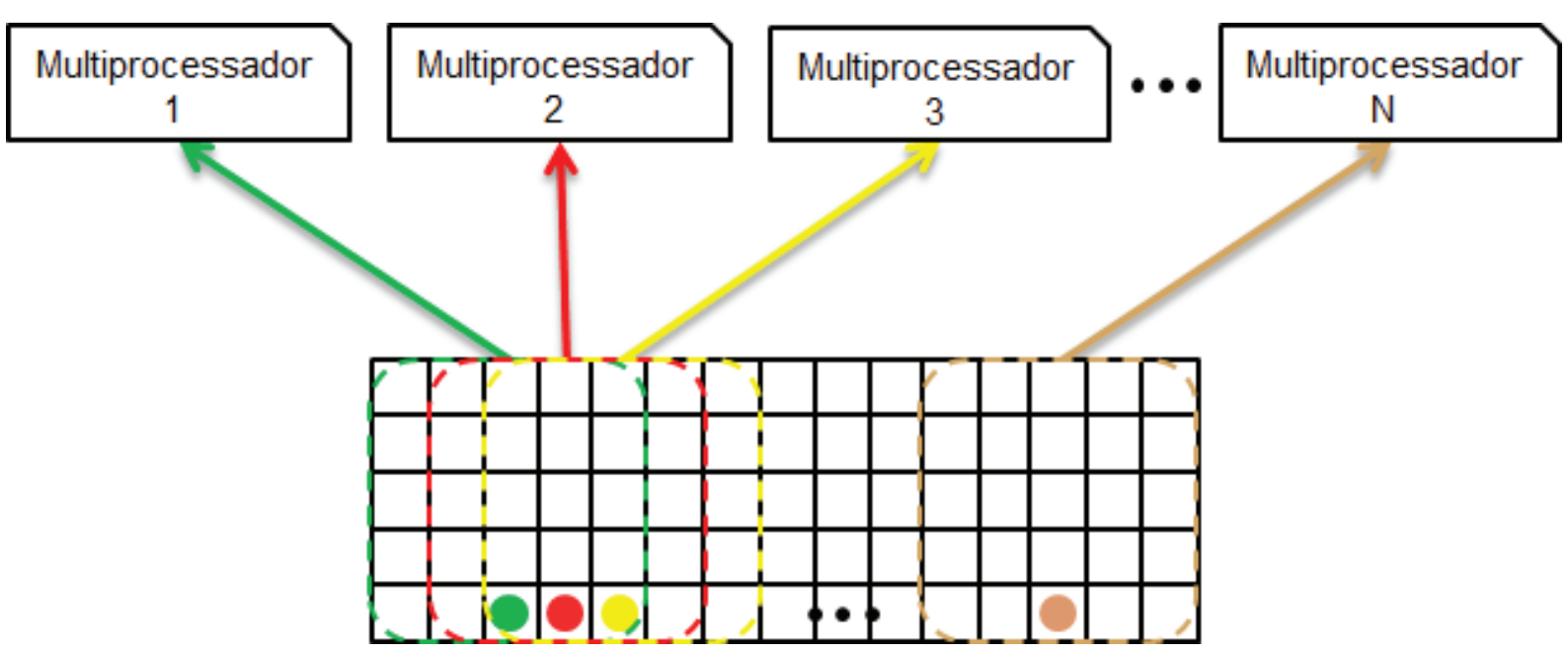

Figura 4.11: Forma como o processamento foi distribuído pela GPU pela primeira implementação.

de uma coluna de pontos. Por exemplo, no caso de uma janela de 20 por 20 pontos, cada processador deve checar a compatibilidade de 20 pontos e nesse caso o tamanho de um work-group passa de 400 para 20 work-itens. A Figura 4.12 ilustra a mudança.
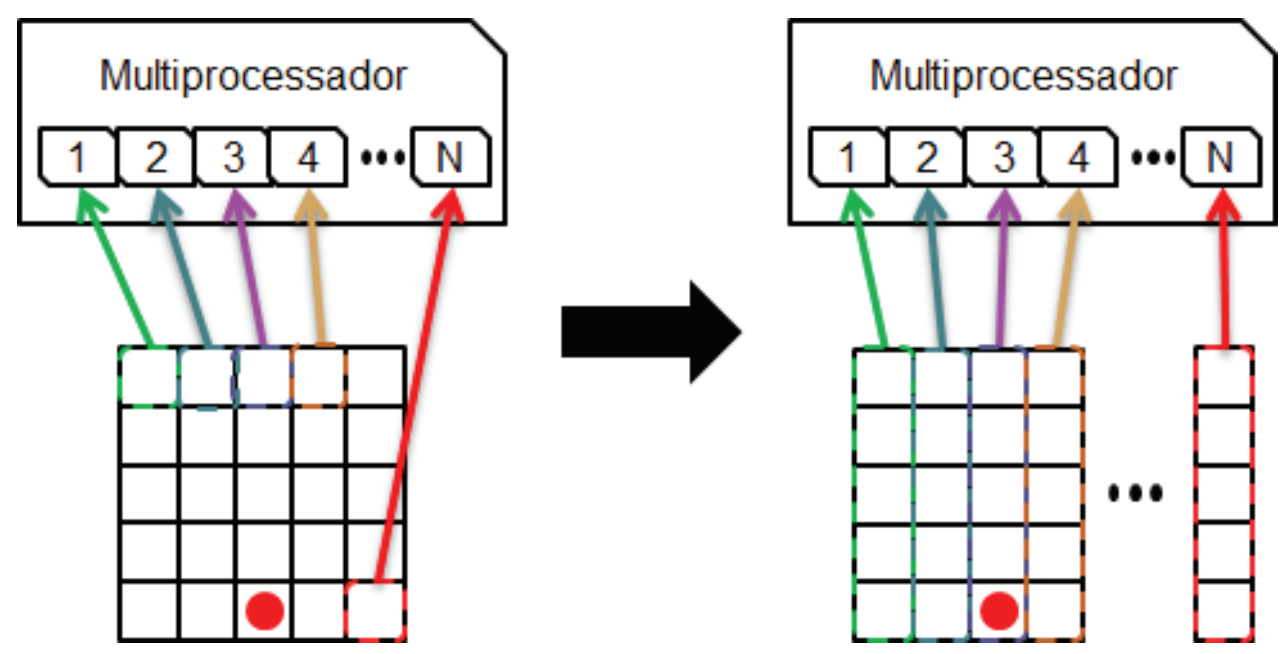

Figura 4.12: Forma como o processamento foi distribuído pela GPU pela segunda implementação.

Um problema encontrado foi o de que o tamanho de um work-group é fixo, porém o tamanho da janela para cada pivô não é, além disso, o tamanho de uma warp nas GPUs da série HD5xxx é de 64. Isso quer dizer que um tamanho de grupo menor que 64 resultaria em uma subutilização crítica da GPU. Uma solução simples seria utilizar apenas janelas de tamanho 64 por 64, que seriam mais que suficiente para acomodar os pontos compatíveis de qualquer distância (coordenada $z$ do pivô) no sistema estéreo utilizado. A solução encontrada para evitar 
esta carga de trabalho desnecessária foi a opção por dois tamanhos de janela fixo: 32 e 64 . O tamanho lateral de cada janela seria computado segundo a equação 4.3, onde $J$ é a função que retorna o tamanho lateral da janela, $P$ é o pivô em questão e $P_{z}$ a coordenada $z$ do pivô.

$$
J(P)=\left\{\begin{array}{lll}
32 & \text { se } & s / P_{z} \leq 32 \\
64 & \text { se } & s / P_{z}>32
\end{array}\right.
$$

Tal função é computada para todo pivô e seu resultado guardado em uma matriz, que posteriormente será enviada a GPU junto com o resto dos dados. Apesar do tamanho da janela ser variável, optou-se por manter o tamanho dos work-groups em 64. Portanto, no caso de uma janela de 64 por 64, seriam 64 processadores a computar a compatibilidade de $64^{2}$ pontos. Nesse caso, a ideia da figura 4.12 é mantida e cada processador computa a compatibilidade de uma coluna, cujo número de pontos é igual a 64.

Por fim, é necessário que os pontos em uma janela de 32 por $32\left(32^{2}\right.$ pontos) sejam distribuídos adequadamente entre os 64 processadores de um grupo. A Figura 4.13 ilustra como é feita esta distribuição. Os processadores são divididos em dois grupos de 32 processadores cada, onde cada processador de cada grupo processa uma coluna de 16 pontos. Os pontos em azul representam os pontos processados pelo primeiro grupo, e em verde os pontos processados pelo segundo. Vale lembrar que são processados 64 pontos por vez, sendo portando coerente com uma warp de tamanho 64.

\subsection{Desvio de Obstáculos e Navegação Autônoma}

Este trabalho usa uma versão modificada do algoritmo VFH para realizar o desvio de obstáculos. A principal diferença entre o algoritmo implementado e o original é que a criação do grid bidimensional é desconsiderado. A modificação foi utilizada para simplificar a implementação e melhorar o desempenho. Ela foi possível devido a natureza bidimensional das informações de profundidade fornecida pela câmera estéreo e a precisão alcançada pelo método estéreo semi-global.

O histograma polar utilizado tem uma largura de 90 píxeis, onde cada píxel representa um grau. No total são 90 graus, valor maior que o ângulo de abertura horizontal da câmera utilizada. Verticalmente, a imagem tem o tamanho de 100 píxeis. A densidade de obstáculos em cada setor é calculada com base na distância do ponto (magnitude do vetor) em relação ao sistema de coordenadas do sensor. Todo ponto considerado obstáculo pelo sistema de detecção de obstáculos é adicionado ao histograma em seu respectivo setor (ou ângulo) e sua altura ou influencia no histograma é igual ao inverso de sua distância. Finalmente, o setor é dimensionado 


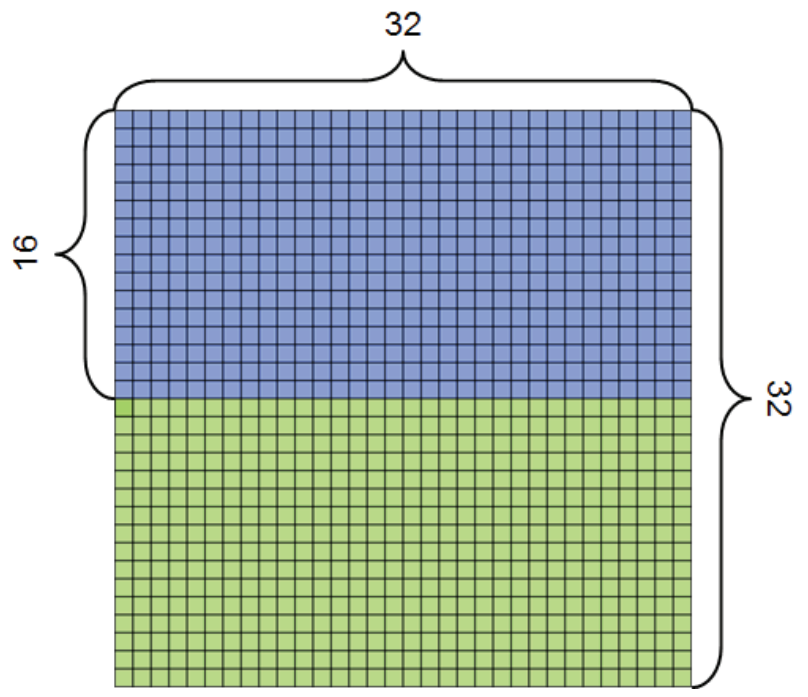

Figura 4.13: Forma como a busca por pontos compatíveis em uma janela de 32 por 32 pontos é distribuída por um work-group de 64 work-itens ou processadores. Os processadores são divididos em dois grupos de 32 processadores, onde cada processador de cada grupo processa uma coluna de 16 pontos. Os pontos em azul representam os pontos processados pelo primeiro grupo, e os em verde os pontos processados pelo segundo.

para se ajustar a altura do histograma (100 píxeis). As equações 4.4 e 4.5 mostram como este cálculo é feito para um ponto $P$, onde $S_{j}$ é o setor $j$ do histograma, $P_{x}$ é a coordenada $x$ do ponto de $P$ e $\|P\|$ é a magnitude do ponto $P$. $S f$ é usado para dimensionar o setor. A influência da distância foi modelada de maneira linear, embora este parâmetro pode ser ajustado para outros casos.

$$
\text { angle }=\arctan \left(\frac{P_{x}}{P_{z}}\right)
$$

$\mathrm{e}$

$$
S_{\text {angle }}=S_{\text {angle }}+\frac{1}{\left\|P_{i, j}\right\|} S f
$$

Vales candidatos são selecionados a partir do histograma. Um vale é candidato caso possua setores abaixo de um limiar definido. Quando há vários vales candidatos, o vale de destino é selecionado com base na sua distância em relação a $S_{\text {targ }}$, referente ao ângulo de destino. Um vale é chamado de largo ou estreito baseado no parâmetro $S_{\max }$. Caso a largura do vale seja maior (em número de setores) que $S_{\text {max }}$, então tal vale é largo caso contrário é estreito. A borda próxima $\left(k_{n}\right)$ do vale de destino é o setor que está mais próximo de $S_{t a r g}$ e a borda longínqua é definida como $k_{f}=k_{n}+S_{\max }$. O setor ou ângulo de esterçamento é selecionado dentro do 
vale destino de acordo com a Equação 4.6. As definições aqui utilizadas podem ser vistas em Borenstein e Koren (1991).

$$
S_{\text {ster }}=\frac{k_{n}+k_{f}}{2}
$$

A velocidade do veículo é calculada para permitir que o veículo desacelere enquanto estiver virando. Este é um passo importante dado a velocidade de esterçamento da plataforma utilizada. A velocidade é definida pela Equação:

$$
V=\frac{V_{\max }}{S_{\text {ster }} \Omega_{\max }}+V_{\min }
$$

onde $V$ é a velocidade calculada, $V_{\max }$ e $V_{\min }$ a velocidade máxima e mínima desejada, $\Omega_{\max }$ o ângulo máximo de esterçamento e $S_{s t e r}$ é o ângulo proveniente da Equação 4.6.

A Figura 4.14 mostra o histograma gerado pelo algoritmo, onde a linha vermelha é o limiar que separa regiões navegáveis das não navegáveis (acima do limiar). Roxo representa a densidade de obstáculos em cada setor e o segmento verde aponta para o vale de destino calculado.
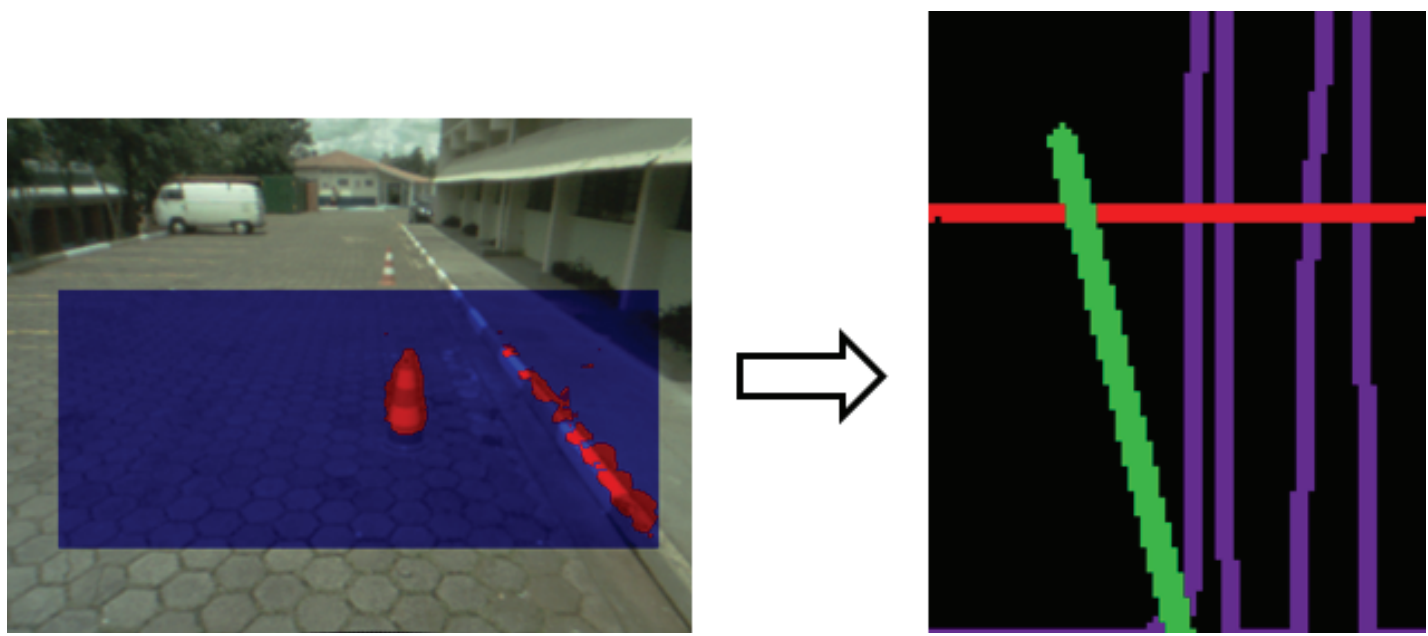

Figura 4.14: Mapa de navegabilidade e seu respectivo histograma de densidade de obstáculos.

O algoritmo VFH não leva em consideração a cinemática do veículo. Para superar essa limitação uma máquina de estados foi criada. Depois de evitar um obstáculo, o algoritmo entra em um estado que ignora o ângulo calculado (a menos que haja um obstáculo iminente) e avança por cerca de 1,5 metros (o comprimento do veículo). Esta máquina de estados mostrou-se necessária para que o veículo possa passar por todo o obstáculo e, portanto, evite bater sua lateral enquanto faz uma curva. 
O sistema de navegação usado conta com um sensor inercial integrado a um GPS para realizar as seguintes tarefas: (I) definir a posição destino, (II) estimar a posição atual; (III) estimar a direção para o objetivo.

Baseando-se nesta informação é possível estimar a diferença entre o ângulo que a frente do veículo aponta e o ângulo de destino $\left(S_{\text {targ }}\right)$ e utilizá-lo como entrada para o algoritmo de desvio de obstáculos. O algoritmo usa essa informação para guiar o veículo, desviando de obstáculos e esterçando em direção ao destino sempre que possível. 

Este capítulo apresenta os resultados obtidos durante todo o desenvolvimento do projeto. O capítulo começa por expor os resultados referentes aos métodos estéreos testados através da Seção 5.1. Os experimentos realizados com os métodos de detecção de obstáculos são mostrados nas seções 5.2.1 e 5.2.2. Concluindo o capítulo, o teste de navegação é apresentado na Seção 5.3.

\subsection{Métodos Estéreos}

Usando as implementações contidas na biblioteca OpenCV comparamos o método estéreo semi-global semi-global block matching (SGBM) com o algoritmo de correspondência local block-matching (BM). Algumas imagens foram capturadas (Figura 5.1) e ambos os métodos foram avaliados em termos de custo computacional e densidade do mapa de disparidades gerado. Foi utilizada uma resolução de 400 por 300 píxeis nas imagens, as etapas de pré/pós processamento foram as mesmas para ambos os métodos e o número máximo de disparidades foi de 32. A porcentagem de desconhecido é a porcentagem de píxeis que o método estéreo não pode encontrar uma correspondência, possuindo assim nenhuma informação de profundidade. O computador utilizado no teste contou com o processador Intel Core i5-2500.

A Figura 5.2 mostra a comparação entre o método local BM e o semi-global SGBM em termos de quadros por segundo (QPS) e tamanho do bloco. O tamanho do bloco teve pouca 


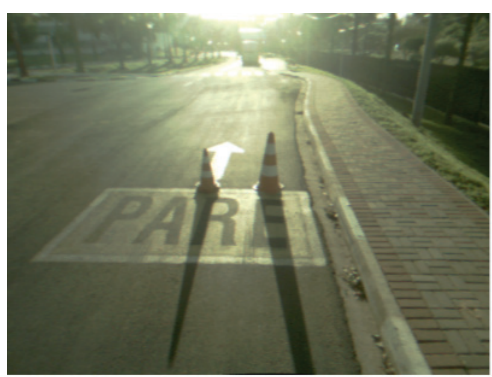

Imagem Esquerda

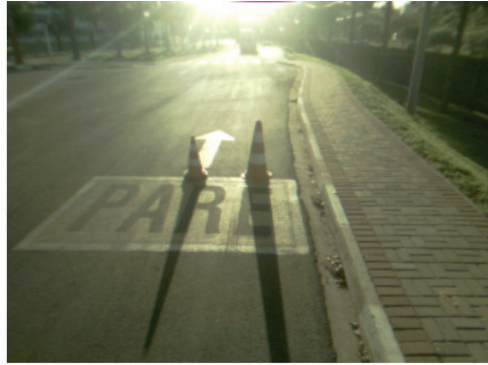

Imagem Direita

Figura 5.1: Imagens esquerda e direita utilizadas para o teste de desempenho.

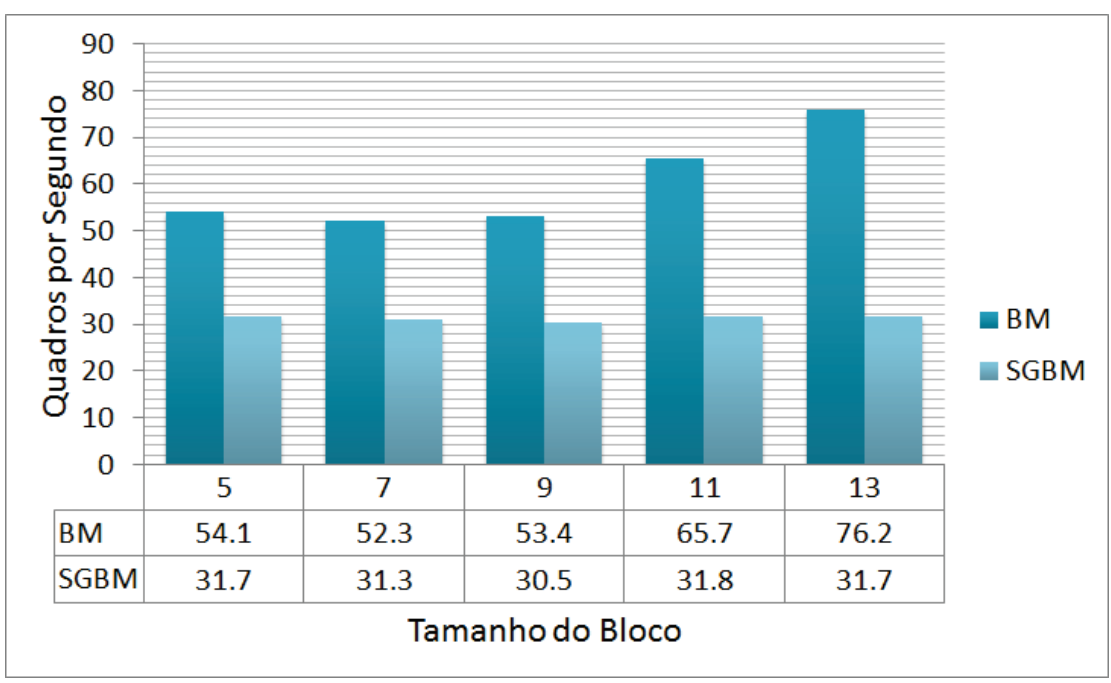

Figura 5.2: Gráfico de comparação entre o método local BM e o semi-global SGBM em termos de quadros por segundo e tamanho de bloco.

influência sobre o desempenho com relação a implementação da biblioteca $O p e n C V$, provavelmente devido as otimizações SIMD (Simple Instruction Multiple Data) utilizadas pela biblioteca. O método de correspondência local é cerca de duas vezes mais rápido que o semi-global, mas ainda assim o método semi-global pôde atingir 30 QPS.

Enquanto o método local é mais rápido, o método semi-global é capaz de gerar um mapa de disparidades consideravelmente mais denso usando um bloco de menor tamanho, como a Figura 5.3 mostra. Isso é importante para preservar os detalhes da cena.

A fim de se obter um mapa de disparidades denso com o método local de correspondência é necessário aumentar o tamanho do bloco, mas isso acaba por ofuscar as bordas de objetos. A Figura 5.4 mostra como um bloco grande pode ocultar detalhes: usando o bloco de 25 por 25 píxeis não há fronteiras entre os dois cones de trânsito no mapa de disparidades.

É importante notar que este trabalho não pretende fazer uma avaliação estatística completa dos métodos. O objetivo é apenas dar uma intuição entre as diferenças destes dois métodos. 


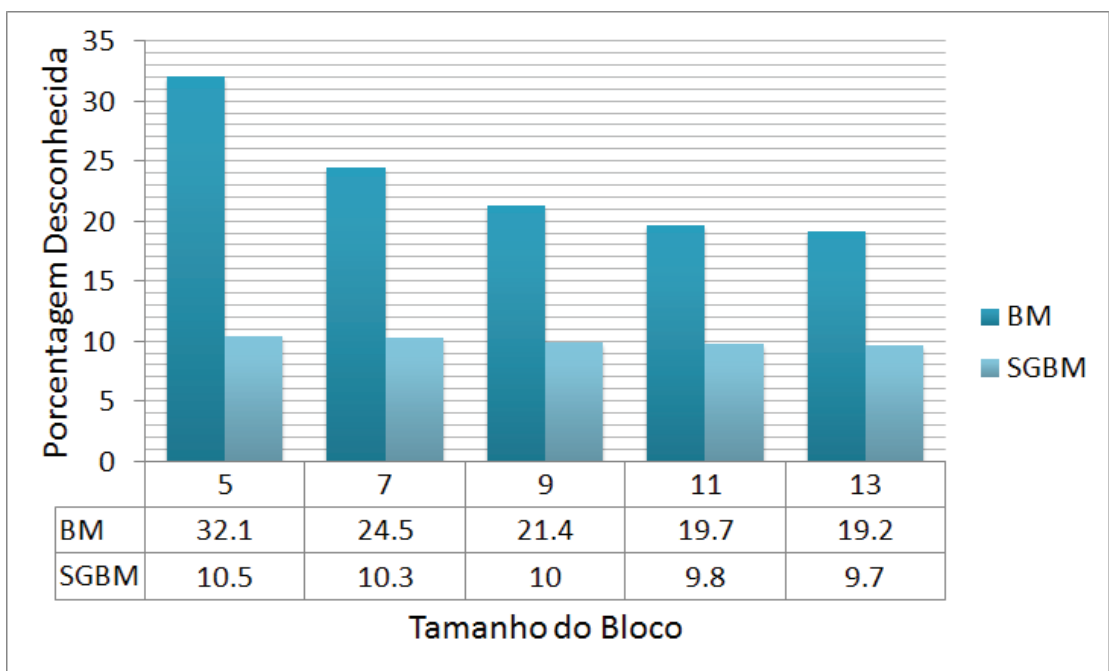

Figura 5.3: Gráfico de comparação entre o método local BM e o semi-global SGBM em termos de porcentagem de disparidades desconhecidas e tamanho do bloco.

Tamanho do bloco:

9
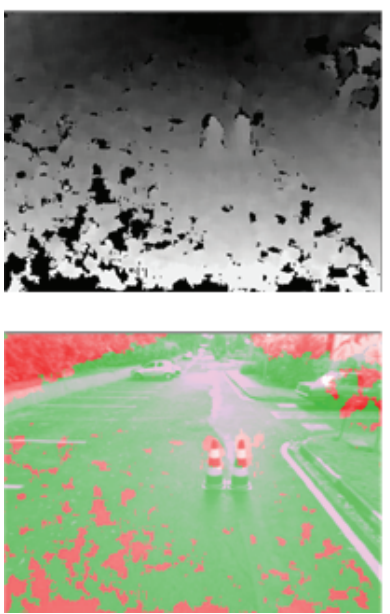

15
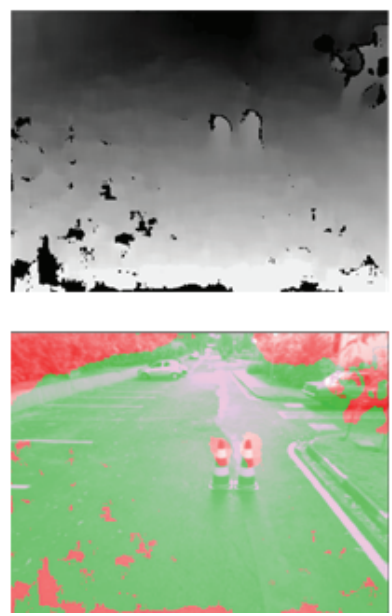

25

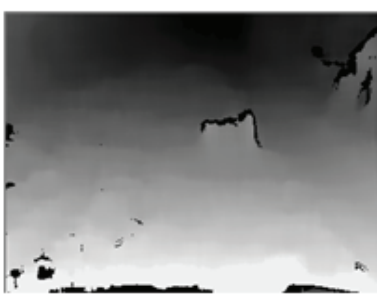

Mapa de disparidades

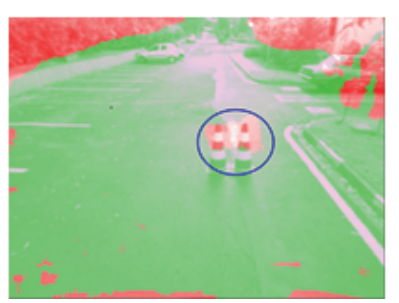

Mapa de navegabilidade

Figura 5.4: Ilustração dos efeitos de um bloco grande circulado em azul.

\subsection{Detecção de Obstáculos}

Nesta Seção serão apresentados os resultados de ambos os métodos utilizados para detecção de obstáculos em cenários reais. No caso da detecção baseada em cone, também é feita uma análise das otimizações realizadas. 


\subsubsection{Detecção Baseada em Plano}

O primeiro método utilizado atingiu um desempenho suficiente para terrenos planos em termos de classificação. Nesta Seção é feita apenas uma análise qualitativa do método, porém esta foi o suficiente para identificar suas limitações. Estas são próprias de seu funcionamento como visto na Seção 4.3.1. Para os testes foi utilizada uma resolução de 320 por 220 nas imagens e o limiar foi definido em 25 centímetros.

Observando a Figura 5.5, referente à classificação resultante de cenários planos, é possível observar que o método detecta especialmente bem obstáculos próximos e com um determinado nível mínimo de altura. Isso acontece por dois motivos: (I) a precisão do mapa de disparidades (e portando da nuvem de pontos) se degrada conforme a distância; (II) a distância amplifica as vibrações do carro que deslocam o plano estimado inicialmente.

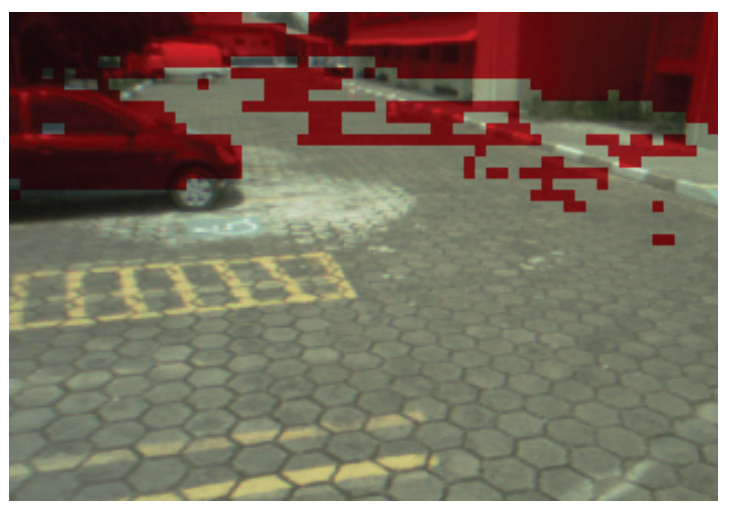

(a) Detecção de veículo e guia.

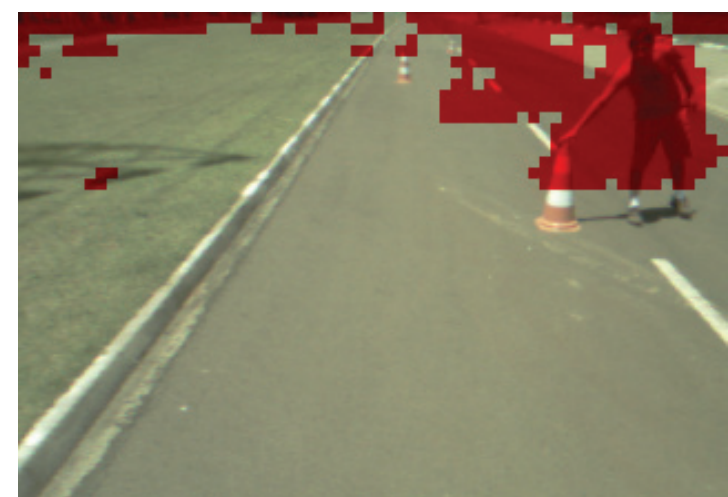

(b) Detecção de pessoa e cones.

Figura 5.5: Resultados da detecção de obstáculos baseada em plano onde píxeis vermelhos são considerados obstáculos.

No caso de um cenário onde a área navegável é curvada, o método se torna menos útil pois não é possível estimar um plano que represente fielmente a área navegável. Sendo assim, a qualidade da classificação pode variar consideravelmente conforme a angulatura da câmera em relação ao terreno e em relação a curvatura do próprio terreno. A Figura 5.6 ilustra o problema.

\subsubsection{Detecção Baseada em Cone}

Por conta das limitações presentes na detecção de obstáculos baseada em plano, optou-se por avaliar outra forma de detecção de obstáculos. Este outro método se mostrou robusto o suficiente para lidar com os cenários propostos, mesmo no caso de terrenos acidentados o método conseguiu se manter consistente na classificação. Os testes realizados com o método utiliza- 


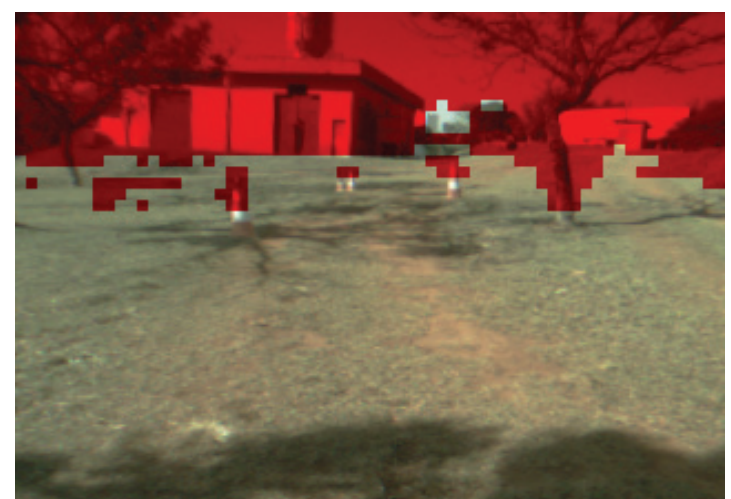

(a) Detecção de cones e árvores.

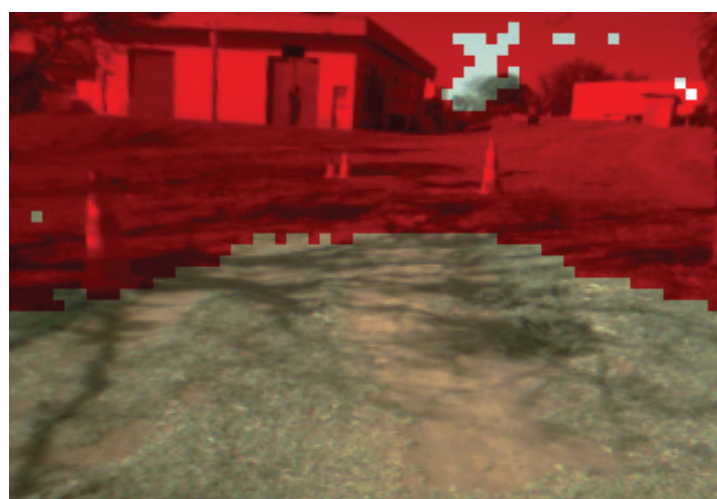

(b) Detecção prejudicada por conta da mudança de angulatura do terreno.

Figura 5.6: Resultados da detecção de obstáculos baseada em plano em um terreno curvado.

ram uma resolução de 320 por 220 no par de imagens estéreo e os parâmetros do método são apresentados na Tabela 5.1.

Tabela 5.1: Parâmetros selecionados para os testes com o método de detecção de obstáculos baseado em cone.

\begin{tabular}{c|c}
\hline Parâmetro & Valor \\
\hline$H_{T}$ & $16 \mathrm{~cm}$ \\
$H_{\max }$ & $40 \mathrm{~cm}$ \\
$\theta_{T}$ & 45 graus \\
$s$ & 120 \\
\hline
\end{tabular}

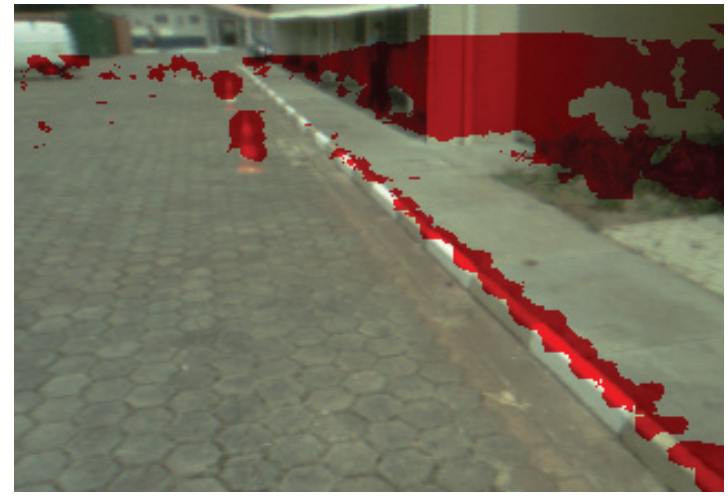

(a) Detecção de cones, guias e prédios.

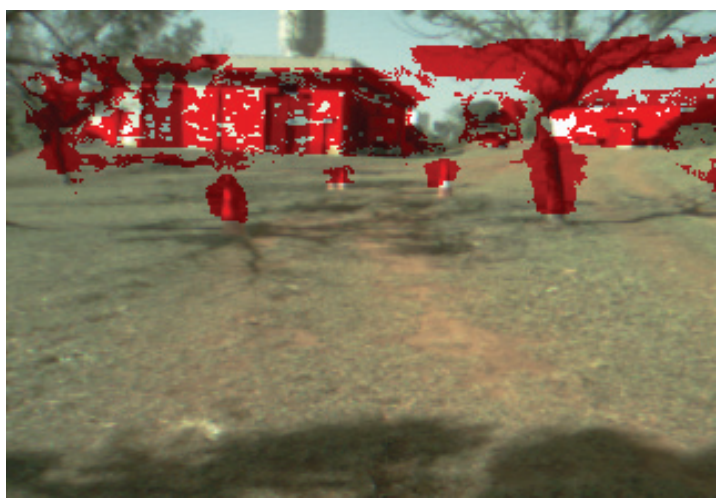

(b) Detecção de cones e árvores em um terreno curvado.

Figura 5.7: Resultados da detecção de obstáculos baseada em cone. 
Como se pode observar na Figura 5.7, os resultados do método são satisfatórios em diversos cenários, possibilitando inclusive a detecção de obstáculos tão baixos quanto uma guia. As únicas limitações do método são referentes a quantidade de ruído, que aumenta com a distância e que, em sua maioria, são advindas do próprio método estéreo. A implementação de um filtro poderia minimizar o problema. Outra limitação é seu custo computacional, mas como os resultados da Seção 5.2.2.2 mostram, este pode ser resolvido utilizando uma implementação em GPU.

\subsubsection{Validando Aproximação Realizada}

Uma vez realizada a aproximação descrita na Seção 4.3.2, foram feitos alguns testes a fim de validá-la. Os testes consistem em comparar o resultado da aproximação (i.e. modo aproximado) com o resultado do processamento completo (i.e. modo completo), isto é, comparando todos os pontos entre si. Além disso, foram efetuados testes de desempenho visando avaliar o ganho computacional relacionado a aproximação.

Tabela 5.2: Quantidade de pontos não classificados pela aproximação referente ao método de detecção de obstáculos baseado em cone.

\begin{tabular}{c|ccc}
\hline Cenário & Número total de pontos & Número do pontos não classificados & Porcentagem de pontos não classificados \\
\hline 1 & 417600 & 1595 & $0.4 \%$ \\
2 & 417600 & 2731 & $0.7 \%$ \\
\hline
\end{tabular}

A Tabela 5.2 mostra o número de pontos não classificados utilizando a aproximação e sua porcentagem em relação ao número total de pontos. A Figura 5.8 mostra a diferença entre os dois modos. Como se pode notar, as diferenças não são significativas pois nenhum obstáculo maior foi perdido. Com isto em mente, decidiu-se manter a aproximação para os experimentos seguintes.

Alguns testes foram realizados para averiguar o ganho computacional resultante da aproximação. A Tabela 5.3 mostra os tempos obtidos no processamento de uma nuvem de pontos de 320 por 220 pontos. Verificou-se, portanto, que tal método só poderia chegar a processar uma nuvem de pontos em tempo real utilizando algum tipo de aproximação.

\subsubsection{Testes de Desempenho}

Foram realizados testes de desempenho utilizando uma nuvem de pontos de 320 por 220 pontos ou 70400 pontos. Nos testes foram comparadas: a implementação que utiliza um núcleo; a implementação realizada com a biblioteca OpenMP utilizando quatro núcleos; a implementação 


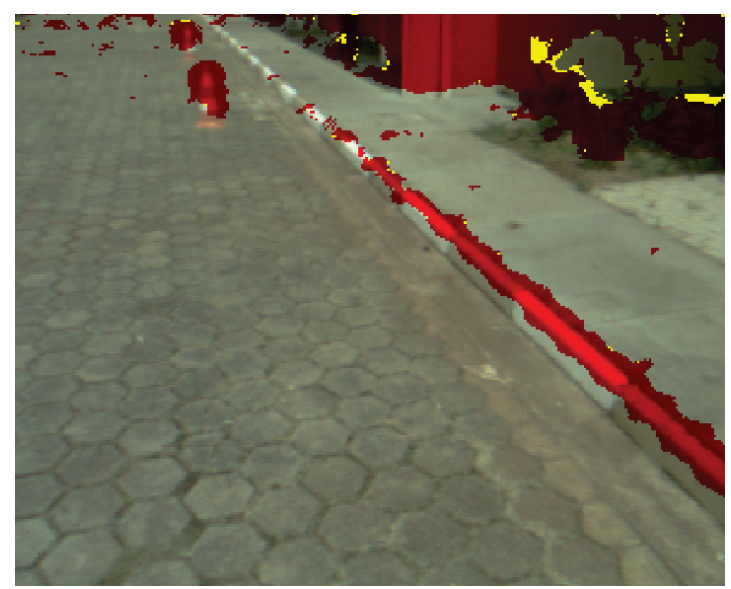

(a) Diferença entre o processamento completo e o aproximado no primeiro cenário.

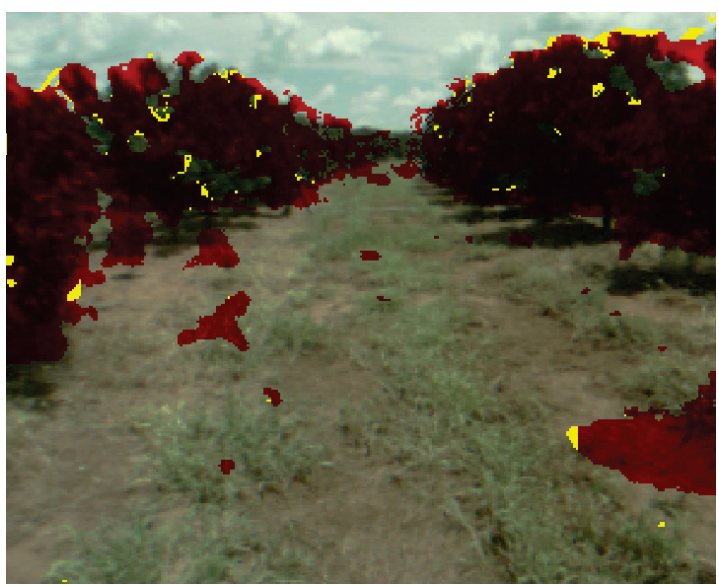

(b) Diferença entre o processamento completo e o aproximado no segundo cenário.

Figura 5.8: Comparação entre o resultado da classificação utilizando aproximação e o processamento completo. Píxeis amarelos representam os pontos não classificados pela aproximação.

Tabela 5.3: Comparação entre o tempo médio de processamento utilizando a aproximação e o processamento completo.

\begin{tabular}{c|cc}
\hline Modo & Tempo médio & Ganho de desempenho \\
\hline Completo & $11546 \mathrm{~ms}$ & 1 \\
Aproximado & $168.594 \mathrm{~ms}$ & 68.48 \\
\hline
\end{tabular}

utilizando GPU. O equipamento utilizado nos testes consiste uma CPU Intel i5 2500 operando a 4 Ghz e uma GPU AMD RADEON 5850.

Tabela 5.4: Tempos de processamento para cada forma diferente de implementação do método de detecção de obstáculos baseado em cone.

\begin{tabular}{c|cccc}
\hline Forma de processamento & Tempo médio & Tempo máximo & Tempo mínimo & Ganho de desempenho (tempo médio) \\
\hline 1 núcleo & $168.594 \mathrm{~ms}$ & $194.495 \mathrm{~ms}$ & $154.223 \mathrm{~ms}$ & 1 \\
4 núcleos & $84.444 \mathrm{~ms}$ & $112.995 \mathrm{~ms}$ & $68.08 \mathrm{~ms}$ & 1.99 \\
GPU & $17.94378 \mathrm{~ms}$ & $44.08124 \mathrm{~ms}$ & $15.01299 \mathrm{~ms}$ & 9.39 \\
\hline
\end{tabular}

Observando a Tabela 5.4 podemos notar um ganho de aproximadamente duas vezes da implementação utilizando 4 núcleos em relação a que utiliza apenas 1 núcleo. No caso da GPU o ganho foi ainda maior, sendo em torno de 10 vezes mais rápido que a que utiliza um núcleo. A variação dos tempos se dão por conta da variação do tamanho da janela, implicando em mais ou menos pontos a serem processados. O ganho obtido utilizando a GPU não foi maior por conta 
de suas restrições em termos do tamanho da janela. O método foi executado 64 vezes em cada modo para obtenção dos dados.

Utilizando a ferramenta AMD APP Profiler ${ }^{1}$ de análise de desempenho foi possível obter dados detalhados da execução do método pela GPU, como mostra a Tabela 5.5. Tal tabela mostra como a maior parte do processamento se dá na própria execução do kernel, o tempo gasto pela leitura/escrita de buffers é desprezível. O tempo de execução é o tempo de execução do kernel mais três vezes o tempo de escrita do buffer e mais o tempo de leitura do buffer. Isso porque são feitas três escritas de buffer por execução.

Tabela 5.5: Detalhamento dos tempos de processamento do método pela GPU.

\begin{tabular}{c|cccc}
\hline Etapa & Número de chamadas & Tempo médio & Tempo máximo & Tempo mínimo \\
\hline Execução do kernel & 64 & $14.06542 \mathrm{~ms}$ & $29.42765 \mathrm{~ms}$ & $12.88704 \mathrm{~ms}$ \\
Escrita dos buffers & 192 & $0.8162 \mathrm{~ms}$ & $3.5599 \mathrm{~ms}$ & $0.22881 \mathrm{~ms}$ \\
Leitura dos buffers & 64 & $1.42976 \mathrm{~ms}$ & $15.01299 \mathrm{~ms}$ & 0.26474 \\
Tempo por execução & - & $17.94378 \mathrm{~ms}$ & $44.08124 \mathrm{~ms}$ & $15.01299 \mathrm{~ms}$ \\
\hline
\end{tabular}

A implementação em GPU possibilita executar a detecção de obstáculos por volta de 55 vezes por segundo, o que supera os 30 quadros por segundos fornecidos pela câmera. Isso significa que o problema de desempenho do método foi resolvido para o presente sistema.

\subsection{Navegação Autônoma}

Diversos experimentos foram conduzidos onde o veículo elétrico do projeto CArro Robótico Inteligente para Navegação Autônoma (CARINA), disponível no Laboratório de Robótica Móvel (LRM - USP) foi capaz de navegar autonomamente, desviando de obstáculos (cones de trânsito, carros e pessoas) e alcançar seguramente seu destino.

O ambiente escolhido para os experimentos foi um estacionamento na USP, campus São Carlos. Foram escolhidos o ponto de partida e o de destino de modo que o veículo necessitasse desviar de obstáculos para alcançar seu destino. Foram organizados dois cones no trajeto esperado do veículo, além disso, haviam dois carros e uma pessoa no trajeto. Um diagrama de blocos do sistema desenvolvido pode ser visto na Figura 5.9.

Primeiramente o par de imagens estéreo é processado pelo método estéreo semi-global, gerando o mapa de disparidades, este é convertido em uma nuvem de pontos. No caso do primeiro frame, é estimado um plano utilizando o paradigma RANSAC a fim de alinhar virtualmente a câmera aos eixos $x$ e $z$. Com a câmera virtualmente alinhada, o método de desvio de obstáculos

\footnotetext{
${ }^{1}$ http://developer.amd.com/tools/AMDAPPProfiler/Pages/default.aspx
} 


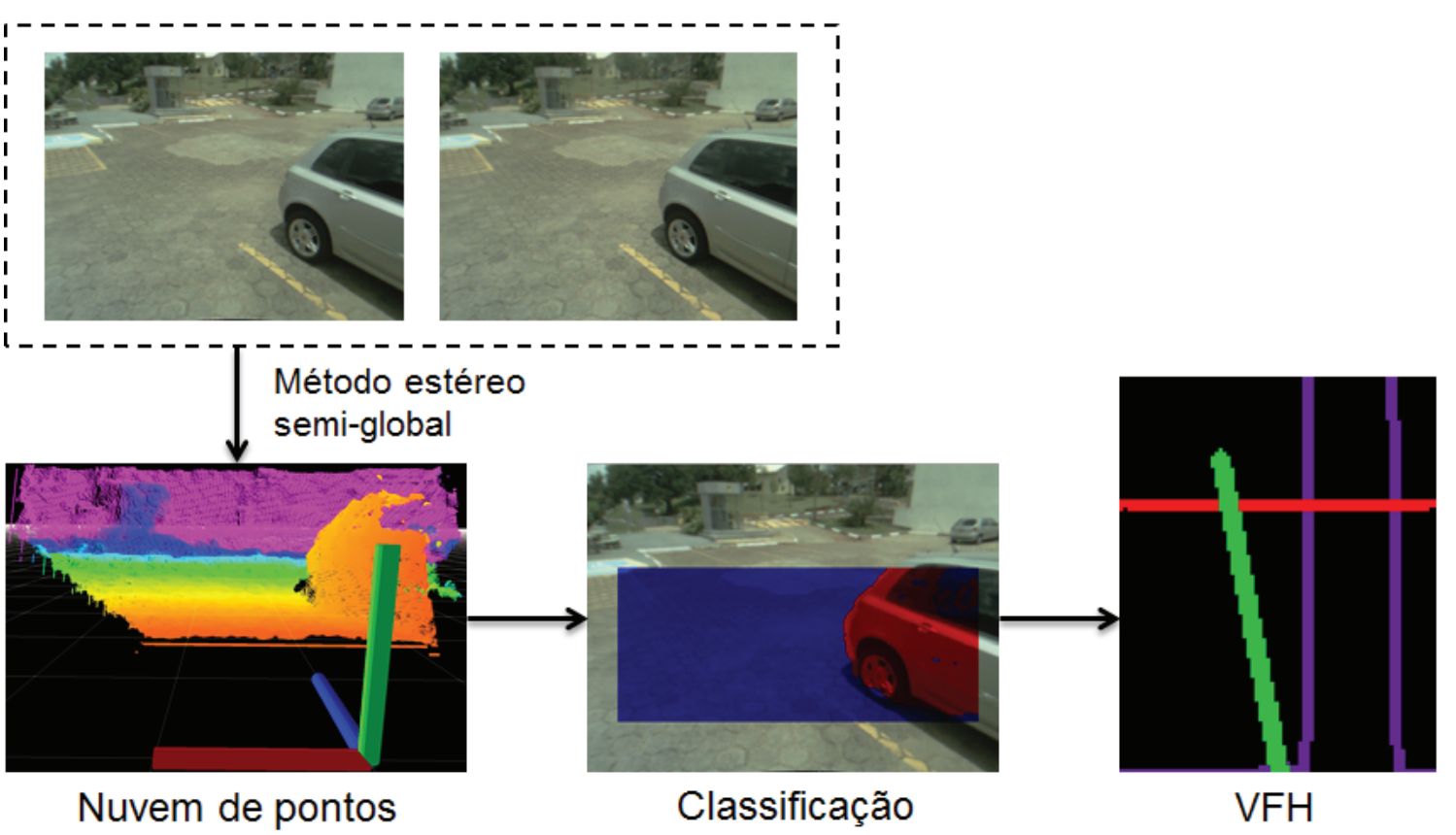

Figura 5.9: Diagrama de blocos da metodologia utilizada no experimento final.

baseado em cone é executado e a classificação do terreno é gerada. Por fim, a classificação é repassada ao método de desvio de obstáculos VFH que recebe os sinais do GPS e envia os comandos de esterçamento e aceleração ao carro.

Foi utilizada uma câmera estéreo STOC-15CM-M-MINI da marca Videre Design ${ }^{2}$ como sensor principal; o controlador de motor elétrico da marca Roboteq ${ }^{3}$, modelo AX-2850 para o esterçamento; a plataforma aberta Arduino para controlar a aceleração; um sensor inercial integrado a um GPS da marca Xsens ${ }^{4}$ modelo MTi-G.

Em termos de software, foi utilizada a plataforma Player ${ }^{5}$ para o controle dos atuadores; a biblioteca $O p e n C V$ foi utilizada para o cálculo do mapa de disparidades; o framework Robot Operating System (ROS) ${ }^{6}$ para armazenar o registro e visualizar o trajeto posteriormente. A biblioteca Point Clouds Library (PCL) ${ }^{7}$ foi utilizada para manipular a nuvem de pontos. Todo o código desenvolvido pode ser acessado via git pelo site http: / / code.google.com/p/ obstacle-avoidance/. O digrama de classes do sistema implementado pode ser visto na Figura 5.10.

\footnotetext{
${ }^{2}$ http://www.videredesign.com

${ }^{3}$ http://www.roboteq.com/

${ }^{4}$ http://www.xsens.com/

${ }^{5}$ http://playerstage.sourceforge.net/

${ }^{6}$ http://www.ros.org/

${ }^{7} \mathrm{http}: / / w w w . p o i n t c l o u d s . o r g /$
} 


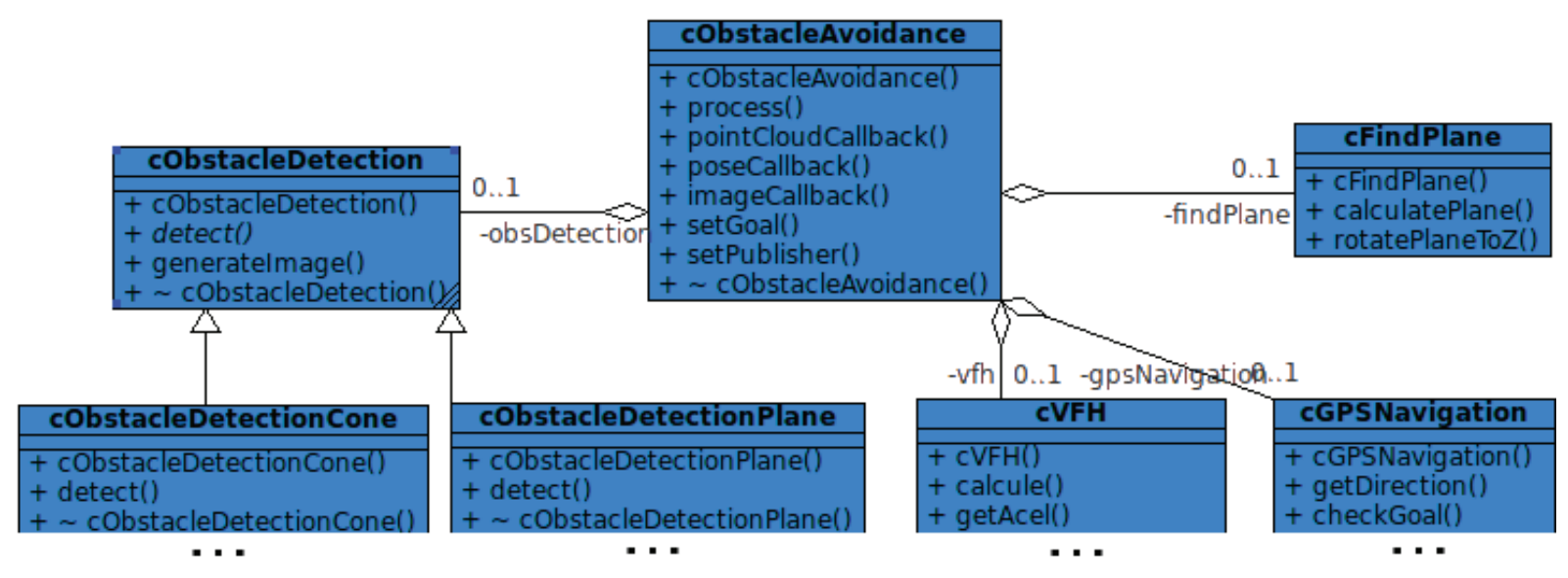

Figura 5.10: Diagrama de classes da implementação final do sistema de navegação.

A Figura 5.11 mostra uma sequência de imagens que ilustram o desvio de obstáculos e a chegada do veículo ao seu destino. O veículo inicia sua trajetória sem qualquer obstáculo visível e imediatamente esterça em direção ao destino. Após alguns poucos metros o veículo detecta a guia, desvia para a esquerda e segue ao lado da guia. Em seguida, dois cones de trânsito são detectados, o veículo desvia dos dois e volta a beirar a guia. Finalizando a guia, o veículo encontra um automóvel, desvia deste e volta a esterçar para o ângulo de destino. Por fim, o veículo desvia de mais um automóvel, de uma pessoa e chega ao seu destino seguramente.

Como é possível observar, a precisão do mapa de disparidades (e, portanto, da nuvem de pontos) permitiu a detecção e desvio de obstáculos tão baixos quanto 10 centímetros (guia), tornando o sistema adequado para ambientes urbanos. A trajetória realizada pelo veículo é apresentada na Figura 5.12, onde o segmento verde representa seu caminho fornecido pelo sensor $M T i$ - $G$, os cilindros vermelhos são os cones de trânsito, os retângulos azuis os carros, o círculo amarelo uma pessoa e os círculos verdes o início e fim do trajeto.

Os parâmetros foram selecionados com base no ambiente, as avaliações presentes neste capítulo e a capacidade de processamento do sistema. O tamanho do bloco selecionado para o método estéreo foi de 7 e o número máximo de disparidades 32. O paradigma RANSAC teve um limite de 1000 iterações que foram suficientes para uma estimativa precisa do plano inicial. Como se pode observar na classificação da Figura 5.9 apenas uma parte da nuvem de pontos foi classificada. Isso aconteceu devido as limitações de processamento de nosso computador móvel. Não foi possível utilizar a implementação em GPU do método de detecção de obstáculos baseado em cone.

Apesar de não possuir uma placa de vídeo compatível com a linguagem OpenCL todo o sistema teve um desempenho adequado para a sua aplicação em tempo real. O ângulo de esterçamento foi atualizado a uma taxa de aproximadamente 5 hertz usando uma resolução de 

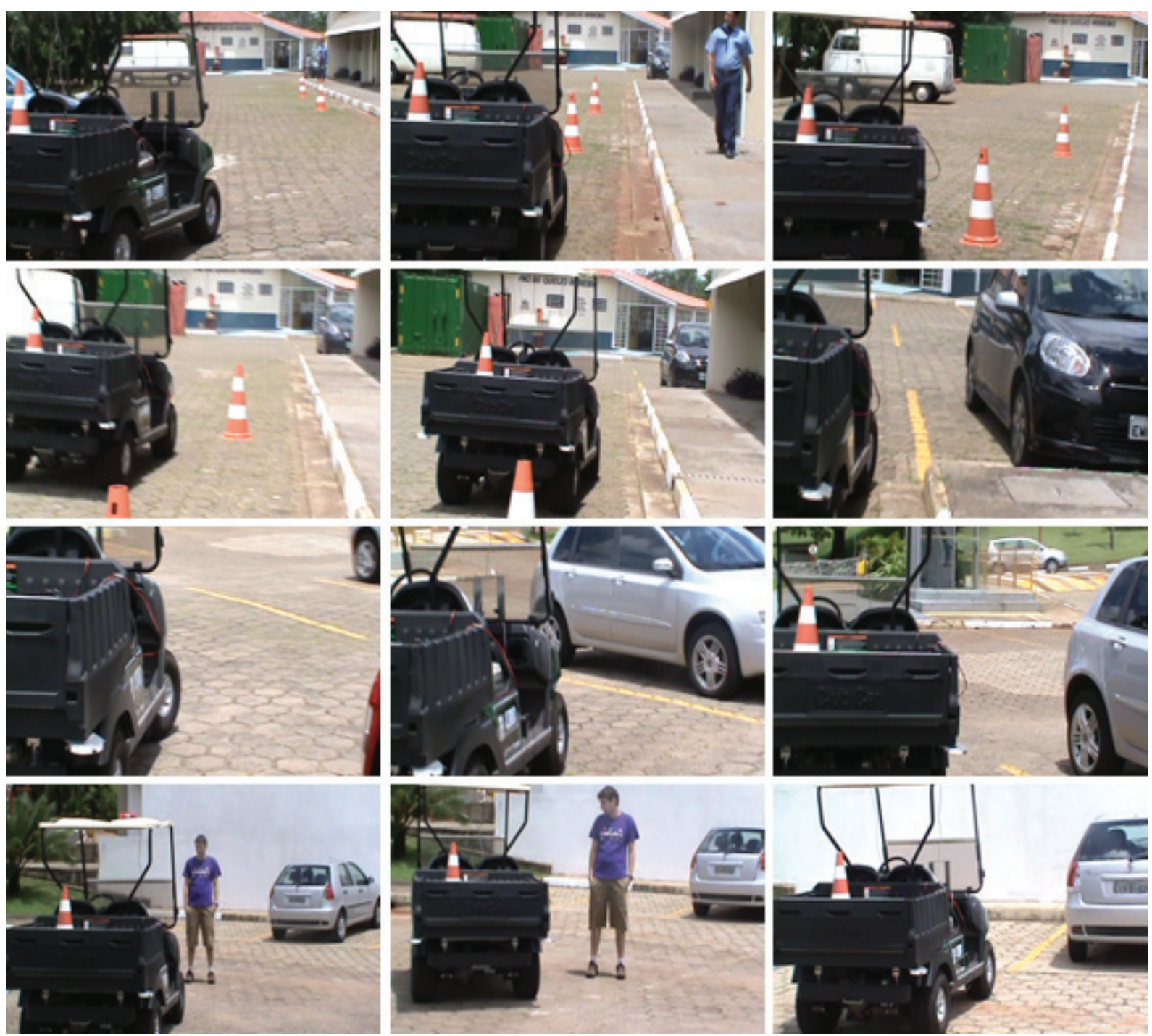

Figura 5.11: Sequência de imagens mostrando o veículo elétrico desviando de obstáculos e se encaminhando para o destino final.

400 por 300 no par de imagens estéreo. Os testes foram realizados usando um notebook Semp Toshiba modelo $1413 G$ com o processador Intel Core 2 Duo T6500. Um vídeo que mostra o experimento realizado está disponível em: http://www.youtube.com/watch?v=vJz9qKx5QE8 


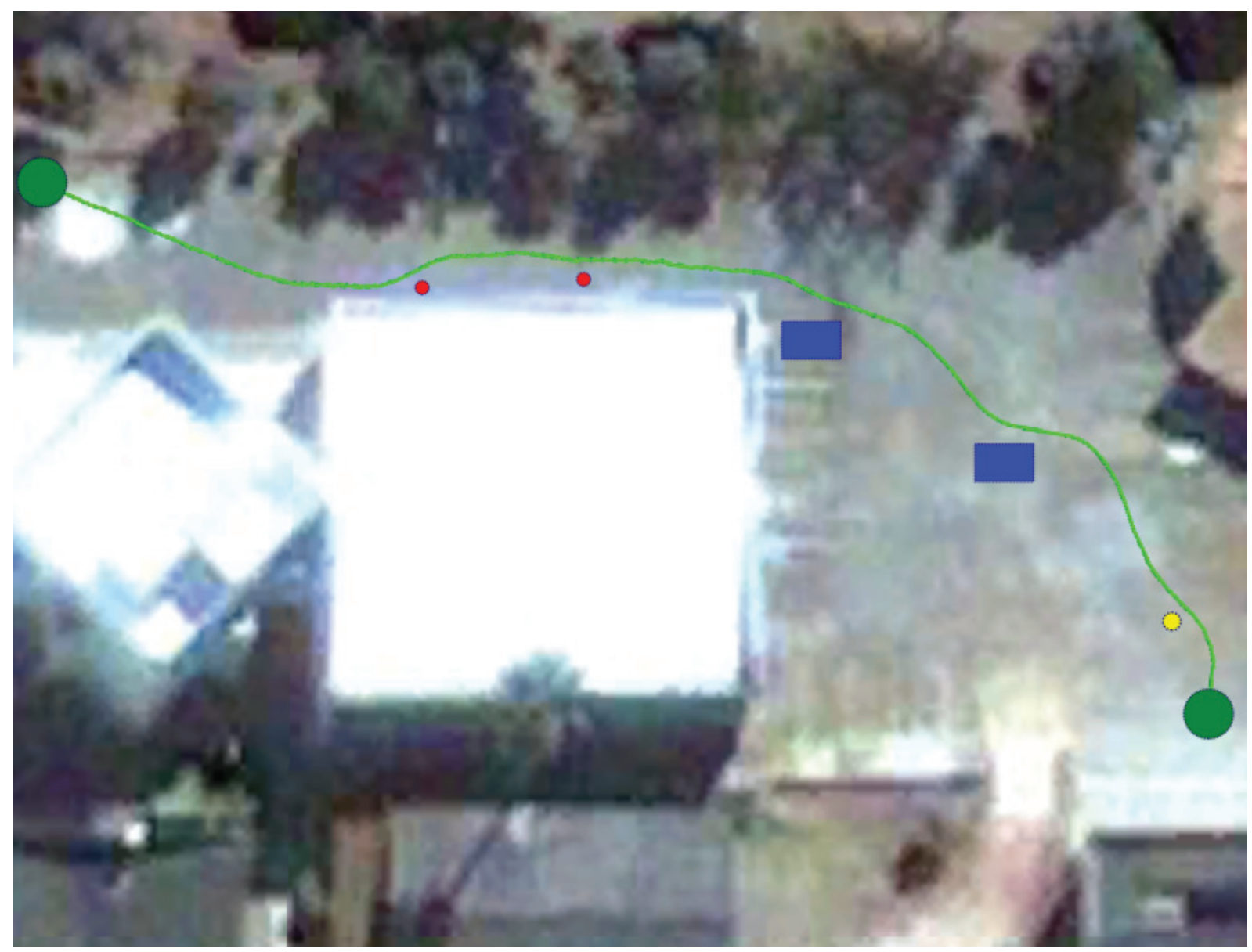

Figura 5.12: Trajetória do veículo (em verde) dada pelo sensor MTi-G. Cilindros vermelhos representam os cones de trânsito, os retângulos azuis os carros, o círculo amarelo uma pessoa e os círculos verdes o início e fim do trajeto. 


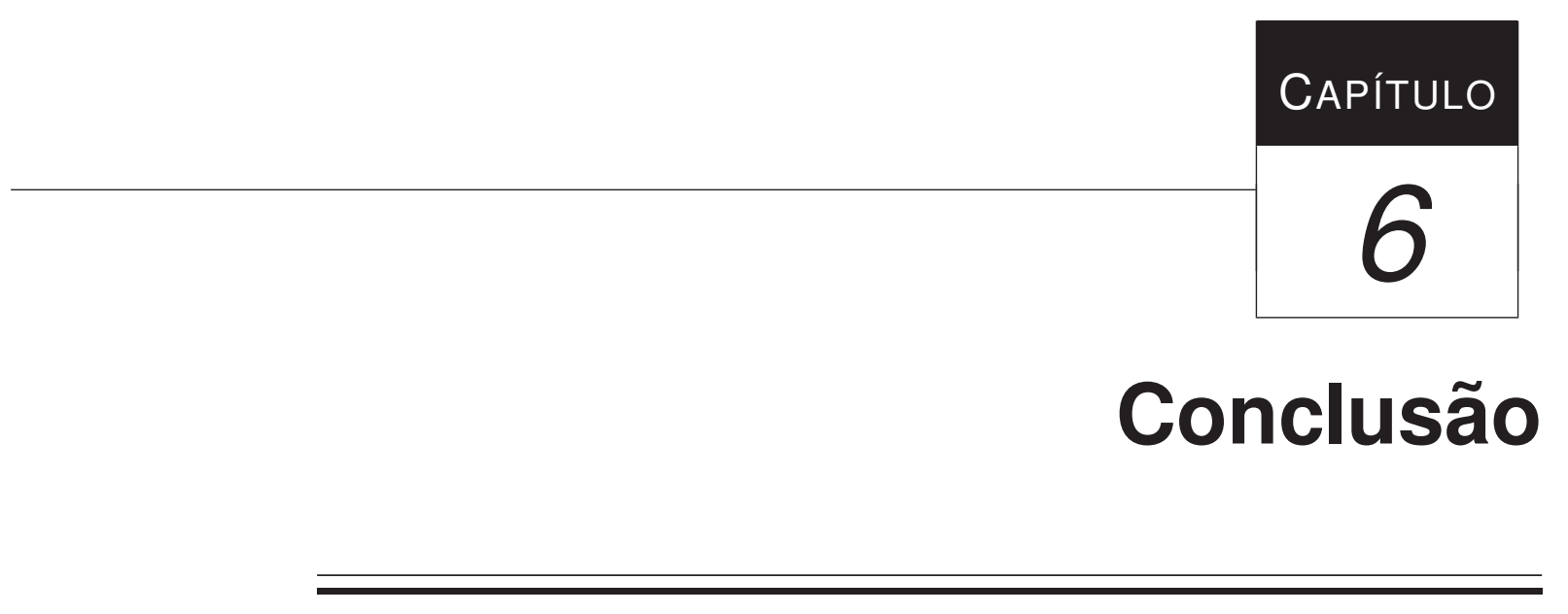

Esta dissertação apresentou uma análise de métodos estéreos para fins de navegação autônoma e dois métodos de detecção de obstáculos. Expôs-se as vantagens de métodos estéreos semi-globais. Estes demonstram um balanço entre custo computacional e desempenho implicando em uma ótima opção para fins de navegação autônoma. Os experimentos referentes aos métodos de detecção de obstáculos ilustraram as limitações dos métodos baseados em plano; que é apenas funcional em ambientes totalmente planos. No caso do método baseado em cone, com uma implementação em GPU, sem precedentes na literatura consultada, superou-se sua principal desvantagem; que é seu custo computacional. Deste modo obteve-se um método rápido e robusto para detecção de obstáculos.

Como forma de concluir o trabalho e demonstrar na prática a validade das opções realizadas e métodos desenvolvidos, foram integrados o método estéreo semi-global e o sistema de detecção de obstáculos com um método de desvio de obstáculos. Foi obtido, portanto, um sistema de navegação completo. Utilizando a plataforma experimental CARINA foram feitos alguns testes de navegação em um estacionamento da USP campus São Carlos. Os resultados desta etapa foram satisfatórios, a plataforma experimental foi capaz de desviar dos obstáculos e alcançar seu destino com segurança.

Por fim, este trabalho procurou maneiras inovadoras de realizar uma navegação autônoma utilizando uma câmera estéreo, realizando pesquisa sobre alguns dos diversos componentes que formam um sistema de navegação autônoma. 



\section{Referências Bibliográficas}

Borenstein, J.; Koren, Y. The vector field histogram-fast obstacle avoidance for mobile robots. Robotics and Automation, IEEE Transactions on, v. 7, n. 3, p. 278 -288, 1991.

Bradski, G.; KAEHLER, A. Learning opencv. O’Reilly Media Inc., 2008.

Broggi, A.; Bertè, S. Vision-based road detection in automotive systems: A real-time expectation-driven approach. Journal of Artificial Intelligence Research, v. 3, p. 325-348, 1995.

Broggi, A.; CARAfFi, C.; Fedriga, R.; Grisleri, P. Obstacle detection with stereo vision for off-road vehicle navigation. In: Computer Vision and Pattern Recognition - Workshops, 2005. CVPR Workshops. IEEE Computer Society Conference on, 2005, p. 65.

Brown, M.; BurschKa, D.; Hager, G. Advances in computational stereo. Pattern Analysis and Machine Intelligence, IEEE Transactions on, v. 25, n. 8, p. 993 - 1008, 2003.

Campbell, M.; Garcia, E.; Miller, D. H.; Moran, P.; Nathan, A.; Schimpf, B.; Catlin, N. Z.; Chelarescu, F.; Fujishima, H.; andSergei Lupashin, F.-R. K.; Reitmann, M.; Shapiro, A.; Wong, J. Team cornell: Technical review of the darpa urban challenge vehicle. 2007. 
CARAfFi, C.; CAtTAni, S.; Grisleri, P. Off-road path and obstacle detection using decision networks and stereo vision. Intelligent Transportation Systems, IEEE Transactions on, v. 8, n. 4, p. $607-618,2007$.

CASE, L. GeForce 8800 GTX: 3D Architecture Overview. 2006.

Disponível em http://www.pcmag.com/article2/0,2817,2054120,00.asp (Acessado em 26 de fevereiro de 2012)

Chaturvedi, P.; Malcolm, A.; lbanez Guzman, J. Real-time road following in natural terrain. Cybernetics and Intelligent Systems, 2004 IEEE Conference on, v. 2, p. 815 -820, 2004.

CNM Mapeamento das Mortes por Acidente de Trânsito no Brasil. 2009.

Disponível em http://www.cnm.org.br/index.php?option=com_ docman\&task=doc_download\&gid=150\&Itemid=4 (Acessado em 26 de fevereiro de 2012)

CYGANEK, B. An introduction to $3 d$ computer vision techniques and algorithms. John Wiley \& Sons, 2007.

DARPA DARPA Grand Challenge. 2005.

Disponível em http: / / www. darpa.mil/grandchal lenge05/ (Acessado em 24 de dezembro de 2010)

DARPA DARPA Urban Challenge. 2007.

Disponível em http://www.darpa.mil/grandchallenge/index.asp (Acessado em 24 de dezembro de 2010)

ELROB The European Robot Trial. 2011.

Disponível em http: / / www. elrob. org (Acessado em 26 de fevereiro de 2012)

Erkan, A.; Hadsell, R.; Sermanet, P.; Ben, J.; Muller, U.; LeCun, Y. Adaptive long range vision in unstructured terrain. Intelligent Robots and Systems, 2007. IROS 2007. IEEE/RSJ International Conference on, p. 2421 -2426, 2007.

Fischler, M. A.; Bolles, R. C. Random sample consensus: a paradigm for model fitting with applications to image analysis and automated cartography. Commun. ACM, v. 24, p. 381-395, 1981. 
Guo, Y.; Gerasimov, V.; Poulton, G. Vision-based drivable surface detection in autonomous ground vehicles. Intelligent Robots and Systems, 2006 IEEE/RSJ International Conference on, p. $3273-3278,2006$.

Hadsell, R.; Sermanet, P.; Ben, J.; Erkan, A.; Scoffier, M.; Kavukcuoglu, K.; MulleR, U.; LECUN, Y. Learning long-range vision for autonomous off-road driving. $J$. Field Robotics, v. 26, n. 2, p. 120-144, 2009.

Haller, I.; Pantilie, C.; Oniga, F.; Nedevschi, S. Real-time semi-global dense stereo solution with improved sub-pixel accuracy. In: Intelligent Vehicles Symposium (IV), 2010 IEEE, 2010, p. $369-376$.

HAPPOLD, M.; Ollis, M. Autonomous learning of terrain classification within imagery for robot navigation. In: Systems, Man and Cybernetics, 2006. SMC '06. IEEE International Conference on, 2006, p. $260-266$.

HiRschmuller, H. Accurate and efficient stereo processing by semi-global matching and mutual information. In: Computer Vision and Pattern Recognition, 2005. CVPR 2005. IEEE Computer Society Conference on, 2005, p. 807 - 814 vol. 2.

Hirschmuller, H. Stereo processing by semiglobal matching and mutual information. Pattern Analysis and Machine Intelligence, IEEE Transactions on, v. 30, n. 2, p. 328 -341, 2008.

IBGE Tendências Demográficas: Uma análise dos resultados da amostra do Censo Demográfico 2000. 2004.

Disponível em http://www.ibge.gov.br/home/estatistica/populacao/ censo2000/tendencias_demograficas/tendencias.pdf (Acessado em 26 de fevereiro de 2012)

JEOnG, P.; NeDEvSCHI, S. Local difference probability (ldp)-based environment adaptive algorithm for unmanned ground vehicle. Intelligent Transportation Systems, IEEE Transactions on, v. 7, n. 3, p. $282-292,2006$.

KILGARIFF, E.; FERnANDO, R. The geforce 6 series gpu architecture. In: ACM SIGGRAPH 2005 Courses, SIGGRAPH '05, New York, NY, USA: ACM, 2005 (SIGGRAPH '05, ).

Konolige, K.; Agrawal, M.; Bolles, R.; Cowan, C.; Fischler, M.; Gerkey, B. Outdoor mapping and navigation using stereo vision. In: Experimental Robotics, Springer Berlin / Heidelberg, 2008, p. 179 -190 (Springer Tracts in Advanced Robotics, v.39). 
LAbayrade, R.; Aubert, D.; TARel, J.-P. Real time obstacle detection in stereovision on non flat road geometry through "v-disparity"representation. In: Intelligent Vehicle Symposium, 2002. IEEE, 2002, p. 646 - 651 vol.2.

LAGR Learning Applied to Ground Robots. 2005.

Disponível em http://www.darpa.mil/i2o/programs/lagr/lagr.asp (Acessado em 3 de abril de 2009)

LEE, J.; CRAnE, C. Road following in an unstructured desert environment based on the em(expectation-maximization) algorithm. SICE-ICASE, 2006. International Joint Conference, p. $2969-2974,2006$.

LIMA, D.; G.A.S., P. Um sistema de visão estéreo para navegação de um carro autônomo em ambientes com obstáculos. XVII Congresso Brasileiro de Automática, p. 224 -231, 2010.

LU, J.; YANG, M.; WANG, H.; ZHANG, B. Vision-based real-time road detection in urban traffic. 2002.

van der Mark, W.; VAn den Heuvel, J.; Groen, F. Stereo based obstacle detection with uncertainty in rough terrain. In: Intelligent Vehicles Symposium, 2007 IEEE, 2007, p. $1005-1012$.

Matтосcia, S. Stereo Vision: Algorithms and Applications. 2010.

Disponível em http://www.vision.deis.unibo.it/smatt/Seminars/ StereoVision.pdf (Acessado em 26 de fevereiro de 2012)

MRS Make Roads Safe: A decade for of action for road safety. 2009.

Disponível em http://www.makeroadssafe.org/publications/ Documents/decade_of_action_report_lr.pdf (Acessado em 26 de fevereiro de 2012)

Murarka, A.; Kuipers, B. A stereo vision based mapping algorithm for detecting inclines, drop-offs, and obstacles for safe local navigation. Intelligent Robots and Systems, 2009. IROS 2009. IEEE/RSJ International Conference on, p. 1646 -1653, 2009.

Murarka, A.; Sridharan, M.; Kuipers, B. Detecting obstacles and drop-offs using stereo and motion cues for safe local motion. In: Intelligent Robots and Systems, 2008. IROS 2008. IEEE/RSJ International Conference on, 2008, p. 702 -708. 
MurRay, D.; Jennings, C. Stereo vision based mapping and navigation for mobile robots. In: Robotics and Automation, 1997. Proceedings., 1997 IEEE International Conference on, 1997, p. $1694-1699$ vol.2.

NA, I.; Choi, J.; JeOng, H. Robust fast belief propagation for real-time stereo matching. In: Advanced Communication Technology, 2009. ICACT 2009. 11th International Conference on, 2009, p. $1175-1179$.

Newman, W.; LEAD, T. Team case and the 2007 darpa urban challenge. 2007.

NVIDIA OpenCL Programming Guide for the CUDA Architecture. 2010.

Disponível em http://developer.download.nvidia.com/compute/cuda/ 3_1/toolkit/docs/NVIDIA_OpenCL_ProgrammingGuide.pdf (Acessado em 26 de fevereiro de 2012)

PVS Por Vias Seguras. 2012.

Disponível em http://www.vias-seguras.com/os_acidentes/causas_de_ acidentes (Acessado em 26 de fevereiro de 2012)

Ramstrom, O.; Christensen, H. A method for following unmarked roads. Intelligent Vehicles Symposium, 2005. Proceedings. IEEE, p. 650 - 655, 2005.

Rankin, A.; Huertas, A.; Matthies, L. Evaluation of stereo vision obstacle detection algorithms for off-road autonomous navigation. 2005.

RASMussen, C. Grouping dominant orientations for ill-structured road following. In: Computer Vision and Pattern Recognition, 2004. CVPR 2004. Proceedings of the 2004 IEEE Computer Society Conference on, 2004, p. I-470 - I-477 Vol.1.

Santana, P.; Santos, P.; Correia, L.; Barata, J. Cross-country obstacle detection: Space-variant resolution and outliers removal. In: Intelligent Robots and Systems, 2008. IROS 2008. IEEE/RSJ International Conference on, 2008, p. 1836 -1841.

SCharstein, D. View synthesis using stereo vision. Berlin, Heidelberg: Springer-Verlag, 1999.

Scharstein, D.; Szeliski, R. A taxonomy and evaluation of dense two-frame stereo correspondence algorithms. International Journal of Computer Vision, v. 47, p. 7-42, 2002.

Sermanet, P.; Hadsell, R.; Scoffier, M.; Muller, U.; LeCun, Y. Mapping and planning under uncertainty in mobile robots with long-range perception. Intelligent Robots and Systems, 2008. IROS 2008. IEEE/RSJ International Conference on, p. 2525 -2530, 2008. 
SIEGWART, R.; NOURBAKHSH, I. R. Introduction to autonomous mobile robots. Scituate, MA, USA: Bradford Company, 2004.

Talukder, A.; Manduchi, R.; Rankin, A.; Matthies, L. Fast and reliable obstacle detection and segmentation for cross-country navigation. In: In IEEE Intelligent Vehicles Symposium, 2002, p. 610-618.

Tan, C.; Hong, T.; Chang, T.; Shneier, M. Color model-based real-time learning for road following. Intelligent Transportation Systems Conference, 2006. ITSC 'O6. IEEE, p. 939 $-944,2006$.

Thrun, S.; Montemerlo, M.; Dahlkamp, H.; Stavens, D.; Aron, A.; Diebel, J.; Fong, P.; Gale, J.; Halpenny, M.; Hoffmann, G.; Lau, K.; OAKley, C.; PAlatucci, M.; Pratt, V.; Stang, P.; Strohband, S.; Dupont, C.; Jendrossek, L.-E.; Koelen, C.; Markey, C.; Rummel, C.; van Niekerk, J.; Jensen, E.; AlesSAndrini, P.; Bradski, G.; Davies, B.; Ettinger, S.; KAehler, A.; Nefian, A.; MAHONEY, P. Stanley: The robot that won the darpa grand challenge. Journal of Field Robotics, v. 23, n. 1, p. 661-692, 2006.

WAnG, L.; Gong, M.; Gong, M.; YANG, R. How far can we go with local optimization in real-time stereo matching. In: 3D Data Processing, Visualization, and Transmission, Third International Symposium on, 2006a, p. $129-136$.

Wang, L.; LiaO, M.; Gong, M.; YAnG, R.; Nister, D. High-quality real-time stereo using adaptive cost aggregation and dynamic programming. In: 3D Data Processing, Visualization, and Transmission, Third International Symposium on, 2006b, p. 798 -805.

WAng, Y.; TEOH, E. K.; SHEn, D. Lane detection using b-snake. Information Intelligence and Systems, 1999. Proceedings. 1999 International Conference on, p. 438 -443, 1999.

ZHANG, Z. A flexible new technique for camera calibration. Relatório técnico MSR-TR-98-71, Microsoft Research, 2008. 